\title{
Tactics for Forsaken Territories Infrastructural Catalysis Within Disturbed Residual Spaces
}

TIM PATRICK COOK 

A C K N O W L E D G E M E N T S

First and foremost I offer my sincerest gratitude to my supervisor, Penny Allan, for her patience, knowledge and support throughout my thesis, and her ability to refocus my work when it became sidetracked or too broad in scope. I would also like to thank my family, friends and colleagues, whose support and encouragement proved invaluable during the completion of this thesis. 



\section{Tactics for Forsaken Territories}

Infrastructural Catalysis Within

Disturbed Residual Spaces

\section{TIM PATRICK COOK}

A 120 point thesis submitted to the School of Architecture and Design, Victoria University of Wellington, in partial fulfilment of the requirements for the degree of Master of Landscape Architecture

\section{VICTORIA UNIVERSITY OF}

WELLINGTON

2012 


\section{CONTENTS}


8 Abstract

12 Introduction

17 Part I | The Convergence of Landscape and Infrastructure

18 The Shortcomings of Conventional Industrial Infrastructural Systems

24 Landscape as Infrastructure: An Incomplete Paradigm Shift

31 Part II | Forgotten Territories of Industry

32 Landscapes of Abandonment: Disturbance, Dereliction and Romance

38 Tensions Within the Landscape: Time, Memory and Place

45 Part III | Tactics for Forsaken Territories

46 Principles for Design and Working Assumptions

59 Part IV $\mid$ Design

60 Site

61 Site Context and Character Overview

62 Site Definition

64 Site Inventory

68 Current Uses and Activities

69 History of the Woburn Railway Workshops/Seaview Rail Corridor

70 Current and Anticipated Actions

74 An Exercise in Infrastructural Design

101 Final Design

120 Conclusions and Reflections

125 Table of Images

128 Bibliography 
ABSTRACT 
The perceived dichotomy between the industrial and the ecological or amenity has led to a loss or misperception of identity and value of industrial landscapes. Conventional industrial precinct greening moves or the design of parks within these spaces fail to establish any sense of identity or contribute to the growth and development of these environments. Looking beyond the notion of a park as a respite from the urban condition, the challenge lies in developing parks that capitalise on what is perceived as negative and exploit it as amenity.

In search of a strategy, the discourse on the relationship between landscape and infrastructure and the ensuing paradigm shift in the way we understand infrastructure, is examined. What has conventionally existed as a mono-programmatic object for the sake of managing a technical problem is being redefined into a multi-layered spatial field, performing over time as well as space. However care must be taken in how we go about redefining the notion of infrastructure; when we keep broadening its definition it begins to lose significance. If infrastructure is to be reinterpreted from a rigid object to a field that is able to engage with open and unpredictable systems, rather than defining what an infrastructural thing may be, it becomes more important to define how something might perform or develop 'infrastructurally'. 
Much of the discourse surrounding landscape infrastructure focuses on the efficiency that is to be gained by the layering of multiple flexible systems or employing it as a means to remediate a site. While many contemporary landscape infrastructure projects seek to reintroduce the ecological histories that have been suppressed by urban development, their attempts to do so often erase much of what is too readily dismissed as negative, and with it meaningful social histories and qualities that may be exploited as opportunity.

In focussing on the disturbed and residual spaces and the opportunities these territories offer, this thesis seeks to explore the potential of designing infrastructurally to not only reintegrate these forgotten spaces in the urban fabric of their industrial context but to coordinate their development and/or their deterioration in such a way that they become fundamental to the area's identity and growth.

Drawing on Stan Allen's propositions for infrastructure and reinterpreting them through the lens of landscape as a catalytic infrastructure, an architectural strategy is proposed that capitalises upon the qualities found within the abandoned landscapes of the Seaview/Gracefield industrial precinct in Wellington, New Zealand, and recognises them as an opportunity to develop the concept of park in this context into something that reflects the important social histories of these sites while also presenting a proving ground for future operations. These spaces aim to question the way in which we assess infrastructural efficiency, their performance valued not just in quantitative output but also in qualitative terms. 


\section{INTRODUCTION}


This research is an investigation into the notion of landscape as an infrastructural catalyst for growth within disturbed residual spaces of the industrial environment. The main question within the research is how an infrastructurally designed landscape can capitalise upon the qualities found within the abandoned landscapes of industry and recognise them as opportunities to develop the concept of park in this context as something beyond a respite from the urban condition; a landscape that reflects the important social histories of these sites while also presenting a proving ground for future operations. The research aims to challenge the way in which we perceive infrastructural efficiency, where the value placed on performance is not just in quantitative output but also in the conveyance of nonquantitative phenomena.

Part I - The Convergence of Landscape and Infrastructure examines the discourse surrounding the concept of landscape as infrastructure. The Shortcomings of Conventional Industrial Infrastructural Systems sets about establishing the failures of conventional understandings of infrastructure and the consequences the perceived dichotomy between the industrial and the ecological has had, leading to a loss or misperception of identity or value of industrial landscapes. 
Having recognised the limitations of the conventional infrastructure-landscape relationship, Landscape as Infrastructure: An Incomplete Paradigm Shift traces the development of urban infrastructure into a tool that engages with social and ecological systems and ultimately the more contemporary conception of landscape as infrastructure. However, the value of continually broadening our definition of infrastructure is questioned and a focus on infrastructural process or design rather than the defining of something as being infrastructure is promoted. This suggests that another paradigm shift is to be tested; one in which landscape infrastructure goes beyond replacing conventional infrastructures with ecological systems but begins to redefine the way in which we assess infrastructural efficiency, where performance is valued not just in quantitative output but also qualitative terms.

Part II - Forgotten Territories of Industry examines the challenges and responsibilities presented by the reclamation and redevelopment of abandoned or disused landscapes shaped by industrial use. Even in their abandoned states, residual industrial spaces resound with a powerful sense of meaningful histories of human and mechanical prowess. Disturbed landscapes and the ruins of industry are perceived as negative spaces, but even in this state they resound with a powerful sense of meaningful histories of human and mechanical prowess. Beneath the rust and contamination lies potential; providing opportunities for the development of landscapes that reconnect us with the surrounding industrial area as well as challenging the way industrial precincts function and the way we understand them.

Having recognised the shortcomings of landscape infrastructure as being the failure to reach beyond the management of quantitative flows and the shortfall of capitalising on landscape's potential to manage more qualitative phenomena, the chapter Tensions Within the Landscape: Time, Memory and 
Place looks to explore exactly what these qualitative flows might be so that relevant physical and organisational structures can be designed around the phenomena that are so embedded within the residual spaces of an industrial environment.

Part III - Tactics for Forsaken Territories looks to develop a theoretical framework to inform the infrastructural design process. Architect Stan Allen's propositions for infrastructure are reinterpreted through the lens of landscape as a catalytic infrastructure within the industrial environment, and in a contextually relevant form, are employed to provide a testable framework for analysing the site(s) for design intervention as well as presenting principles for design. While raising the question regarding how these principles for infrastructure will perform if we are to explore landscape as an infrastructure and its role in disturbed residual sites within the industrial environment, Allen's propositions act as an instrument that provides strategies of analysis beyond conventional landscape analysis techniques.

Ultimately, this research will inform a combination of architectural form and programmatic strategies while also exploring the interpretation of non-quantitative phenomena to challenge understanding of place and transform the usual perceptions of these spaces of waste and neglect, as discussed in Part IV - Design. The tactics for infrastructural design are tested on three different sites along the residual rail corridor within the industrial precinct of Seaview/Gracefield, responding to different site conditions and the influence of the qualitative processes of disturbance. 


\section{THE SHORTCOMINGS OF CONVENTIONAL INDUSTRIAL INFRASTRUCTURAL SYSTEMS}


Infrastructure no longer exists exclusively in the disciplines of engineering and urban planning. Exploring the relationship between landscape and infrastructure has instigated a paradigm shift in the way we understand infrastructure. What has conventionally existed as a mono-programmatic object for the sake of managing a technical problem is being redefined into a multi-layered active spatial field that has the potential to engage with the openness and unpredictability of ecological and social systems, performing over time as well as space.

In their work on the subject, Raxworthy and Blood (2004) point out that infrastructure is often taken for granted, almost by definition. The term infrastructure has conventionally referred to the structures that lie beneath the surface; the composition of the word suggesting that while it is a crucial, structural term, it is inherently hidden from view. Its significance comes from its ability to facilitate other processes and interactions than itself. "Writing about infrastructure is, it seems, like writing about the background: it is always there, but the closer you get to it, the more background there is behind it" (Raxworthy \& Blood, 2004, p. 10). Raxworthy and Blood (2004) suggest that the concepts of infrastructure and landscape are inherently related, because:

At its most basic, the landscape is the literal surface upon which all the objects and activities 
of nature and culture take place: it is the set for the play that is existence. One could in effect define the entire environment as various combinations of landscape, architecture and infrastructure. (Raxworthy \& Blood, 2004, p. 13)

The industrial environment presents an ideal setting for examining how the concept of infrastructure can be questioned and reinterpreted to develop a relevant model for public space, as it has been conceived as a landscape of conventional infrastructures organised for technical efficiency and quantitative output. Our conventional understanding of infrastructure as a mono-programmatic object for the sake of managing a technical problem has historically led to the biophysical landscape being suppressed by industrial systems. These systems are rigid, vulnerable to disturbance and devoid of any value other than technical efficiency. Kathy Poole (1998) states "Through roughly 150 years of industrialization we have come to believe that the politics of efficiency are beyond question and that standardization is the ultimate expression of democracy” (p. 131). Because infrastructure has always been granted an independent technical priority over the landscape in which it is placed, it has somehow become exempt from having to perform socially, aesthetically, or ecologically (Paul, 2010).The development of conventional infrastructure in such a manner has led to the industrial environments they have been inserted in becoming sites of exclusively quantitative production, isolated and disengaged from other spaces of the city and devoid of any qualitative value.

The perceived dichotomy between the industrial and the ecological is also clearly evident in the manner in which we insert infrastructures into the landscape. Flows of resources are buried underground or concealed from view and the attitude of 'out of sight, out of mind' prevails. Hiding infrastructural processes from view has resulted many city dwellers to take for granted the availability of resources and 
ease of waste disposal, and as a result wasteful use practices have become common-place. (Napawan,

2011). As Napawan (2011) states;

In separating resource cycles including water and nutrients, unilateral flows of energy and product pour into cities, but the waste is directed outward to watersheds, atmosphere, and remote landscapes far from the city source. The result is increased infrastructural demand on the modern city and an intellectual disconnect between resources and the landscapes that produce them. (p. 5)

Industrial operations are inserted into the landscape with no regard to existing ecological processes under the presumption that the two are mutually exclusive, disengaged from the city within industrial sites exempt from any performance expectations other than technical efficiency. Industrial precinct greening efforts or the placement of conventional parks within these spaces fail to establish any sense of identity or contribute to the growth and development of these environments. Traditionally, the role of the landscape architect has been to mask or camouflage hulking industrial forms through the use of vegetation or other design elements, so that any ecological value that might be gained is a complete misrepresentation of the area's actual identity and a merely superficial approach to providing what can hardly be construed as public amenity value.

This is not so in the context of disused industrial sites landscapes. Landscape architecture's focus on post-industrial sites continues to swell as these spaces provide some of the most available unused territories around the world. Many parks or landscape architectural projects are concerned with postindustrial landscape reclamation and embrace infrastructural forms in a state of ruin. We are attracted by the industrial aesthetic and the sense of nostalgia we experience within these parks. 
However, the fact these parks no longer sit within an operating industrial context and their development of the spaces they occupy into recreational retreats in a state of completion often means they become disconnected from the industrial operations, economics and important social histories of their environments. In the Landschaftspark in Duisburg-Nord, Germany, perhaps the most well known contemporary post-industrial park, recreational programs begin to violate the authenticity and histories of the residual infrastructures. Climbing walls, skate parks and diving basins mask past operations and the industrial forms they sit within are reduced to visual spectacles. Similarly, in Gas Works Park in Seattle, monolithic structures are rearranged and composed so as to provide an aesthetic spectacle within what functions very much as a conventional park. While these are both very successful landscape architectural projects, they function as respites from their surrounding fabric, the meaning we find in them constructed through myth and narratives that centre around the monumental structures that now lie dormant.

The role of parks located in residual industrial territories that exist within operating industrial environments urges closer examination. Here their complex surrounding conditions, as well as the evocative qualitative phenomena we experience in them, presents the potential for understanding how these might reflect a relevant and authentic sense of place. The difficulty then lies in moving from rhetoric to design. This is all too evident in the High Line project, an elevated linear park along the disused freight railroad through New York's former meatpacking district. Here, the disturbed, wild qualities of the forsaken space are lost in its transformation into what performs as the conventional notion of a park as a healthy respite from the urban condition. It is beautiful in its materiality and craft, however, herein lies the problem. The High Line masks the deterioration of its site and as a result loses any sense of forsaken identity. What if we capitalise on the disturbed qualities conventional 
approaches to such sites try to conceal? What if rather than using landscape as a medium to define an

identity that is not relevant, we use it to express one that already exists and make it explicit, tangible and contestable? 


\section{LANDSCAPE AS INFRASTRUCTURE:} AN INCOMPLETE PARADIGM SHIFT 
There are many historical examples of urban infrastructures that have been designed to prevent or facilitate certain behaviours. Numerous authors have contributed to the discussion of this strategy; some have even explicitly recommended it (Brand, 2005). Sommer (1969) endorses "design for behaviour change," while Lipman (as cited in Joerges, 1977) considers the behaviour of people as "determined by the physical environment" (p. 12). Moos (1975) is a strong advocate of utilizing this mechanism; "the design of environments is ... probably the most powerful technique to influence behaviour" (p. 211). These publications are an indication of the wave of theories associated with the concepts of 'social engineering' and 'environmental planning' that was prominent in the 1960s and 70s. However, many of these approaches have been dismissed as mechanistic and naive, and approaches that place emphasis on the two-way nature of the relationship between infrastructure and human behaviour, or as Hughes (1988) defines it; a "seamless web" with society and technology constantly interacting and shaping each other, coming to the forefront.

In the essay 'Urban Infrastructures and Sustainable Social Practices,' Ralf Brand (2005) recognizes that the observation that the built environment exerts a gravitational pull upon behaviour nevertheless remains one thread of this seamless web. Brand goes on to say that if particular urban forms and infrastructures do indeed have the ability to confine, enforce, or suggest a corridor of behavioural 
choices, "this might raise the attention of sustainability activists who advocate large-scale behavioural changes through education, incentives, or - for that matter - 'prescriptive' infrastructures. Apart from normative democratic qualms one could have with such an approach, its long-term effectiveness is not at all guaranteed.” (p. 2). In other words, he raises the moral issue of whether designers and providers of urban infrastructures should utilise the ability to make people do what is deemed they should do.

Jumping forward in time and theoretical discourse, it is clearly evident that the discussion of infrastructure and landscape has undergone a fundamental shift in how it perceives the social effect of these infrastructural landscapes; from using infrastructure to control to using infrastructure to engage people. What was once seen as a preventative tool has now become a tool with the potential of providing people with an opportunity to participate in the system and so they become more aware about the spaces they inhabit and their sensitivity to disruption.

In the essay 'Potentials for Landscape as Infrastructure,' Poole (2004) argues that creative infrastructure is reliant upon the reciprocation between citizens and ecological forces, and so this means that engaging people in the continued making of these infrastructural landscapes is fundamental. Poole (2004) writes that; "by embracing biological systems and their evolutionary creativity, there is an opportunity for demonstrating more responsible environmental practices, 'sustainable' techniques and the like, that may be a means of getting people to 'behave' more responsibly towards the larger environment" (p.192). Perhaps where Poole's essay is most successful and constructive in contributing to the dialogue concerned with landscape as infrastructure, is in her articulation of specific strategies through which designers can "design infrastructurally," through the use of specific case studies. Without constricting or attempting to control the discussion of landscape as infrastructure Poole's writing advocates rigour 
in the discussion to create an expansion of the potentials of landscape architecture and its importance

as what she terms a "legitimate and necessary cultural art" (p.192).

As the definition of infrastructure has evolved into something that has the potential to engage with the openness and unpredictability of multiple systems, landscape has found itself more and more in the spotlight of the discourse surrounding this. Many authors have articulated the emergence of landscape as a model for contemporary urbanism. Waldheim (2006), who first coined the term in 1996, states;

Landscape urbanism offers an implicit critique of architecture and urban design's inability to offer coherent, competent, and convincing explanations of contemporary urban conditions. In this context, the discourse surrounding landscape urbanism can be read as a disciplinary realignment in which landscape supplants architecture's role as the basic building block of urban design. (p.37)

According to Ying-Yu Hung, infrastructure, within the framework of landscape urbanism, provides us with the next step for further inquiry "as a city's development and economic future is in direct proportion to its ability to collect, exchange, distribute goods and services, resources, knowledge, and people across vast territories" (2010, p.16). Mossop (2006) writes that "...the landscape of infrastructure has become the most effective means to explore the relationship between natural processes and the city, which is the integral factor in a truly synthetic landscape urbanism" (p.165). According to Mossop (2006), if we interpret landscape to be a form of infrastructure that underlies other urban systems it provides us with a workable conceptual framework for the design of urban systems. "This framework of landscape infrastructure should provide the most permanent layer of 
urban development to preserve the viability of natural systems and regional cultures" (Mossop, 2006, p.176).

However care must be taken in how we go about redefining the notion of infrastructure. When we keep broadening the definition of infrastructure it begins to lose significance. If we reinterpret infrastructure from an object to something that is more akin to a spatial field, rather than defining what an infrastructural thing may be perhaps it becomes more important to define how something might perform infrastructurally. According to Allen (1999);

Infrastructure works not so much to propose specific buildings on given sites, but to construct the site itself. Infrastructure prepares the ground for future building and creates the conditions for future events. Its primary modes of operation are: the division, allocation, and construction of surfaces; the provision of services to support future programs: and the establishment of networks for movement, communication, and exchange. Infrastructure's medium is geography. (p.54)

Landscape as infrastructure implies a reinterpretation of the conventional infrastructural object to an active urban/landscape spatial field, configuring the conditions for new interactions and relationships among the things it supports (Guattari, 2008). "As such, the urban surface is dynamic and responsive; like a catalytic emulsion, the surface literally unfolds events in time" (Wall, 1999, p. 247). Paul (2010) states that through this reconfiguration of the urban surface and by precise interventions “infrastructure performs as a 'catalytic social condenser' - which acts not by resolving conflicts, but by setting up the conditions from which negotiations might begin to withstand the excess of popular culture - restless mobility, consumption, density, waste, spectacle, and information" (p. 1). So it 
becomes apparent that one of the major developments of infrastructure under this new definition is

the ability to function as a stage for all the occurring operations, planned and unplanned, to perform on, and to foster these operations as well as trigger new ones.

Reinterpreting landscape as infrastructure has led to the provision of a groundwork for infrastructure that can synthesise what in conventional infrastructural configurations exists as multiple systems while also remediating and reprogramming the site it occupies, performing over time as well as space. In his article "Landscape as Infrastructure," Bélanger (2009) probes current sectors of economic change in order to provide insight into contemporary, flexible, and more efficient approaches to infrastructure. He discusses three contemporary streams of development; urban ecologies, bio- industries, and waste economies. Bélanger argues that "the shift from conventionally large, centralized industries of mass production to a decentralized pattern of production signals a new era for urban economic reregeneration, land use distributions, and site redevelopment opportunities" (Bélanger, 2009, p. 856).

The synergies and spin-offs from contemporary streams of development demonstrate how new efficiencies and new spaces may be created when urban systems are designed to be tightly integrated into regional land-based resources. When compounded, these streams of development point towards the effectiveness of landscape-based strategies that can solve multiple challenges at once. (Bélanger, 2009, p. 89)

Much of the discourse surrounding landscape infrastructure focuses on the efficiency that is to be gained by the layering of multiple flexible systems or employing it as a means to remediate a site. However, while many contemporary landscape infrastructure projects seek to reintroduce the 
ecological histories that have been suppressed by urban development, their attempts to do so often erase much of what is too readily dismissed as negative, and with it meaningful social histories and qualities that may be exploited as amenity. This is especially true in the design of parks within disturbed spaces, where the need to provide green space or other landscape amenity value overrides the opportunity to express important histories and foster a relevant identity as well as develop the precinct and cultivate a community.

This research is centred on the suggestion that in this context the paradigm shift in how we understand infrastructure has not gone far enough, and that landscape infrastructure often remains the design of conventional infrastructures through landscape architectural mediums. This points to the need for another paradigm shift to be tested; one in which landscape infrastructure goes beyond replacing conventional infrastructural structures with ecological systems but completely redefines the way in which we assess infrastructural efficiency, where performance is valued not just in quantitative output but also qualitative terms. This redefining of efficiency and output is fundamental if we are to conceive infrastructure through a performative landscape lens. Landscape infrastructure not only presents major ecological and economic opportunities but it provides us with a catalyst to trigger a shift in the way people understand their industrial environment and their conception that the industrial is to be autonomous from the ecological or cultural through allowing them to engage with recreational and educational programs. 



\section{LANDSCAPES OF ABANDONMENT: DISTURBANCE, DERELICTION AND ROMANCE}


The reclamation and redevelopment of abandoned or disused landscapes, specifically those that have been shaped by industrial use, presents a set of particular challenges and responsibilities. These areas have been severely affected, and the social implications and aesthetic issues inherent in introducing landscape infrastructures within these derelict sites warrant major thought and consideration. In her written work on the subject of such spaces, Meyer (2007) refers to them as "disturbed sites," arguing that the term "captures the effect as well as the character of these sites" (p. 59). "They have been disturbed by new processes - interrupted and interfered with - and that alteration disturbs us, makes us uneasy, anxious, worried, agitated" (Meyer, 2007, p.59). "Disturbed" also resonates with urban ecology and resilience theories; Holling (2007) defining resilience as the degree of change that a system is able to absorb while still maintaining function, with the capacity of that system to respond actively to disturbances and absorb change being referred to as its adaptive capacity. Landscape architect Peter Latz, who is convinced that the discipline's principal concern today should be dealing with such places, calls these damaged landscapes "bad places." Latz defines these somewhat bluntly; "Bad places include anywhere I wouldn't allow my four year-old granddaughter to play," adding that "these can be very exciting places" (Weilacher, 2008, p. 80). The term "bad" in this sense not only has moral or ethical implications but is also suggestive of the aggressiveness of the disturbance and the 
design problem these spaces pose.

In contemporary landscape architecture literature an intensifying spotlight has been cast on the reclamation of post-industrial landscapes. Much of the discourse regarding the development of "disturbed sites" into parks is primarily concerned with processes of remediation required to decontaminate them so that they can be regarded safe to be used by people. Although the engineering and remediation strategies developed to adapt these disused wastelands into habitable spaces present innovative acts of reclamation, this particular focus fails to show what these space might mean to the communities that use them (Meyer, 2007).

What does the large metropolitan park constructed on a site degraded by the processes of human consumption and industrial production mean? The urban institution known as the public park, once associated with landscapes affording urban dwellers respite from the world of work, consumption, and production, is now made on the detritus and the uncertain, perhaps toxic, byproducts of that realm. (Meyer, 2007, p.60)

Meyer (2007) states that many of the first parks built on disturbed sites were modelled on the "ubiquitous, placeless recreational park or open-space park" of the mid-twentieth century; these being "more a form of amnesia, a practice of forgetting site histories, than indices of regional character and identity" (p.62). Within the undertakings of bureaucrats and council planners the insular attitude that the sooner these disfigurements of the landscape are healed or concealed, the better, tends to prevail. In regards to these early parks on industrial sites Meyer (2007) refers to what Engler (1995) terms the "camouflage approach," a practice in forgetting and deception. According to Meyer (2007) this approach results in a disconnect between the parks and those that use them, as the histories and 
processes of the disturbed industrial sites are cloaked, rendering the redeveloped spaces less meaningful

than they might be. The ambitions of landscape architects and urban designers when designing within these contexts seem to be driven by the aim of attaining attractive cities where the role of a 'park' is constrained by the conventional notion of a green space for recreation, functioning as a respite from the severity of the urban condition.

Meyer (2007) expresses the importance of disturbed industrial spaces to be read as sites of consumption as well as production;

As the residue of collective consumption and mass production, slag heaps and belowground chemical plumes are direct manifestations of the unacknowledged and largely unseen consequences of technological processes and industrial manufacturing. (p. 62)

The capacity of these spaces to tell stories about our histories of consumption is even more important in residual spaces sited within an operating industrial context, where access to these disturbed landscapes allows us to see the effect of and question the structure of these neighbouring industrial operations. These spaces are an important tool in exploring the perceived dichotomy between the industrial and the ecological with the potential of making communities aware of the connection between consumption, production and pollution. If we look beyond the contamination or dereliction, can these sites present us with opportunities to gain footholds for intervention that questions the form, program and community of an industrial precinct?

Though these "disturbed" sites are unkempt, derelict, sometimes dangerous, they possess a seductive quality; their state of abandonment and decay an alluring disruption to the surrounding fabric. 
What is the beauty in abandoned sites? Certainly it includes colour, form, texture and a particular materiality, but there is much more. There is the interplay of light and dark, iridescence and reflection, as well as evocative sounds and smells. Both sublime and picturesque, both powerful and vulnerable, the aesthetics within abandoned sites form a complex embroidery of decay. (p. 13)

Even in their abandoned states, residual industrial spaces resound with a powerful sense of meaningful histories of human and mechanical prowess. Corroding ruins of industrial pasts lie dormant; their forms defined by function and efficiency, now taking on a romantic, sometimes sinister, architectural quality. The disused infrastructures distort and abstract, this disconnection from reality adding to the picturesque quality of the sites, but also potentially disconnecting people from the layers of historical evidence embedded in their ruins. Chan (2009) examines the relationship between cultural perceptions of industry, its ruins, and parks containing industrial ruins, exploring how we might design these spaces in ways that reveal the multiplicities of history. Developing these sites into parks presents a complex challenge; particularly in regard to the role of their ruins of industry and manufacturing. These tend to function as follies in such parks; the enduring structures tend to be impressive in scale and materiality, but ambiguous in their function. The spectacle of ruin and industry also often eclipses the ecological histories of the sites and the issues associated with remediation (Chan, 2009).

These spaces make up a fascinating landscape, one that does not conform to the rigorously programmed constraints of the industrial and commercial operations that surround it. Industrial landscapes have become so inescapably programmed and regulated, that their abandoned territories remain some of 
the only spaces that allow for sensorial perception and genuine identity of place to manifest.

Standing in contrast to these aesthetically and socially regulated spaces, neglected sites can accommodate reflective meditations where marginal places provide a different beauty in the city. They evoke an aesthetic of disorder, surprise and sensuality, offering ghostly glimpses into the past and tactile encounters with a forgotten materiality. (Armstrong, 2006, p.119)

Disturbed landscapes and their ruins of industry are commonly seen as negative spaces, indicators of economic decline, but beneath the contamination lies potential; providing opportunities for the development of places that reconnect us with the surrounding industrial area as well as challenging the way industrial precincts function and the way we understand them. The uncertainty that resonates within these voids provokes inventive uses, both of the temporary and more permanent nature, that explore culturally rich pasts and probe new futures. 


\section{TENSIONS WITHIN THE LANDSCAPE:} TIME, MEMORY AND PLACE 
If we recognise the shortcomings of landscape infrastructure to be the failure to reach beyond the management of quantitative flows and capitalise on the potential to manage more qualitative conditions, then the reinterpretation of landscape as infrastructure that does so requires us to explore exactly what these qualitative flows might be. While the disturbed landscapes of industry are commonly dismissed as negative spaces, they are laden with a sense of time, memory and other non-quantitative phenomena. These are conveyed in such insightful and piercing manners that these spaces convey a sense of identity or awareness that is so much more relevant than that of their programmatically regulated surroundings. Our sense of time and place are inherent within the cultural construct that is landscape. Infrastructurally designed landscapes have the potential to not only represent an identity or sense of place, but to allow one to develop and keep developing over time. Armstrong (2006) states ;

In these wastelands we can commune with 'place' as a layered landscape - complex and disturbing as much as reassuring. Here we can regain the ability to accept the 'ugly' and learn from its strange and resonating qualities. (117-118)

"Place and memory are embedded in our cultural landscape" (Wasserman, 2002, p.190). However, the landscape itself is embedded within and implicated in the processes of social and cultural reproduction; 
it is not innocent. The landscape and how we manipulate it is what reveals the interaction between people and place. It is the space and the medium through which people articulate individual or collective memories and identities.

The landscape is not only a result of particular ideologies, but it sustains them: It communicates. It is political. It has power to condition our social relationships as we shape it with our markers of difference, whether through race, gender, ethnicity, class, or other dimensions of belonging or being 'Other'. (Mills, 2005, p. 1)

The notions of memory and time are in constant dialogue with the landscape and it is when we become aware of these things that we begin to gain an understanding of place and how we, as individuals and as a collective, fit into the picture. Though these concepts are no more relevant within industrial landscapes of abandonment, they are often more explicit and revealing within these contested landscapes that have bared witness to much disturbance, where intervening may mean negotiating between seeking redemption within these spaces or recognizing the perceived negative qualities and exploiting these. Though beset with memories of industrial brutality and the suppression of the biophysical environment, landscapes of disturbance also evoke a sinister, yet equally seductive, beauty. Exploring these spaces presents opportunities for exploring notions of time, for reflection of past infrastructural triumphs and their subsequent failures, of present neglect and sensuality, and also of future innovations and opportunities for growth.

If the notions of time and memory are entrenched within our cultural landscapes, how do we make memory explicit and tangible through design? How can we select what to preserve and to what extent do we preserve it? The culture of memory, this marking out of significant historic moments, is a 
universal cultural phenomenon that is integral to the very core of who we are and how we experience space. Continuing to remember the multitude of stories within the landscape, either through designed terrains or preserving significant moments, can assist in maintaining cultural continuity into the future or the creation of landscapes that address how future generations will engage with each other and the land. Through memory, internal selves have connected with external environments, pasts with presents, random experiences with unconscious routines. Memory has connected us with the larger world on many levels, linking the lived with the mythological, the children of the future with the ancestors of the past, the personal lives of individuals with the shared experience of the collective (Zelizer, 1995).

Mayo (2009) observes that we can be shocked by the change of a place, swift or gradual, or its lack of change, but we struggle to understand change without human markers that make and keep us aware of time in relation to this change. The abandonment of spaces provides an interesting shift in the legibility of time in these territories, where urban operations become succeeded by ecological processes. While the built environment is somewhat analogous to a clock that measures time slowly, through the gradual aging of buildings and urban development, this reading of time differs greatly when we look at a forest, as it often appears timeless since the lack of buildings or other built artefacts fails to provide markers that function as clocks to keep time in these natural landscapes (Mayo, 2009). But it is not these artefacts alone that provide us with an understanding of time. The ways in which we relate to one another helps to emphasize what time is within a place. Jackson (1994) states that:

What brings us together with people is not that we live near each other, but that we share the same timetable: the same work hours, the same religious observances, the same habits 
and customs. That is why we are more aware of time and the rhythm of the community. It is our sense of time, our sense of ritual, which in the long run creates our sense of place and of community. (p. 160)

Developing a landscape infrastructure that promotes senses of time and place then requires developing spaces that facilitate and encourage ritualistic use which progresses as a community's identity does. Conventional expressions of time within architecture or architectural space of historical or cultural significance involve employing heritage and preservation practices to suspend it within a preferred period of its development. Yet landscapes and the buildings that sit within them come together in increments over long periods of time, the sense of place they hold ever-changing, so that the act of suspending a single stage of their existence misrepresents the history that preservation aims to maintain. This freeze frame approach confines any experience of memory or time to a manufactured commodity of 'heritage'. So if we aim to develop landscape infrastructure so that it acknowledges flows of time, the facilitation of adaptation and change over time, not just the archiving of what are deemed significant phases or moments within the landscape, becomes equally or perhaps even more relevant.

The urban landscape is often conceived as a permanent feature. Our many definitions for landscape often assume a permanence that does not always exist. Mayo (2009) challenges these and defines temporary landscapes as:

...Place events contingent upon the social conditions that shape them. Societies can plan events, react to them, or do both, and the outcomes can be either enriching or corrosive. Given these contingencies temporary landscapes can be places for rituals, epiphanies, crimes 
and wars, and natural and human disasters. Temporary landscapes have enduring principles,

which are requirements and possibilities that relate either to social actions or to memories.

(p.125)

Although any landscape is ultimately temporary, it is the uniqueness of events and their effects that justifies exploration of how temporary landscapes might perform and how they might be in some way choreographed. Mayo (2009) questions what temporary in relation to these landscapes means, stating that some temporary landscapes may only ever be a single occurrence while others are seasonal landscapes that are experienced on an annual basis. Some landscapes present us with temporary conditions to experience on a weekly or daily basis; and in these circumstances, this notion of temporary becomes so repetitive that it is inclined to lose meaning. However, it could be argued that when these weekly or daily cycles occur with a sense of progression or transformation over time, where the same or similar rituals continue to occur within a landscape that continues to cultivate a sense of identity, and these are overlaid with a sense of time of a much larger scale so that more mundane events sit within more powerful social histories, a much more holistic and relatable sense of time and place within the landscape could be attained.

Wingwall (1984) states that in the creation, understanding or analysis of the places around us, time becomes one of the boundaries we wish to see. She notes that in the places that we call historic, where we are stimulated by all the visible fragments of its stages, it is easy to imagine various different times. In other places, other times may not have these visible fragments. Wingwall, however, states that we must be capable of imagining what might have happened that we don't see; events which have enriched the fabrication and the memory of place. Through careful manipulation of the landscape 
and the placement of emphasis on characters or qualities through designed elements, we have the opportunity to aid in how spaces are read.

Our memory responds to shape, overlaying a room or garden or a square with another experience, adding memory of a place existing only in time to that of our own backyard. Places can exist simultaneously in both physical and mental ways, ensuring that the visual order we see is considerably enlivened and expanded by the places still in our heads. Places take time. (Wingwall, 1984, p.2)

While conventional infrastructures degrade with time, infrastructural landscapes should perform through time. 


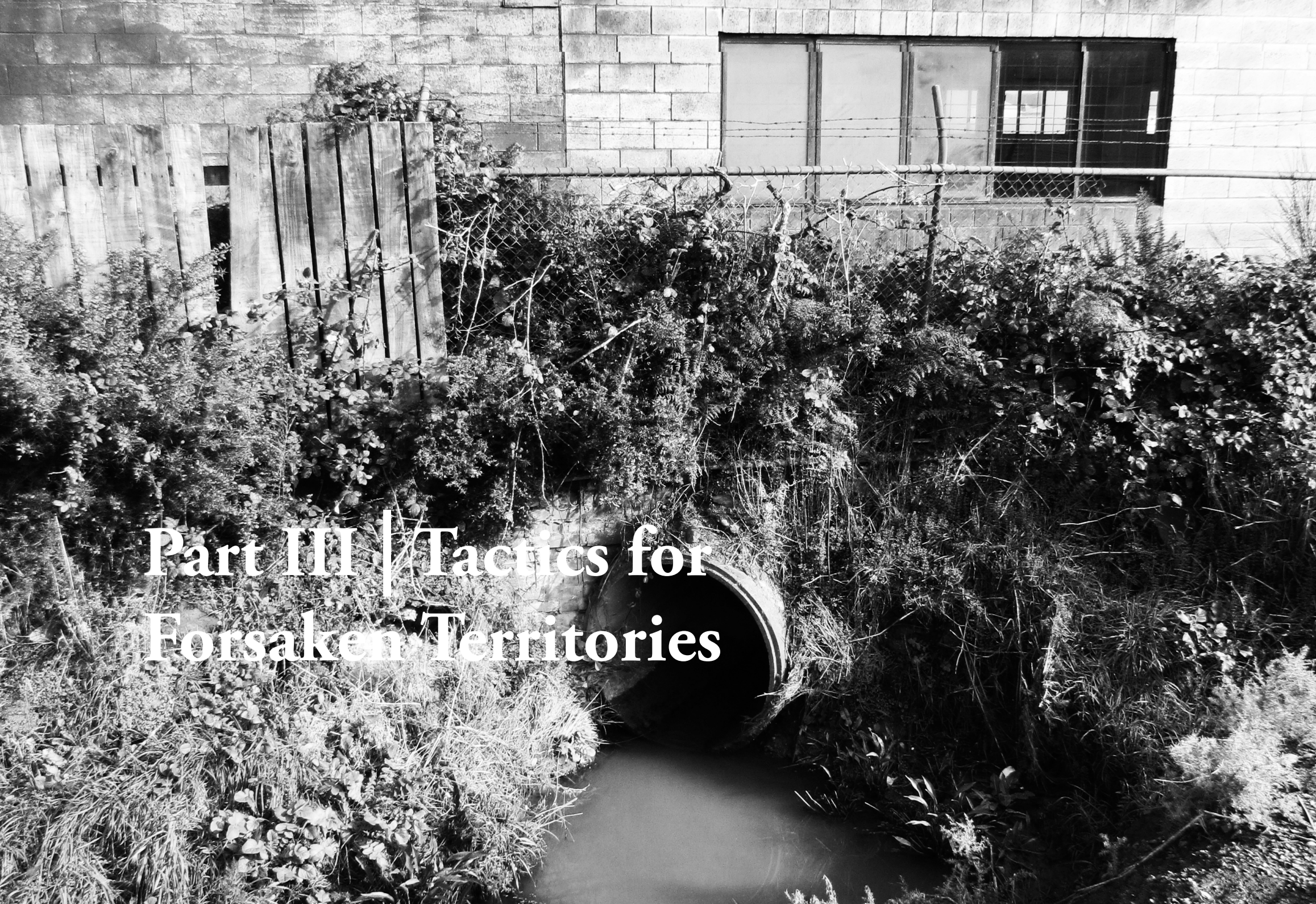

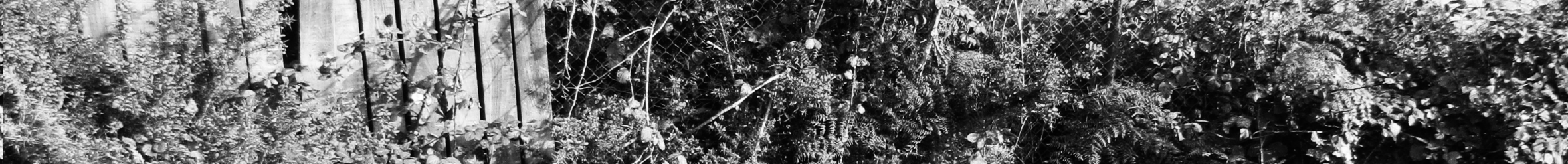
tom

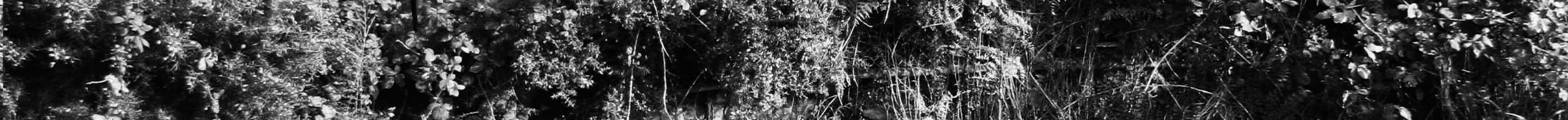

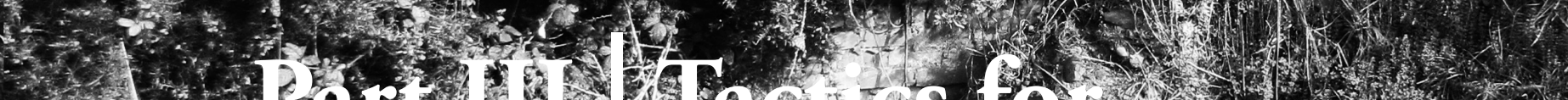
Wulwher 2.4.

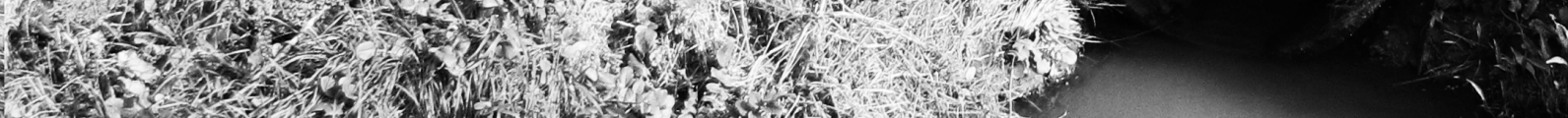
2. 1. 1. 1.8.

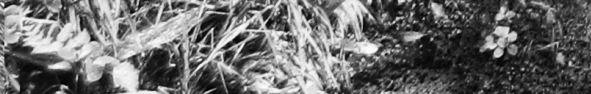

then . a.

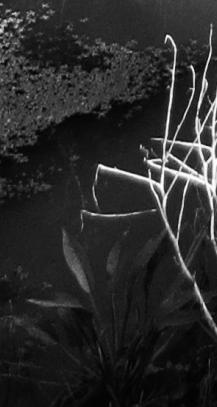

ald

1. $+x^{2}+3$ $1 \times-3=$ ( 


\section{PRINCIPLES FOR DESIGN AND WORKING} ASSUMPTIONS 
While previous chapters have examined the qualities that make abandoned sites distinct from socially and programmatically controlled spaces, and the unique engagement with time and insight into the identity of place they allow, this stage of the research addresses how we might go about analysing and subsequently designing and infrastructurally intervening within these spaces.

Photographers and filmmakers have extensively illustrated to us the significant qualities of such spaces through their lenses. In his work, photographer Tim Edensor envisions industrial ruins as refuges for uncontrolled operations of play and art. He embraces the freedom these places offer, where the constraints of the industrial precincts they sit within no longer apply and celebrates the vitality that has risen from the rubble. Edensor (2005) states that his aim is to "acknowledge the blurring of boundaries, and also the inevitability of decay" (p.15). Through his efforts to do so he emphasises the threat that new large-scale urban developments which conform to conventional planning policies pose to retaining the fragmented and unregimented nature of forsaken territories, the very qualities that instil them with a sense of profound meaning.

The art of walking such spaces has been employed by some designers and artists as a tool to critically explore and challenge understanding of place and landscape. German architect and artist Boris 
Sieverts uses walking as a tool to analyse the sensations brought about by encounters in territories of waste and neglect and transform the usual perceptions of these spaces.

Stalker, a collective of architects and artists, carries out projects in the abandoned urban spaces, undertaking walks that construct abstract maps of their journeys through residual spaces. These maps advocate a reorganised reading of the city, where marginal zones become the focus. According to their manifesto; "Stalker is together custodian, guide and artist for these Actual Territories," where Actual Territories "constitute the built city's negative, the interstitial and the marginal, spaces abandoned or in the process of transformation" (Stalker, online).

In the multiple roles we are disposed to confront at once the apparently unsolvable contradictions of salvaging through abandonment, of representation through sensorial perception, of intervening within the unstable and mutable conditions of these areas... To intervene on a territory is not merely an act of planning but an act of creation, an attempt to assemble contradictions and transform them into poetic relationships: ultimately one is more attentive to modifying how space is perceived than the way space itself exists. (Stalker, online)

It is clear that encouraging people to walk through the site has the potential to function as a powerful driver for intervention; that simply facilitating access and the moves to make this possible provide a potential armature for further intervention. Promoting the act of occupation then becomes the primary and most significant event in the phase of intervening through design.

To explore the potential within residual territories of the primarily industrial site of Seaview/Gracefield, 
a set of principles for design has been developed to test the notion of landscape as an infrastructural

catalyst for growth. Architect Stan Allen's (1999) propositions for infrastructure, reinterpreted through the lens of landscape as a catalytic infrastructure within the industrial environment, are examined and, in a contextually relevant form, employed to provide a testable framework. This framework is intended to aid in focusing the analysis of the site as well as presenting principles for designing. Although Allen's propositions were driven by architectural design, their principles remain relevant when considering the development of landscapes and industrial environments if we strive for final outcomes that are infrastructural. While raising the question how these principles will perform if we are to explore landscape as an infrastructure and its role in disturbed residual sites within the industrial environment, Allen's propositions act as a valuable instrument in this research that provides strategies of analysis beyond conventional landscape analysis techniques.

What follows are Allen's original propositions and how these might inform the analysis and design of forsaken territories through landscape infrastructural methods.

Infrastructure works not so much to propose specific buildings on given sites, but to construct thesiteitself.Infrastructurepreparesthegroundforfuturebuildingand createsthe conditionsforfutureevents. Its primarymodes of perationare: thedivision, allocation, and construction of surfaces; the provision of services to support future programs; and the establishment of networks for movement, communication, and exchange. Infrastructure's medium is geography. (Allen, 1999, p. 54)

Through the medium of landscape, infrastructural intervention initiates a thickening of the surface; loading the ground with an underlying framework that facilitates current and future systems. 
Preparing the ground of the residual rail corridor that runs through Seaview/Gracefield means creating a stage for the programmatic conflicts and spatial contestation generated by the juxtaposition of the forsaken territory with the adjacent industrial and commercial operations to unfold. The design of interventions should aspire to function as an armature for future programs and events and have an impact spatially much greater than its footprint. If in the design stage the rail corridor assumes the role as the primary infrastructure within the site, the next step is to test and explore how this system could be manipulated in order to create change within the extent of the entire precinct; change in the way people move through its spaces, in the programs that occur and in the way a sense of place is expressed and identified with.

\section{Infrastructuresareflexibleand anticipatory. Theyworkwith timeandareopen tochange. By specifying what must be fixed and what is subject to change, they can be precise and indeterminate at thesame time. Theywork through management and cultivation, changing slowly toadjust to shifting conditions. They do not progress toward a predeterminedstate (as with master planning strategies), but are always evolving within a loose envelope of constraints. (Allen, 1999, p. 55)}

Conventional infrastructures are constructed for maximum efficiency to perform precise operations, dictating the size and form of its elements. When looking at landscape this becomes more about introducing a series of steering processes that drive the development of form or program. These should be designed with the capability to be adapted or augmented as the temporary landscapes they allow to occur unfold. Forsaken territories are indeterminate landscapes. While it may appeal to do nothing to forsaken industrial spaces, to keep the qualities that make them so seductive intact, this 
would mean ignoring the potential they hold to translate the liberating quality found within them

to their programmatically and aesthetically controlled surroundings. Landscape infrastructural tactics promote the exploration of indeterminacy through landscapes of focussed intensities within more extensive systems, in the case of this research, forsaken spaces in the constraining landscape of the industrial precinct.

\section{Infrastructural work recognizes the collective nature of the city and allows for the participation ofmultipleauthors. Infrastructuresgivedirection tofutureworkinthecitynot by the establishment of rules or codes (top-down), but by fixing points of service, access, and structure (bottom-up). Infrastructure creates a directed field where different architects and designers can contribute, but it sets technical and instrumental limits to their work. Infrastructure itself works strategically, but it encourages tactical improvisation. Infrastructural work moves away from self referentiality and individual expression toward collective enunciation. (Allen, 1999, p. 55)}

What makes forsaken territories such powerful foundations for infrastructural landscapes is that there are no established rules or codes. We can utilise these landscapes as open laboratories for experimental urban practices of ecological remediation and diversification, artistic installations and unplanned or unsanctioned events. The indeterminacy inherent in these spaces promotes the composition of these innovative temporary uses to take on nomadic arrangements designed to probe a future worth and develop future investment. In contemporary cities, there may be some objection to the notion that forsaken industrial territories hold cultural value. Spatial practices could be designed to connect the personal act to the public disturbance, providing tangible models exploring land ethic and industrial 
sustainability, and the step between our values and behaviours. Landscape infrastructure provides an opportunity to facilitate hands-on learning requiring community participation in their ecological function.

4 Infrastructures accommodate local contingency while maintaining overall continuity. of strategies exist to accommodate irregularities in the terrain (doglegs, viaducts, cloverleaves, switchbacks, etc.), which are creatively employed to accommodate existing conditions while maintaining functional continuity. Nevertheless, infrastructure's default condition is regularity-in the desert, the highway runs straight. Infrastructures are above all pragmatic. Because it operates instrumentally, infrastructural design is indifferent to formal debates. Invested neither in (ideal) regularity nor in (disjunctive) irregularity, the designer is free to employ whatever works given any particular condition. (Allen, 1999, p. 55)

While intervening within Seaview/Gracefield may involve the designing of 'parks' along the site's residual rail corridor, these ought to function as more than a respite from the industrial or urban condition. This means while they will need to address local conditions they need to perform as part of a cohesive landscape infrastructure that provides scaffolds for change within the larger environment.

Although static in and of themselves, infrastructures organize and manage complex systems of flow, movement, and exchange. Not only do they provide a network of pathways, they also work through systems of locks, gates, and valves-a series of checks that control and regulate flow. It is therefore a mistake to think that infrastructures 
can in a utopian way enable new freedoms, that there is a possibility of a net gain

through new networks. What seems crucial is the degree of play designed into the system, slots left unoccupied, space left free for unanticipated development. This also opens the question of the formal description of infrastructural systems: infrastructures tend to be hierarchical and tree-like. However, there are effects of scale (a capillary effect when the elements get very numerous and very small) and effects of synergy (when systems overlap and interchange), both of which tend to produce field conditions that disrupt the overall tendency of infrastructural systems to organize themselves in linear fashion. (Allen, 1999, p. 55)

Forsaken territories are unrestrained, not rigorously programmed like the industrial and commercial operations they sit within. It is important that the freedom these places offer is protected when they are intervened upon, that unanticipated or uncontrolled activities or development trends are allowed to occur. More conventional landscape infrastructural systems of movement, program and ecology must be integrated with the qualitative phenomena of time, memory and place that emanate so strongly within these landscapes.

\footnotetext{
6 Infrastructural systems work like artificial ecologies. They manage the flows of energy and resources on a site, and they direct the density and distribution of a habitat. They create the conditions necessary to respond to incremental adjustments in resource availability, and modify thestatusofinhabitation in responsetochangingenvironmental conditions. (Allen, 1999, p. 57)
}

Incremental adjustments are required to diversify and develop use and engagement beyond that 
associated with the deteriorating industrial community. The introduction or fostering of productive ecological processes has the potential to lift the despair relating to the sense of failure that resonates in forsaken territories. The direction the future of the Seaview/Gracefield industrial precinct will take will create shifting environmental conditions that the residual rail corridor, assuming the role as the primary infrastructure within the site, will need to adapt to. Like ecological systems, infrastructure must have the capacity to absorb change into its system. Disturbed infrastructural landscapes must be capable of coping with further disturbance.

Infrastructures allow detailed design of typical elements or repetitive structures, facilitating an architectural approach to urbanism. Instead of moving always down in scale from the general to the specific, infrastructural design begins with the precise delineation of specific architectural elements within specific limits. Unlike other models (planning codes or typological norms for example) that tend to schematize and regulate architectural form and work by prohibition, the limits to architectural design in infrastructural complexes are technical and instrumental. In infrastructural urbanism, form matters, but more for what it can do than for what it looks like. (Allen, 1999, p. 57)

Intricacy is fundamental to a landscape infrastructural approach to intervention in forsaken territories. These spaces possess an inherent intricacy. While Allen draws a distinction between the appearance of architectural form and how it functions as part of an infrastructural system, in forsaken territories the aesthetic of architectural intervention could play an important role in conveying qualitative phenomena. This means that rather than drawing a disconnect regarding what form looks like and 
While somewhat ambiguous and offering no clear directions for the design of (landscape) infrastructures, Allen's propositions are valuable in drawing out and interpreting themes for investigation through the subsequent design experiments. Looking at these themes in relation to the residual rail corridor of Seaview/Gracefield, focusing on the response to qualitative phenomena, then allows for exploration of the qualities of forsaken territories in a framework that promotes infrastructural outputs without limiting the scope to the conventional landscape urbanism approach that Allen's propositions allude to. These propositions act as a tool to set in motion the testing of the potentials of a landscape architectural approach to developing residual spaces in industrial contexts into 'parks', but require looking beyond their implications in order to push the notion of landscape infrastructural performance further to acknowledge the significance of conveying qualitative phenomena in such 'parks'.

Rather than attempt to devise a precise methodology for the infrastructural design of spaces that are inherently imprecise, Allen's propositions and the themes explored within each of them will contribute to the design of a series of open-ended outcomes. Examining these propositions with regard to their implications in forsaken territories, a series of assertions concerning landscape infrastructure have been drawn. These assertions aim to guide the exploration of themes under which the design experiments explore qualitative phenomena as infrastructural output. They are: 
...construct the site, establishing networks for movement, communication and exchange. They create an environment that supports the unfolding of future events (or landscapes), but also uncovers and conveys those of the past.

...employ specific interventions to which existing operations and systems react to, generating diverse consequences which they foster and advance with. They develop forsaken territories into a field of focused design investment while strategically opening up the edges of the site to urban development pressures.

...utilise existing and shape new characteristics in the landscape that encourage a diversity of authors to claim territories and intervene within them. They exploit the openness and unoccupied character of forsaken territories to facilitate unregulated and experimental operations that develop stronger community networks and spatial and programmatic diversity.

...modify the ground in response to their immediate context and its characteristics but perform as a cohesive landscape that stimulates change within the larger environment; change in the way people move through and use its spaces, in the programs that occur and in the way a sense of place is expressed and identified with.

...have an inherent openness that allows for unanticipated development. They integrate movement, program and ecology into a system that works with the qualitative phenomena 
of time, memory and place, promoting a new notion of infrastructural efficiency that is

more concerned with the conveyance and growth of a sense of place than quantitative output.

...function with an understanding of ecology and how the connections they facilitate might be developed for better interaction with the environment. Like ecological systems, landscape infrastructure must have the capacity to absorb change into its system. In instigating shifts in its environmental conditions, it must respond with the deployment of appropriate architectures.

...in forsaken territories possess an inherent intricacy. Concerning the design of architectural elements of infrastructure, Allen draws a distinction (in proposition 7) between the appearance of architectural form and how it functions. However, in infrastructures within forsaken territories the appearance of architectural form is integral to its performance as a conveyer of qualitative phenomena. The finer grain of both the operation and the aesthetic of these places is what makes them so significant in their rough grain industrial context. 


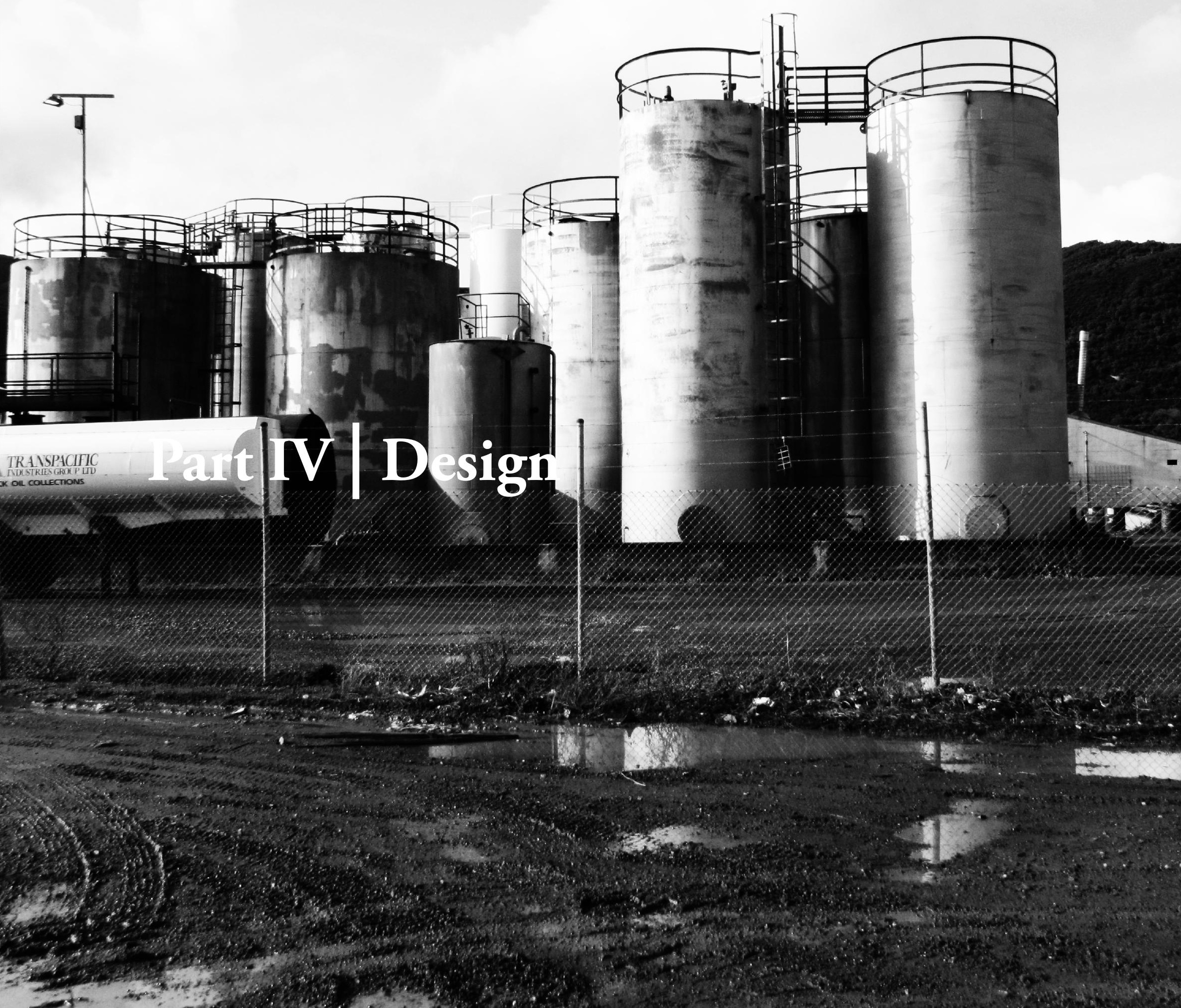


SITE 
Seaview and Gracefield are suburbs of Lower Hutt City, situated at the eastern end of the Petone foreshore. The Seaview/Gracefield area is bordered by the Wainuiomata Hills and the mouth of the Hutt River. Seaview provides a link to the suburb of Eastbourne and Gracefield a link to the suburb of Wainuiomata. Seaview/Gracefield has established itself as an industrial and manufacturing area providing for a range of industrial operations varying in scale, intensity and program. The two sub-areas of Seaview and Gracefield exhibit somewhat differing characters and activity patterns; Seaview encompassing the marina and heavier industry, much of which is associated with oil storage, and Gracefield accommodating predominantly scientific research industries. Seaview/ Gracefield's heavy industrial focus has been offset somewhat over the years through the diversifying of programs by the development of more mixed use areas,

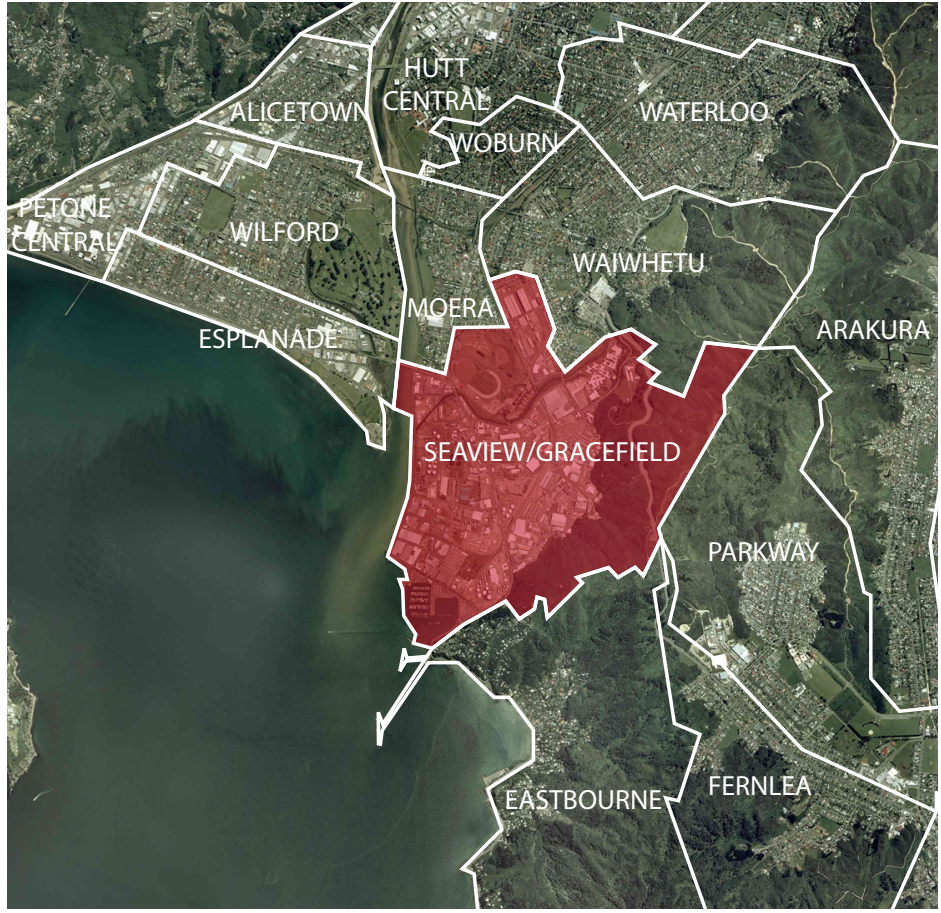

Fig. 1.01 Regional context

however the industrial character remains ever present in the area's infrastructure, both operating and residual. 


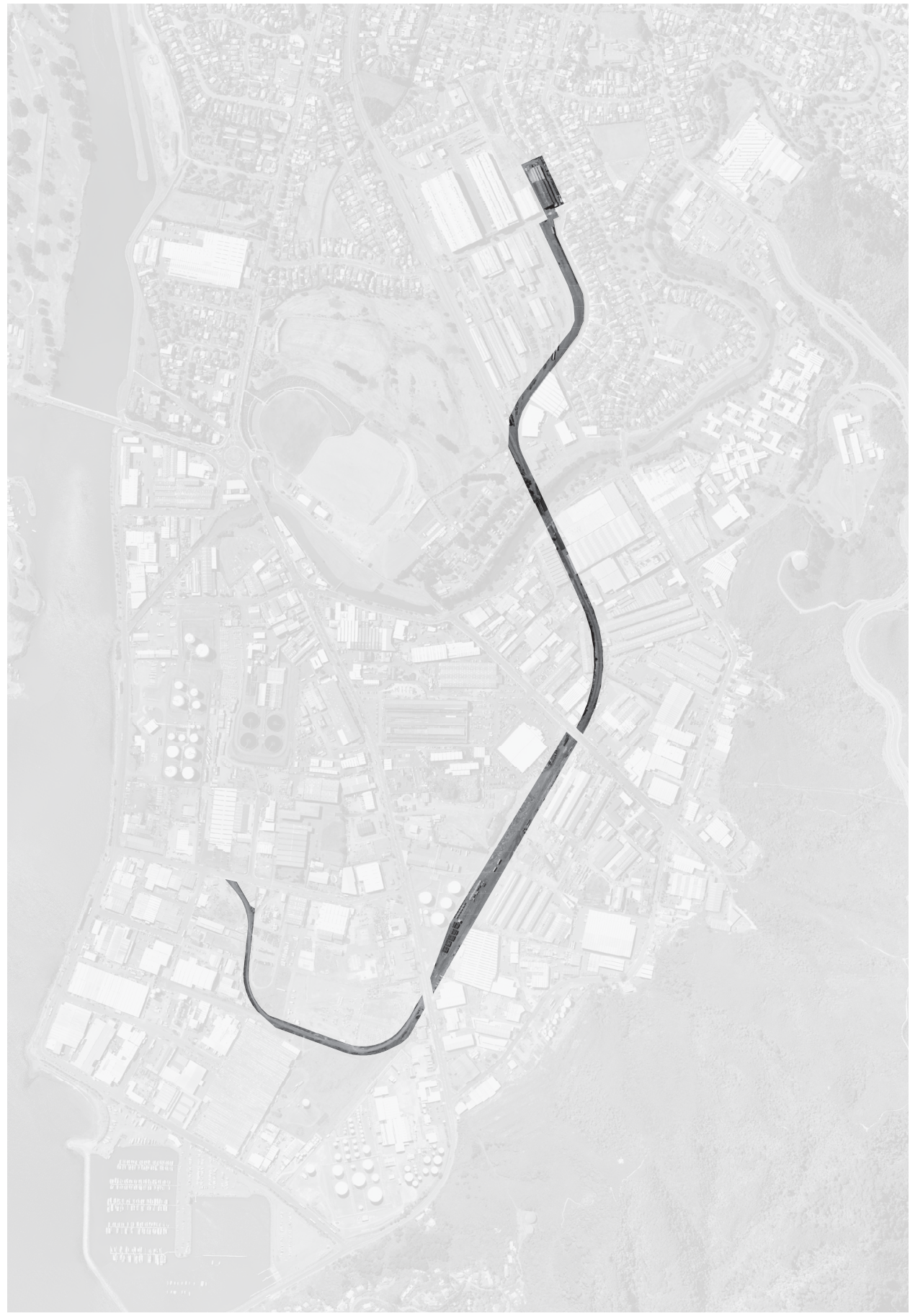

\section{Site Definition:}

Thesite for proposed intervention is the vestigial rail track corridor that runs through the Seaview/ Gracefield area. No direct cross road connection between the two sub-areas exists, however the rail corridor has the potential to act as a linking element. The northern endpoint of the study site is the Hutt Railway Workshops and the rail corridor splits and terminates further south at the Seaview Marina and at the Port Road waterfront edge to the west. Three sites along this rail corridor are focussed on and serve as laboratories for exercises in (landscape) infrastructural design.

Fig. 1.02 Residual rail corridor - Scale 1:15000 
Warehouses, derelict buildings, corroding silos and barbed wire fences frame the rail corridor. Invasive plant species claim abandoned territory. Harsh chemical odours mingle with coastal air. Yet it is precisely this merging of open space and industrial operation, the programmatic conflict and spatial contestation, that offers poignancy to the experience of place, providing a powerful setting for a new landscape design situated within the industrial precinct of Seaview/ Gracefield.

Fig. 1.03 Proposed sites of infrastructural intervention - Scale 1:15000

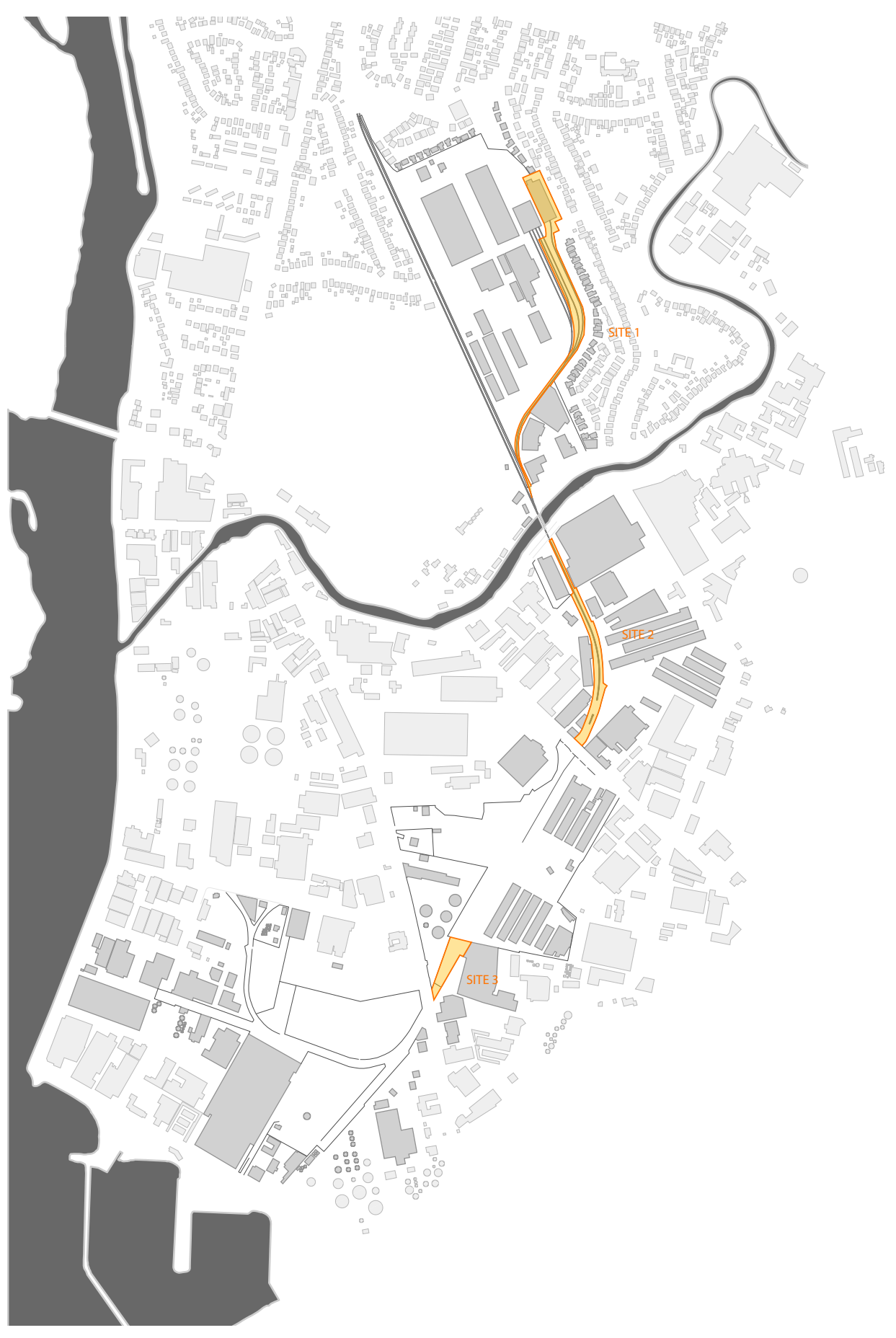




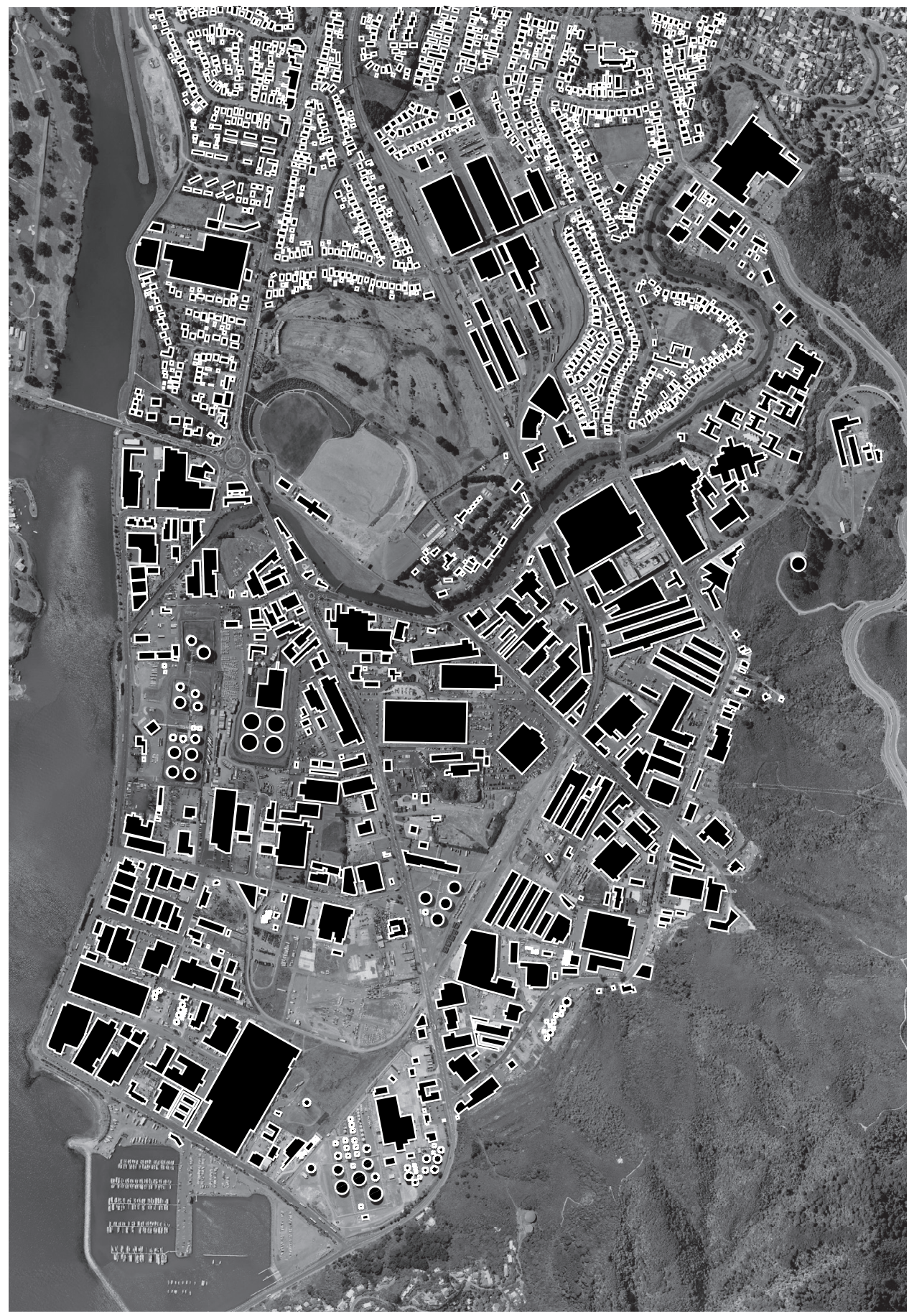

Site Inventory:

Fig. 1.04 Building mass - Scale 1:15000 
Fig. 1.05 Street Network - Scale 1:15000

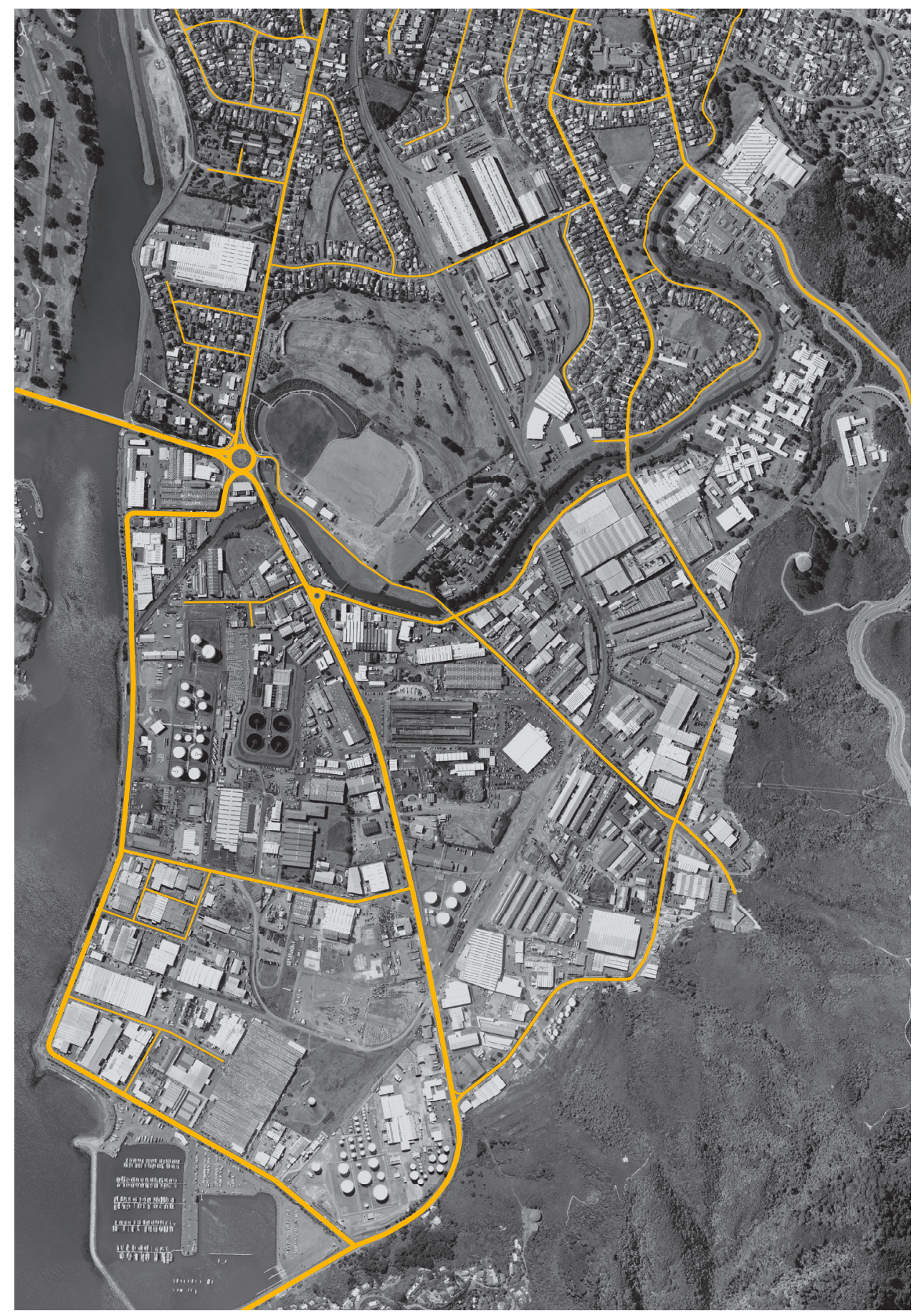




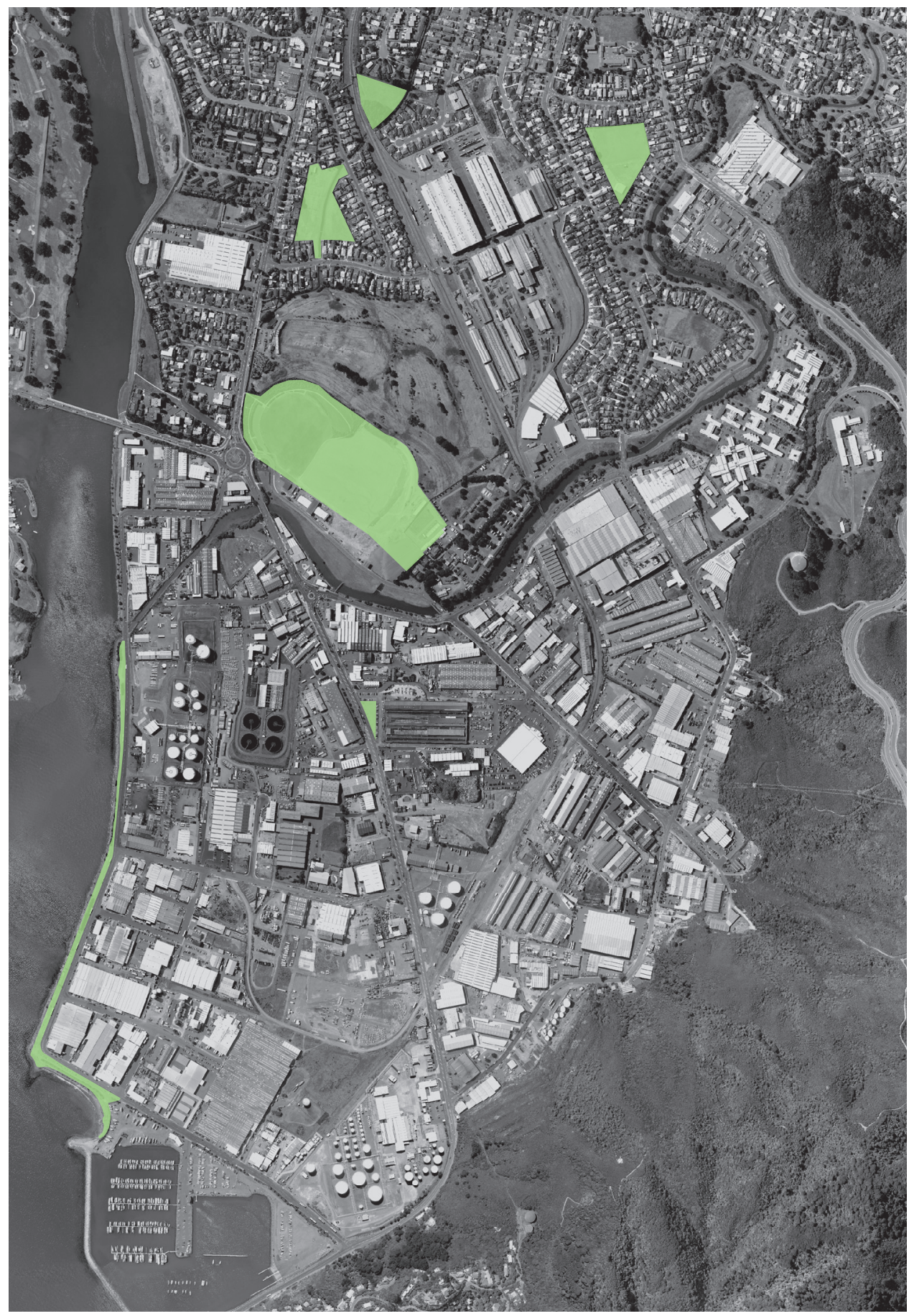

Fig. 1.06 Conventional open spaces Scale 1:15000 
Fig. 1.07 Zoning - Scale 1:15000

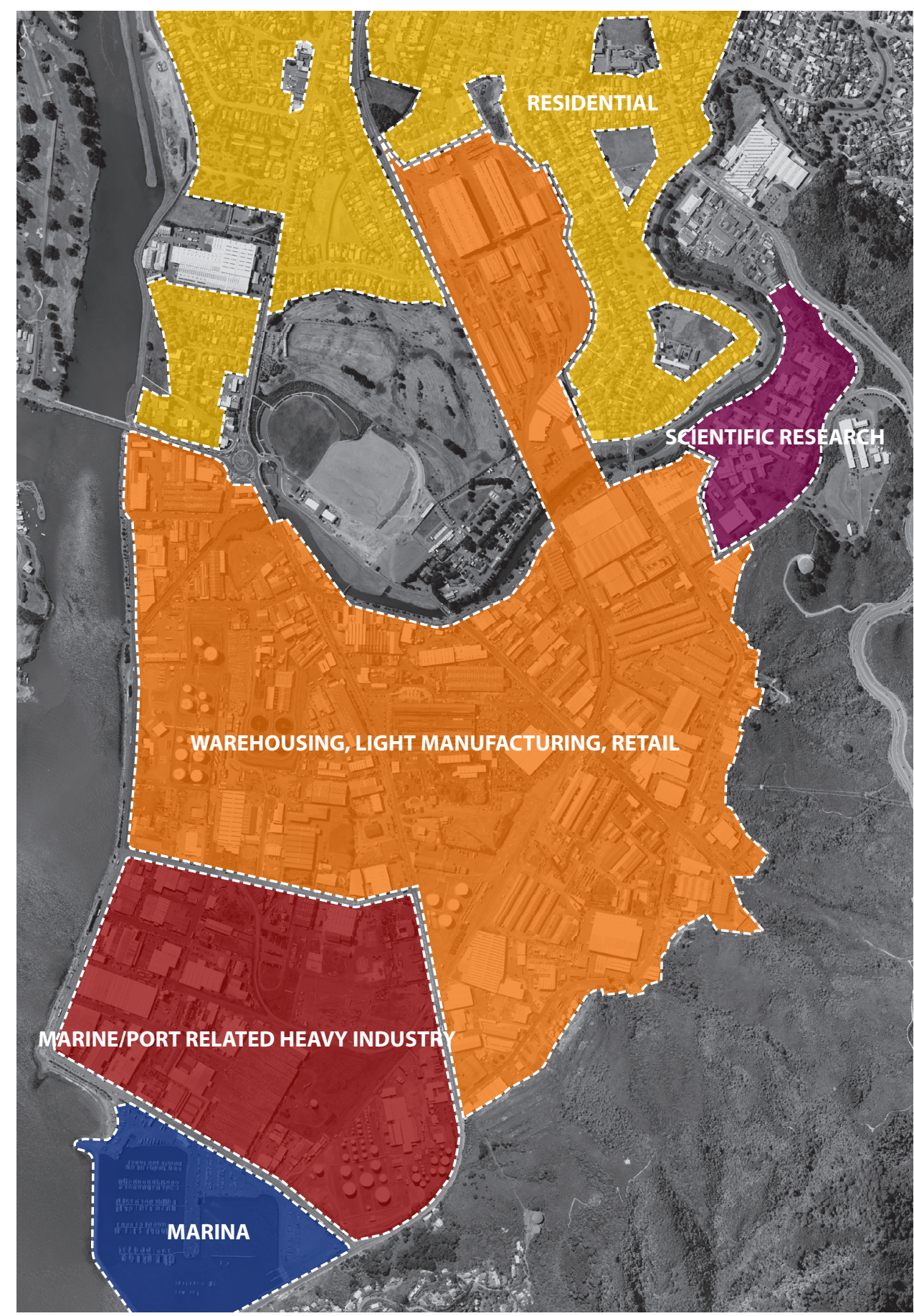


The shift from industries of production to industries of processing and storage have significantly changed the type of activity taking place along the rail corridor. The corresponding shift from rail to road as the active mode of commercial transport has resulted in the residual rail corridor edge of adjacent programs to become inactive and neglected.

Uses along the west side of the rail corridor, from north to south, include the following:

-residential housing -Hutt Valley Golf Centre -motel + caravan sites -(Parkside Road)

-auto repair -plastics manufacturing -steel and aluminium works -derelict building -metal works -automotive repairs -(Hutt Park Road) -car auctions -container storage -industrial warehousing -oil production/storage -(Seaview Road)

-log storage
Uses along the west side of the rail corridor, from north to south, include the following:

-residential housing -packaging and warehousing -(Parkside Road) -pet supplies/chemical manufacturing -warehousing/storage/manufacturing -packaging/warehousing -car dealership/warehousing -freight transport/warehousing -battery smelting and refining -(Hutt Park Road)

-freight transport/warehousing -warehousing/storage -civil construction/road engineering -wind and solar energy/commercial warehouse/ art school

-(Seaview Road) -unoccupied warehouse -oil production/storage 
History of the Woburn Railway Workshops/Seaview Rail Corridor:

Overcrowding and congestion at the Petone workshops led to the commencement of construction of the Hutt Railway Workshops in 1928, which became fully operational by 1929 . By 1940 over 2,200 people were employed on the site. The workshops were to be served by the Hutt Industrial Line, which opened in 1929; its only station being the terminus at Hutt Park. In 1943 the line was extended into Gracefield with a new terminus established there. Subsequent to land reclamation in the 1950's and 1960's, a network of sidings were built at Seaview to serve industrial operations within the area. Gracefield Yard was closed in 2002 and about this time work had started on lifting the Seaview industrial sidings.

Yet the Seaview Rail Corridor remains an idiosyncratic moment in the broader expanse of industrial fabric it has helped expand and develop; now a neglected and contaminated infrastructure that runs through the site in which it has been judged obsolete by advancements in technical and economic efficiency.

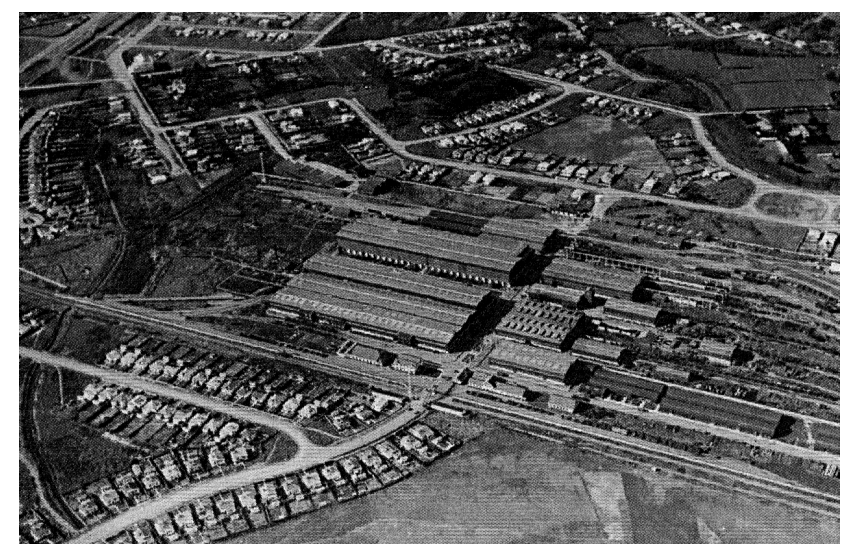

Fig. 1.08 Aerial view of the Woburn Railway Workshops ca.1930

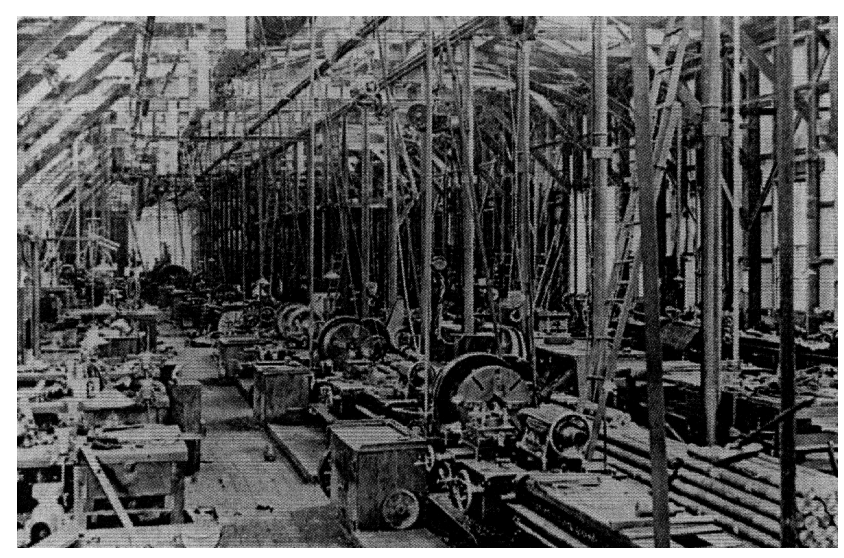

Fig. 1.09 Interior of the old Railway Workshops at Petone ca. 1920 
Extensive remediation and flood risk reduction moves, beginning in 2004, have been undertaken in the lower reaches of the Waiwhetu stream. Once New Zealand's most polluted waterway, past flooding originally drove the need to widen and deepen the channel and this was carried out in conjunction with decontamination of heavy metals, copper, zinc and pesticides. This is set to be followed by a planting and landscape enhancement programme to aid in the protection of the banks, provision of wildlife habitat and capitalise on recreational opportunity. Community engagement through the establishment of the Waiwhetu Stream working group as well as organised public walkovers that provided insight into project developments was employed throughout the restoration process.

Seaview/Gracefield has been identified as an area in which to promote developments and strategies focussing on how to develop the area are being devised. 'Vision Seaview Garcefield 2030' was a vision statement developed in 2010 by the Hutt City Council and presented the current issues and future ideas for the Seaview/Gracefield community. It was developed with the aim of exploring how the potential of Seaview/Gracefield could be optimised over the next twenty years. 'Vision Seaview Garcefield 2030' covers four main themes:

-Providing stability and efficiency to support existing businesses -Creating a suitable environment for the growth of new/emerging businesses

-Making better use of recreational opportunities

- Contributing towards a better environment 
Though falling well short of providing any compelling design implications, under these themes

'Vision Seaview Garcefield 2030' infers the following in regard to the design of parks within this environment;

\section{"Providing stability and efficiency to support existing businesses":}

-drawing attention to the area's industrial histories

-enhancing landscaping and general appearance

-promotion of the area through the staging of events that celebrate local innovations and

achievements

\section{“Creating a suitable environment for the growth of new/emerging businesses":}

-having easily accessible 'social places' where people can socialise as well as meet with colleagues,

clients and visitors

-creating recreational green spaces and promoting incorporate cycling/ jogging/walking routes with connections to the recreational areas

-social-art-cultural activities that provide vibrancy to the area

\section{"Making better use of recreational opportunities":}

-connecting to the sea, hills, river and streams

-promoting the area's unique cultural heritage, artistic and scientific endeavours and make them

visible through the development of a local arts and culture scene

-connecting and valuing the area's green spaces 
-developing Hutt Park into an attractive social and recreational space -developing Seaview Marina into a recreational area

\section{“Contributing towards a better environment":}

-protecting waterways and the harbour and taking preventative measures to stop future pollution post-remediation

-promoting Seaview/Gracefield as a place to demonstrate new environmental-related technologies where visible demonstration of new technologies by local businesses would act as a catalyst to generate and attract other new ideas

-developing ecological use and establishing educational programmes for locals and visitors -using the environmental network to encourage exchange of ideas and drive experiments and prototyping of new technologies 


\section{AN EXERCISE IN INFRASTRUCTURAL} DESIGN 
This chapter aims to present design responses that test the notion of infrastructurally conceived landscapes as catalysts within the forsaken territories of the industrial precinct of Seaview/Gracefield. A renewed approach is proposed, one that advocates exploiting the qualitative phenomena that emanate within these sites and formal, material and programmatic arrangements are proposed.

Initial strategies conformed to the principles for design developed Allen's (1999) propositions for infrastructure, however they were deemed unsuccessful because they exhibited unnecessary overdesigning and so the seductive and meaningful qualities that the sites are laden with were lost and their latent possibilities unrealised. The outputs became organised based on quantitative flows and the programs that can be designed around these and not the qualitative phenomena that make these spaces so unique. These early attempts erased much of what this research argues is too readily dismissed as negative, and with it meaningful social histories and qualities could have been exploited as alternative amenity. 

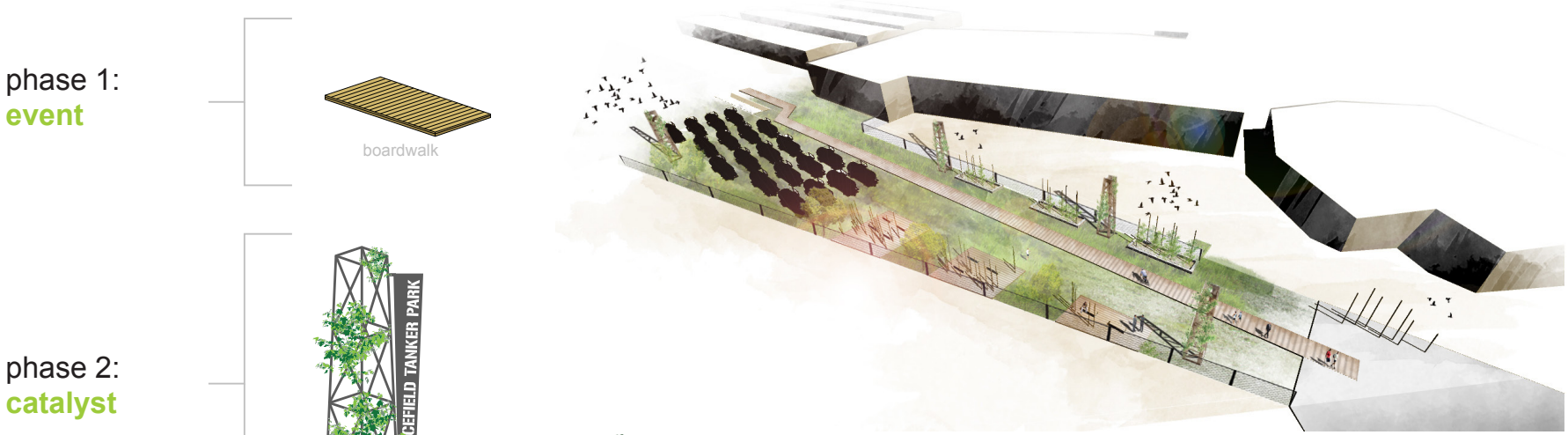

phase 2:

catalyst

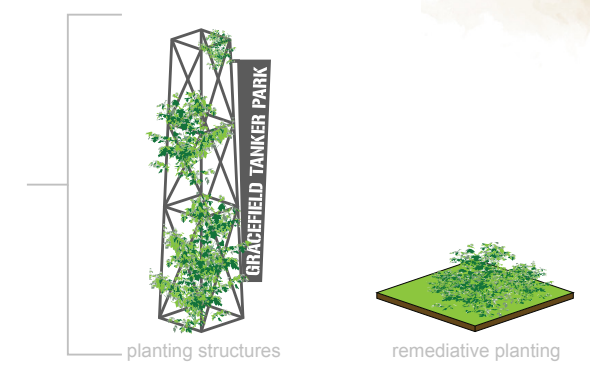

Fig. 2.02

Fig. 2.01-2.03 illustrate an initial intervention strategy comprising the themes: event, catalyst, infrastructure and cultivate. The first phase is the staging of temporary events designed to overcome the physical and psychological disconnect between the site and public by providing access and encouraging participation. These are followed by small-scale interventions that exploit onsite systems, engage community and other stakeholders and initiate consequent developments. Then large-scale infrastructures are put in place to facilitate soil remediation and the processing of stormwater. Ultimately, the final phase of this

phase 3:

infrastructure

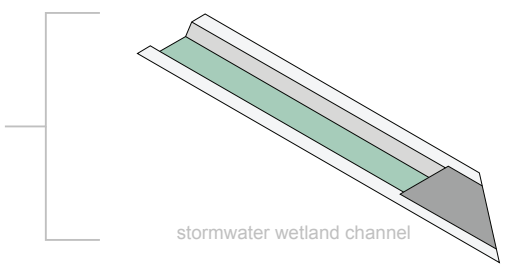
strategy is realised through the development of these residual spaces into parks.

\section{phase 4:} cultivate
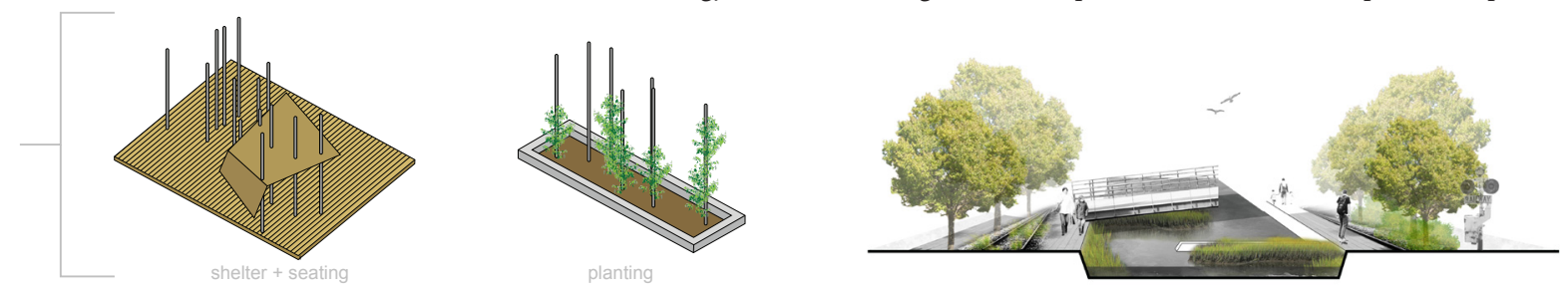

Fig. 2.01

Fig. 2.03 
Throughout the design process it often became necessary to work backwards, with the result of doing less or nothing often proving more successful than contextually-irrelevant over-programming or over-working. On the difficulties of designing forsaken territories, Florian Beigel (1997, as cited in Armstrong, 2006) states;

... the key issue is to do with designing emptiness, to decide where nothing will go. This word emptiness is enigmatic, has a sense of wonder and an almost inbuilt potential for getting one's imagination going .... I feel such 'emptiness' is inherent to certain landscapes. It can also be found in cracks, or holes in the city, where there cease to be rules, leaving the spaces to grow wild. Such places spark not only my imagination but also the imaginations of people who come to inhabit them. Nonetheless, designing in these situations is a very delicate thing because such wildness is so fragile and can all too easily be destroyed.... The key is to do 'almost nothing' as Mies said once. I find this a very provocative statement and a good starting point. (p.55)

Through the process of design it became apparent that the role of the designer was first to become more of a facilitator or enabler. Rather than designing places it became more relevant to the research aims to develop the sites as stages for the programmatic conflicts and spatial contestation to unfold. It is the potential this approach instils within these forsaken spaces and their indeterminacy that promotes a succession of enlightening practices that create a relevant, socially significant sense of place. 
What follows are investigations of how infrastructurally designed landscapes can capitalise upon the qualities found within the residual rail corridor of Seaview/Gracefield and recognise them as opportunities to develop the concept of park in this context as something beyond a respite from the urban condition; a landscape that reflects the important social histories of the area while also presenting a proving ground for future operations. With the working assumptions derived from the examination Allen's propositions in mind, the organisational and physical composition of 'parks' within selected sites of Seaview/Gracefield are explored under themes that convey the qualitative phenomena found within forsaken territories. These themes are program, materiality, form, graphic language and ecology. 


\section{Program}

Despite their location in the industrial margins of the city, forsaken territories are resonant spaces where the rigorous programming of the surrounding environment no longer applies. Situated within areas where uses, architectures and the scale urban blocks are all driven by the pursuit of quantitative efficiency, these voids present us with paradoxical typologies of urban territory that allow for sensory experiences of space.

Seaview/Gracefield's rail corridor provides a stage for all operations, planned and unplanned, sanctioned and unsanctioned, to perform on. Walls and train carriages provide canvases for graffiti. A strong culture of dumping scrap materials exists but one of salvaging is developing, with arts studios and other operations capitalising on the reuse of materials. Forsaken territories perform as a kind of stage for exchange, where endorsed and illicit programs are made explicit but also exploited by new practices. How might we program these spaces so that their innate qualitative phenomena are made more explicit and tangible? How do we incorporate their use into the rituals and practices of their context while allowing for new and liberating operations? What temporary and permanent architectures, spatial allotments, rituals and community structures might be put in place to develop an authentic sense of place and cultivate its growth? 


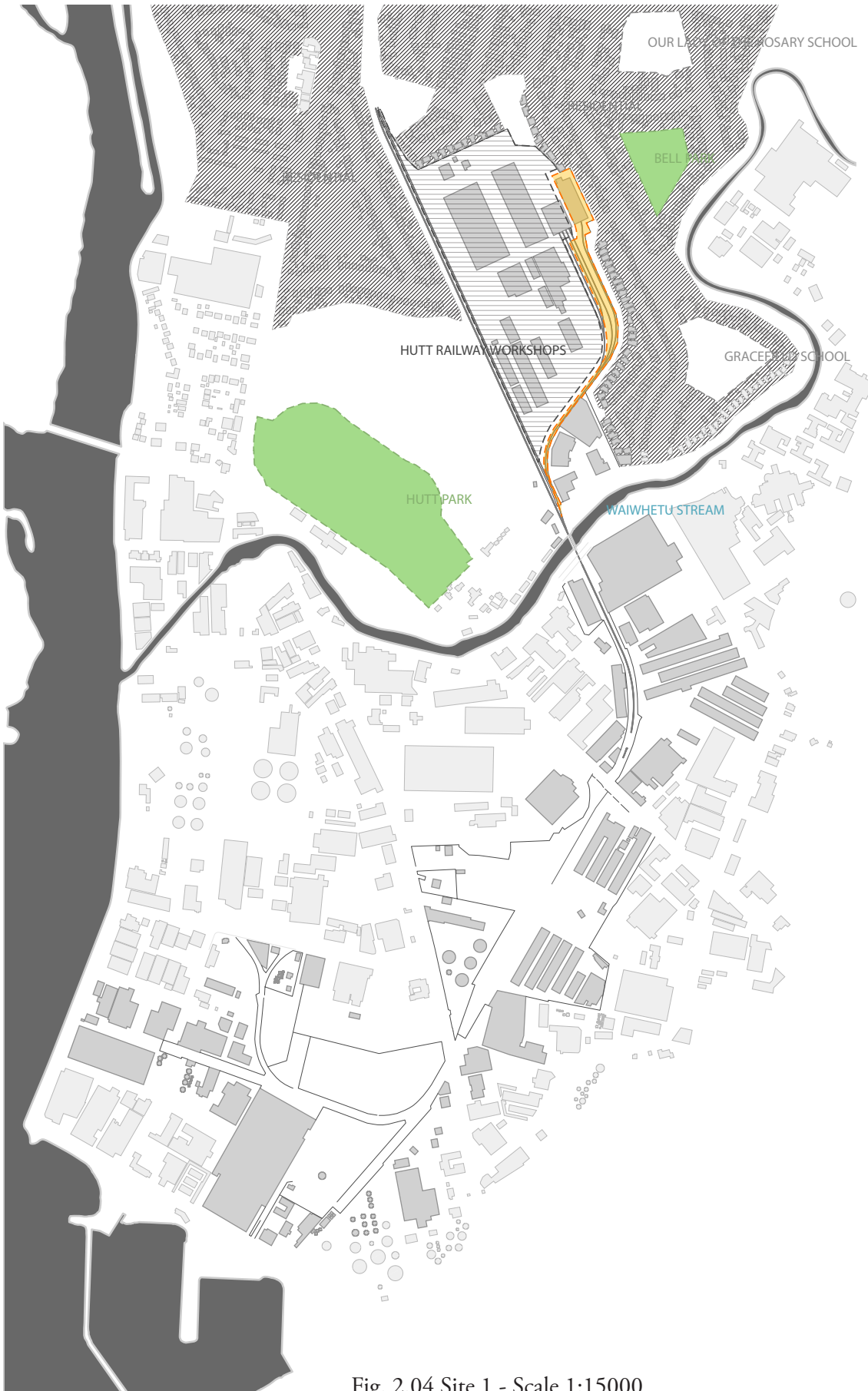

Fig. 2.04 Site 1 - Scale 1:15000
Many of the qualities that we find so seductive in forsaken territories come about through the unprogrammed nature of these spaces. While it may appeal to leave them as they are, to keep their uncontrolled condition intact, this would mean missing out on the potential to develop infrastructures that grow a sense of identity and community as well as diversifying uses as the precinct undergoes change. In order to prepare the ground to support future programs we must understand how each of the sites along the rail corridor fits into the precinct, so as

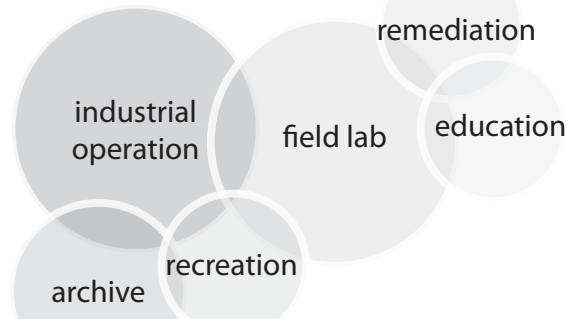

Fig. 2.07 Site 1 - Proposed programs 
to accommodate immediate contingencies while maintaining an overall continuity in the rail corridor as a primary infrastructure within Seaview/ Gracefield. Fig. 2.04-2.06 examine the local conditions that might translate into contextually relevant programs that allow for the greatest establishment of community and associated engagement. Fig. 2.07-2.09 suggest themes under which new programs might be generated and the respective emphasis placed on these throughout the different sites.

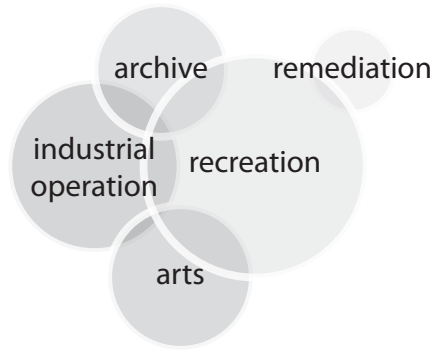

Fig. 2.08 Site 2 - Proposed programs

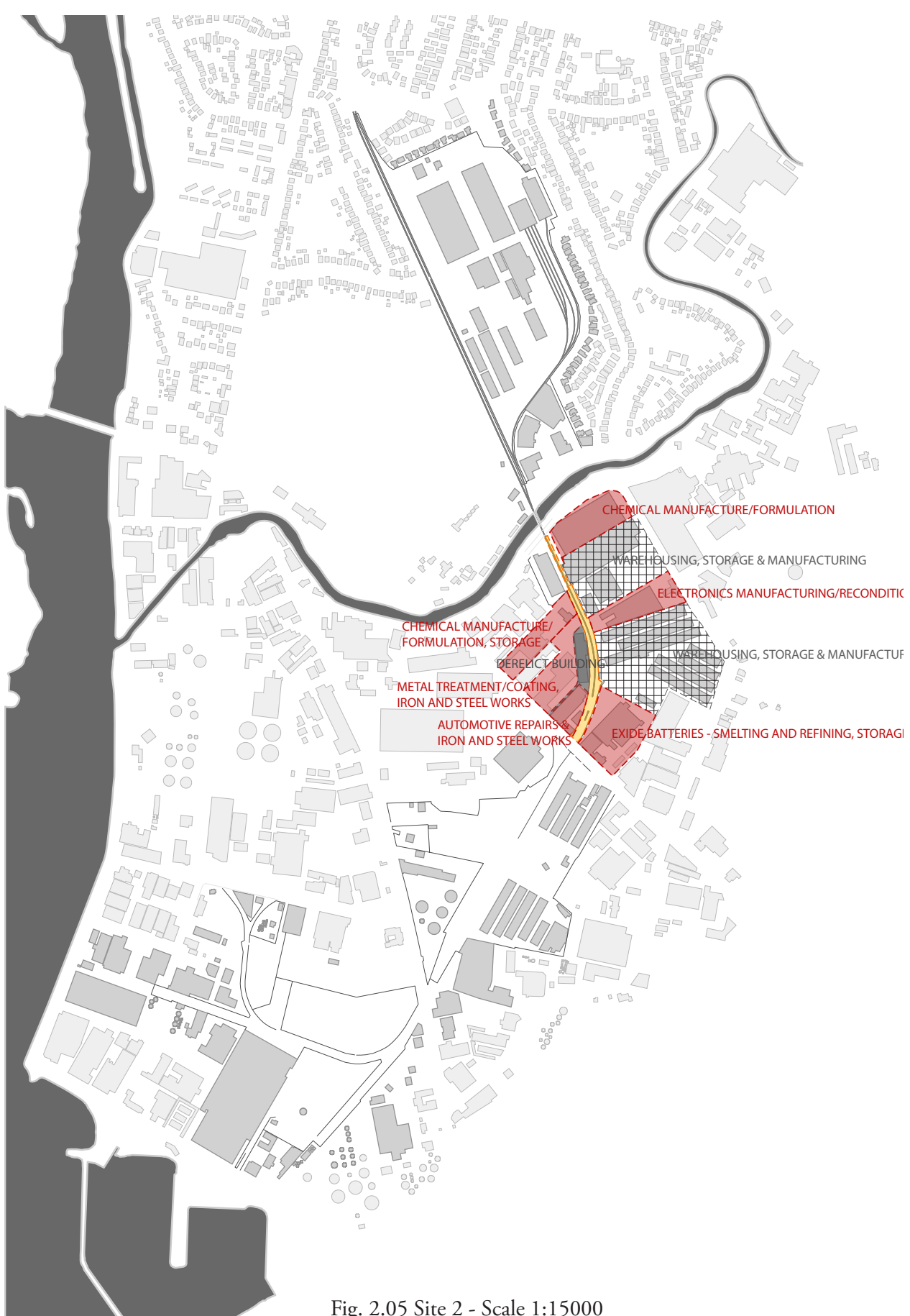

Fig. 2.05 Site 2 - Scale 1:15000 


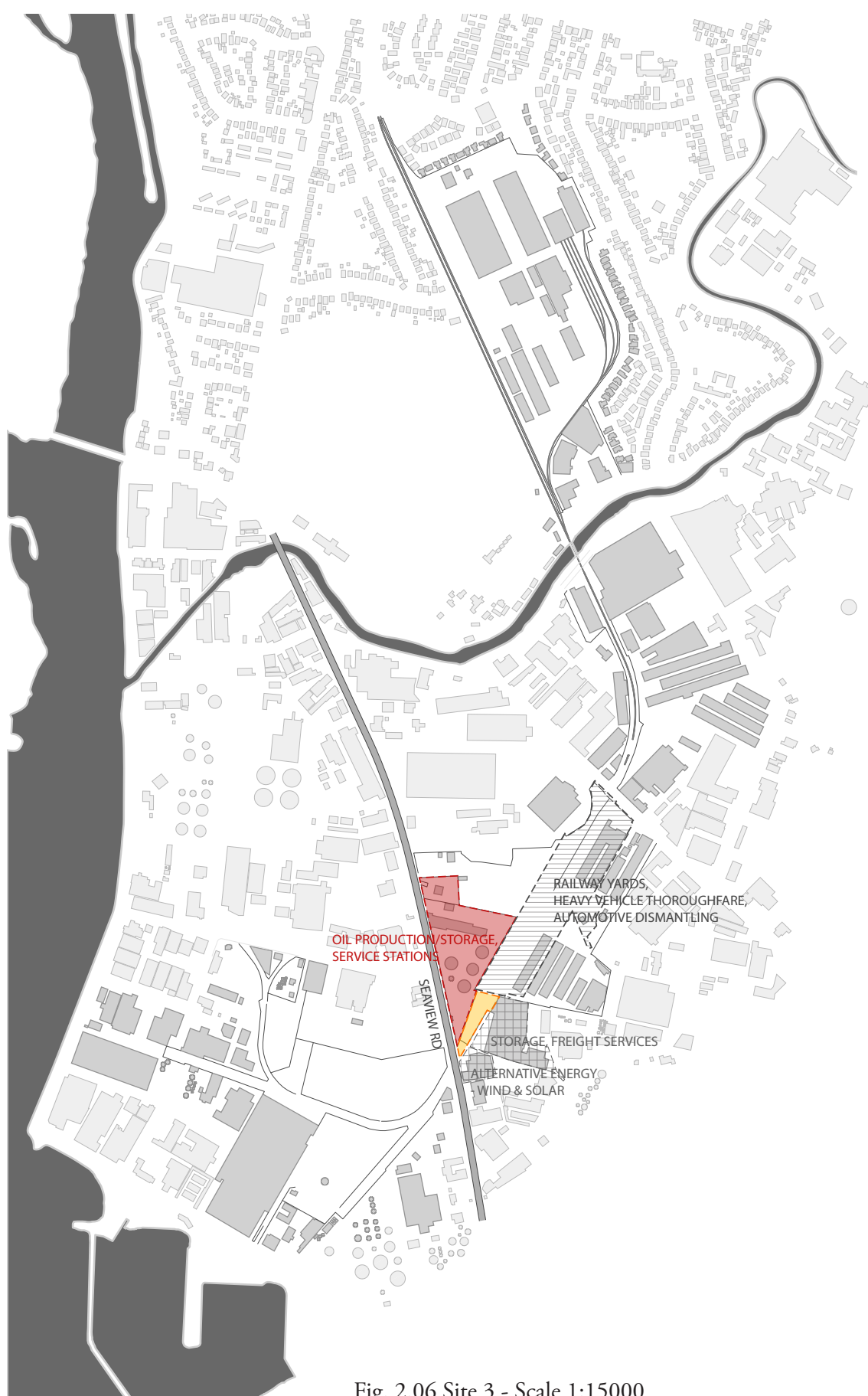

Promoting the act of occupation by facilitating access becomes the first and perhaps most significant event in preparing the ground for future programs. Providing people with a crucial pedestrian link that bisects Seaview/Gracefield, an area whose street network not only privileges vehicular transport but promotes it as the only viable form of transport, is a key move in developing the residual rail corridor into a catalyst. Encouraging people to walk through the sites becomes a tool in breaking the physical and psychological disconnect

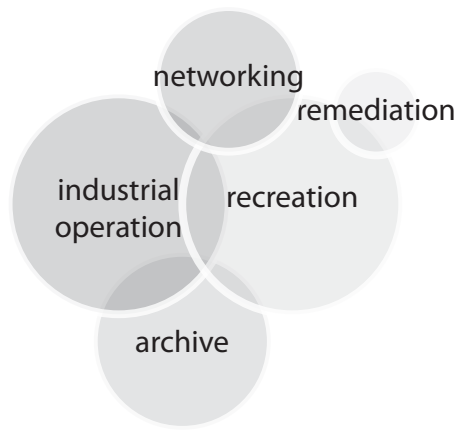

Fig. 2.09 Site 3 - Proposed programs 
between the abandoned sites and the public, and promotes the claiming of territory and the establishment of networks for movement, communication, and exchange.

Fig. 2.10 Program framework

Fig. 2.10 explores a potential organisation of programs in response to the mapping of local conditions and the diagramming of subsequent proposed programs. 
The proposed organisation of programs (see Fig. 2.10) aims to construct the site, establishing networks for movement, communication and exchange. It is intended to perform with an inherent openness that also allows for unanticipated development. This framework seeks to integrate infrastructural programs into a system that works with the qualitative phenomena of time, memory and place.

The proposal for Site I: Hutt Workshops Park makes use of its proximity to an established residential community, encouraging public participation and investment into the proposed 'park' infrastructure. This is achieved through the development of this area as a field lab site. Programs of a plant nursery, phytoremediation plots and educational sites are proposed to function in conjunction with the nearby schools so that beyond functioning as part of a new public-use network, the Hutt Workshops Park facilitates participation in remediation processes and educational programs that endeavour to trigger a shift in the public perception of the site.

Site II: Gracefield Sidings Park is located within a much rougher grain industrial/manufacturing environment and the aspiration to convey its finer grain qualities suggests a much lighter touching on the ground, as much through program as through physical form. The physical and psychological disconnect between the corridor and the adjacent operations intends to be addressed through a diversifying of the edge condition that aims to develop a greater dialogue with the surrounding context. This site is intended to be programmed as a stage for exchange, where both endorsed and illicit operations are allowed to occur.

Site III: Seaview Tanker Park envisions a granting of public access to a pedestrian corridor through 
the northern boundary which currently facilitates programs of automotive dismantling and vehicular access on the former site of the rail yards. Rather than attempt to fix the consequent spatial contestation and programmatic conflicts, these are embraced, allowing for the 'park' to function as a public thoroughfare. Stimulated by the adjacent alternative energy operations, it is proposed that the space perform as a proving ground for technical innovation; an opportunity to test, showcase and advertise new developments.

The proposed park infrastructure framework indicates a field of focused design investment while strategically opening up the edges of the site to urban development pressures. The openness and unoccupied character of forsaken territories is intended to encourage a diversity of authors to claim territories and intervene within them. 


\section{Materiality}

The materiality of Seaview/Gracefield's forsaken territories provides a rich palette to draw from. Concrete, steel and timber are found in various stages of deterioration, corrosion or decay. Glass shards, palettes, crates, drums, plastic and unidentifiable objects of scrap metal embellish the corridor's ground plane of railway sidings and gravel. These spaces offer a rich diversity of textures. Walking amongst the debris of their industrial pasts stimulates a sensory awareness that is so constricted by the rigorously programmed and controlled surroundings. Forsaken territories are sensual spaces. Concerning the introduction of new forms and architectures, it becomes important to address both the sense of permanence that exists in the 'void' that is the rail corridor as well as the more temporary character of the material qualities that can be found within it in addition to the nature of potential activities and structures. 

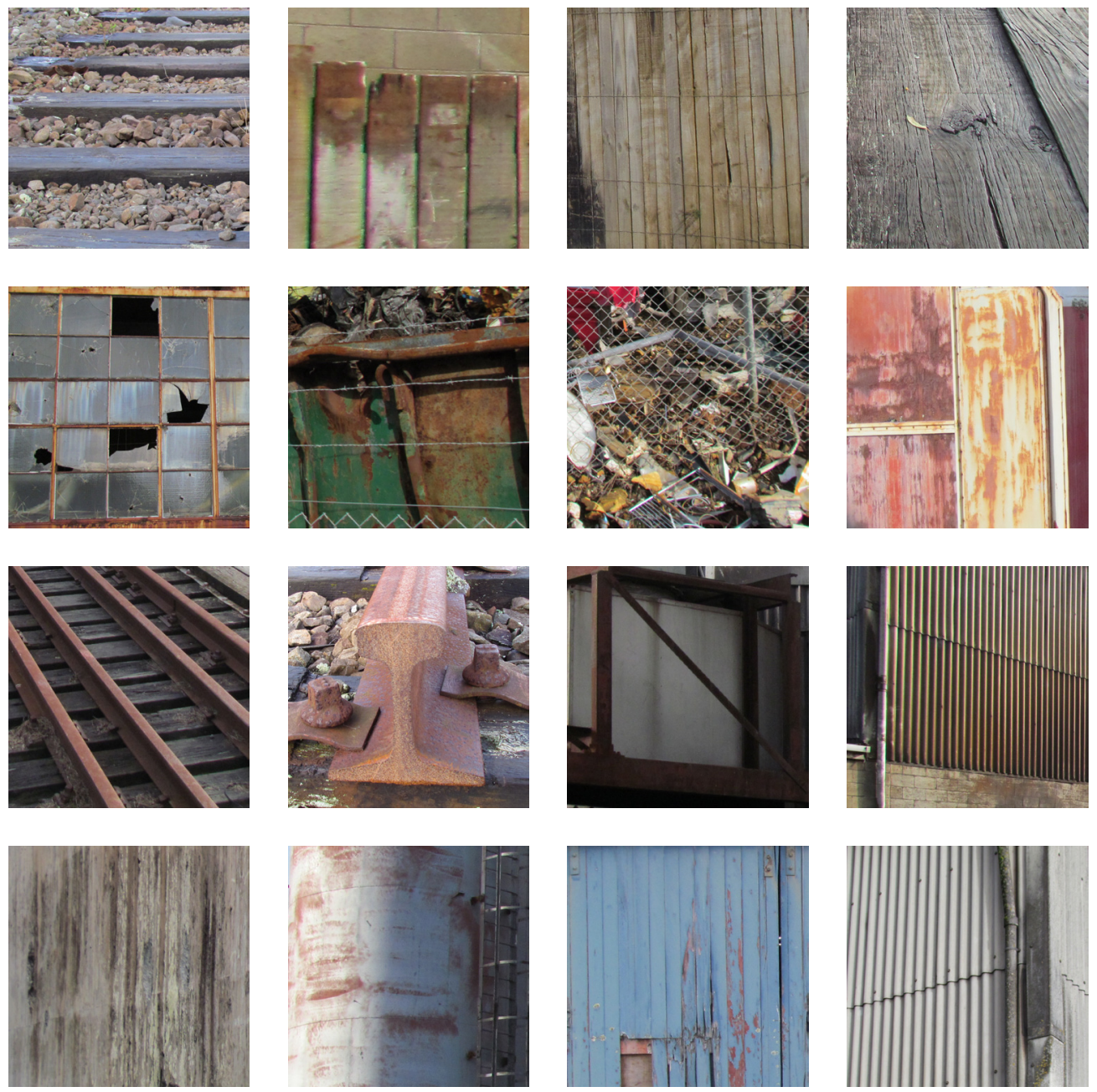

Fig. 2.11 Selected material palette 
The material palette proposed in the intervention within Seaview/Gracefield's rail corridor remains as simple and restrained as that which currently exists onsite. Intricacy is developed through the use, deterioration and disturbance they experience once they are inserted into their environment. Cast concrete, corten steel, and timber offset the patina of rust that embraces the spaces. These materials are repeated and manipulated to create a richness that doesn't overpower what is already there. Timber boardwalks emphasize the rhythm of the railway sleepers that once supported a lifeline of industrial efficiency. Perforated steel walkways allow the textures and colours of the rail corridor to permeate through. While rail tanker carriages and industrial structures lie disused and un-intervened upon, corten steel architectural follies frame the corridor, referencing the residual infrastructures and reinforcing the figural void of the park network. Through a tweaking of the material language that exists, the design's material palette creates a subtle contrast between the ruins of disturbance and new forms that reactivate the space. 


\section{Form}

Developing these sites into parks presents a complex challenge, particularly in regard to the role of their ruins of industry and manufacturing. These often function as architectural follies; the structures that remain tend to be impressive in scale and materiality, but ambiguous in their function (Chan, 2009). Detached from their purpose, buildings and objects become fragments of industrial past isolated from their original contexts, creating new intriguing relationships with the spaces they reside in.

In intervening in industrial ruin sites, perhaps it becomes important to treat these residual infrastructures or ruins primarily as historical evidence and secondly as aesthetic devices. They then function as an archive or a lens into the past but also provide a driver for an applicable aesthetic without becoming overly intervened upon themselves. This creates a contrast between the ruins of disturbance and, through a tweaking of the material and graphic language that exists, new structures that reactivate the space. 

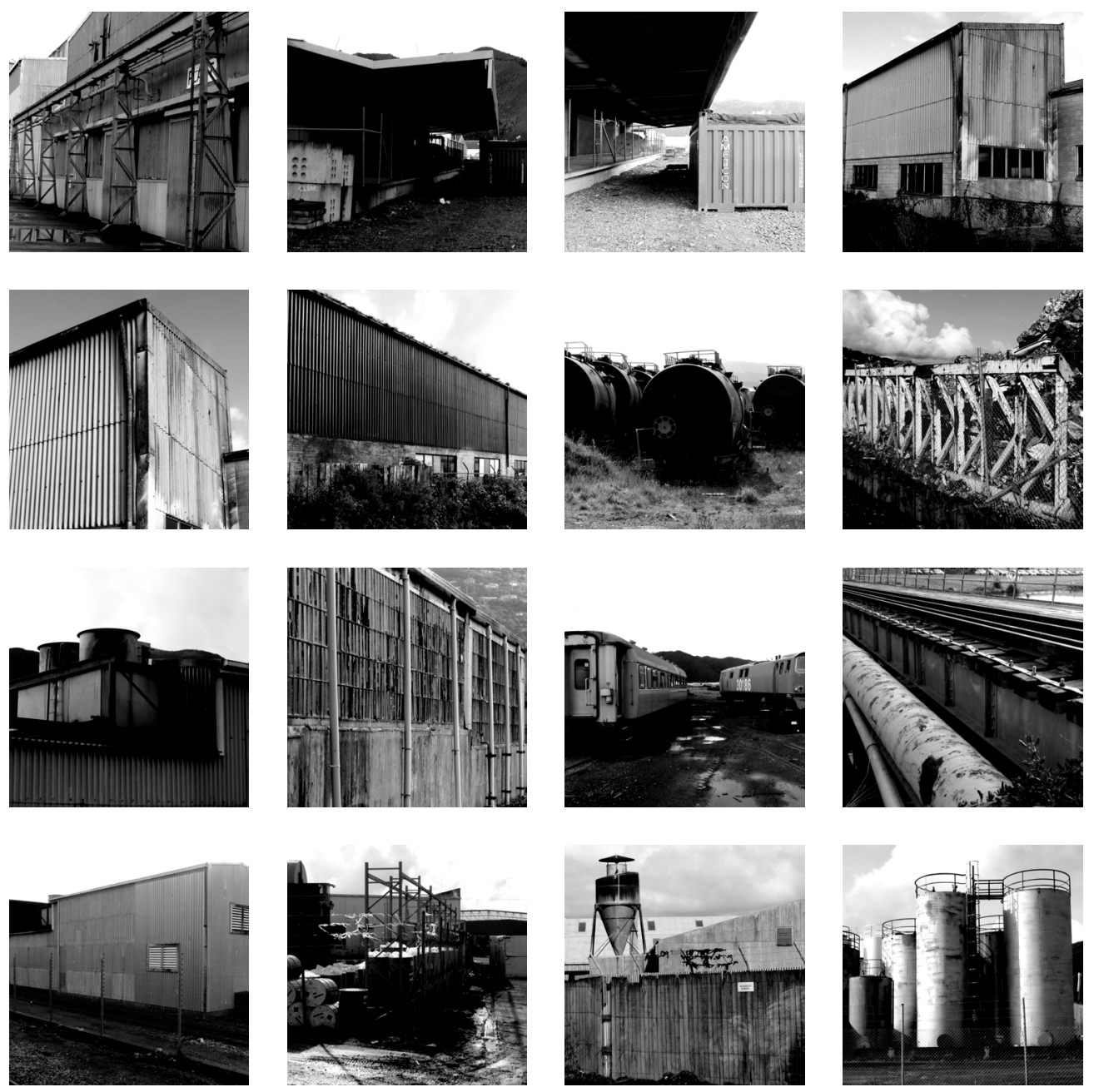

Fig. 2.12 Form inventory 


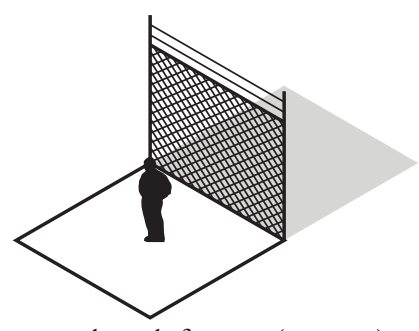

steel mesh fencing (existing)

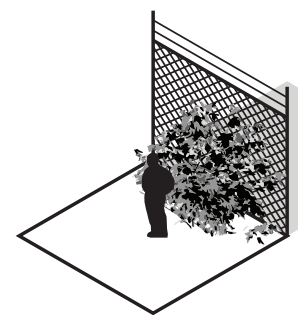

vegetation + steel mesh fencing (existing)

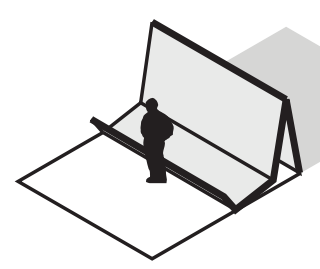

steel dump/salvage material fence (proposed)

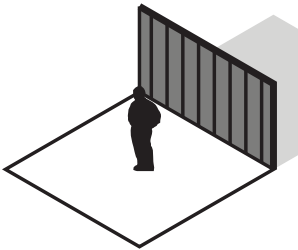

timber fencing (existing)

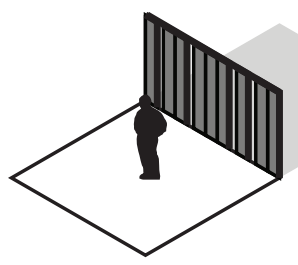

permeable steel fencing (proposed)

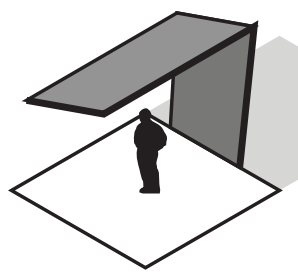

sculptural steel forms emphasising void (proposed)

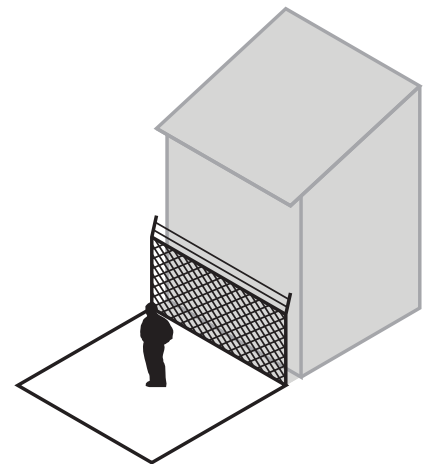

steel mesh fencing + building facade (existing)

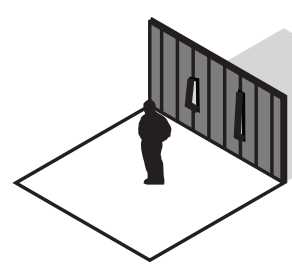

timber fencing + viewports (proposed)

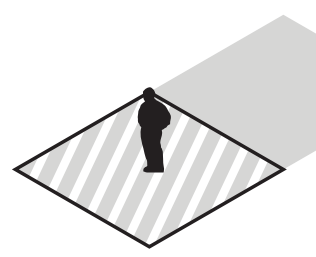

surface demarcation (proposed)

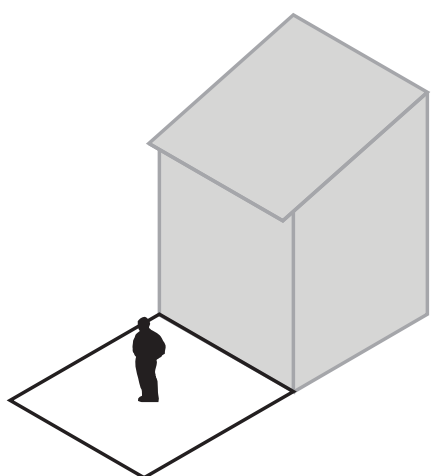

building facade (existing)

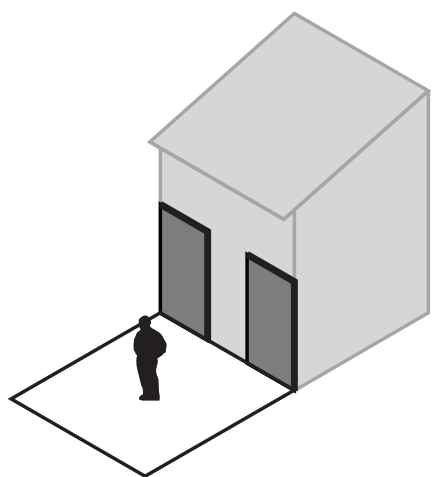

building facade + information panels (proposed)

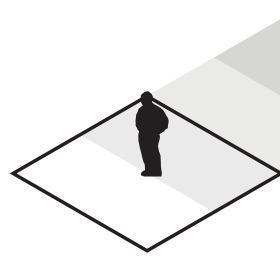

territory overlap (proposed)

Fig. 2.13 Diversification of the edge condition of the rail corridor 
Fig. 2.13 examines the existing edge conditions that occur along the rail corridor and proposes new ones with the intention of not only diversifying these but extending the focus beyond the boundaries of this void that bisects Seaview/Gracefield. These look to develop a greater dialogue with the surrounding context and break down the psychological disconnect between the notion of 'park' and industrial operations. Expanding the zone of design focus allows for a strategic opening up of the edges of the site to existing urban development pressures, so that underutilised adjacent territories may be claimed or shared. Additionally, structures could be introduced at intervals that reinforce the figural void of the park infrastructure, creating a strong image for the identity of the precinct. 
Fig. 2.14-2.16 explore the development of the residual rail corridor into a void of parks and connections that strategically open up the edges of the site to existing urban development pressures, claiming and sharing new territories. As the proposed 'park' infrastructure grows, public access through the site, program diversity, space for development, and connectivity between the green spaces across Seaview/Gracefield are increased.

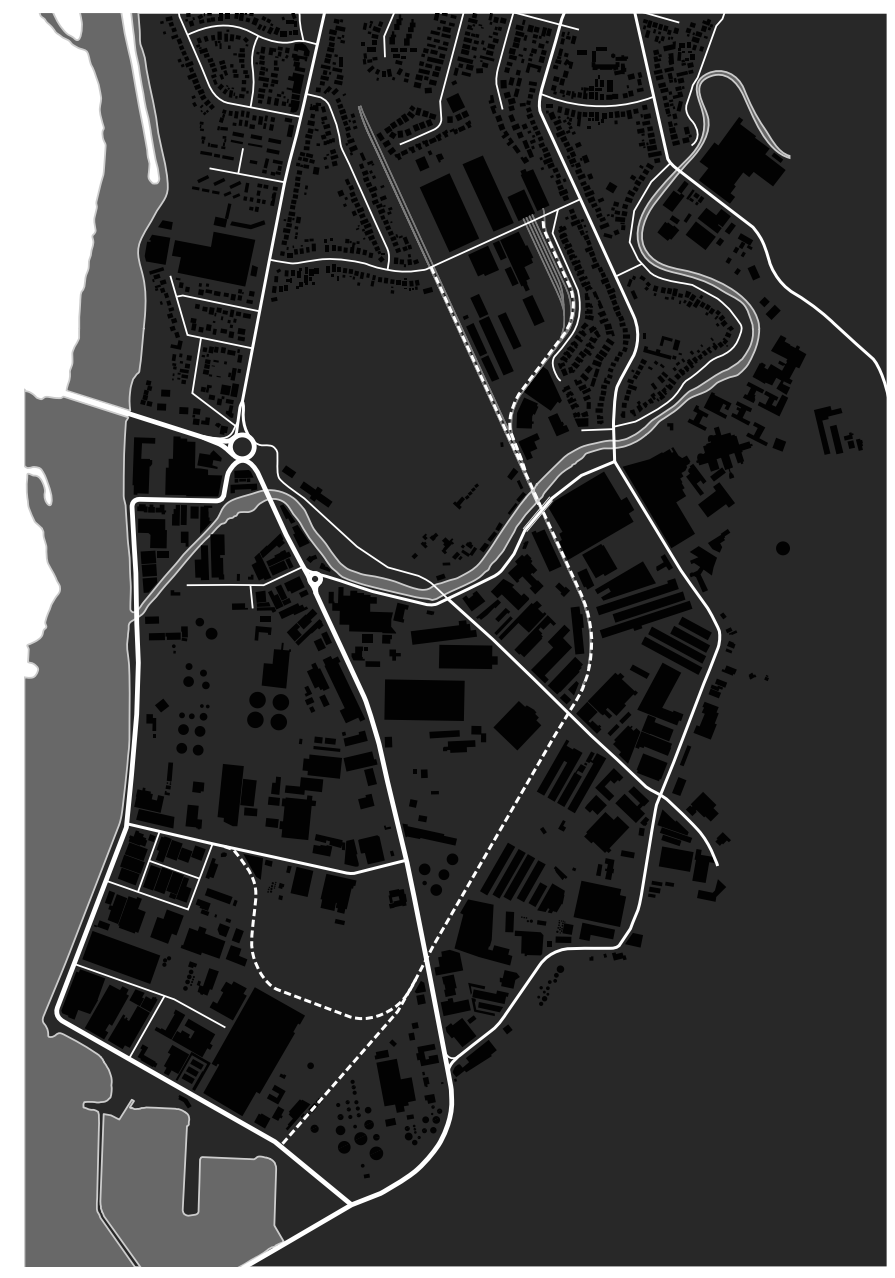

Fig. 2.14 Void stage I 


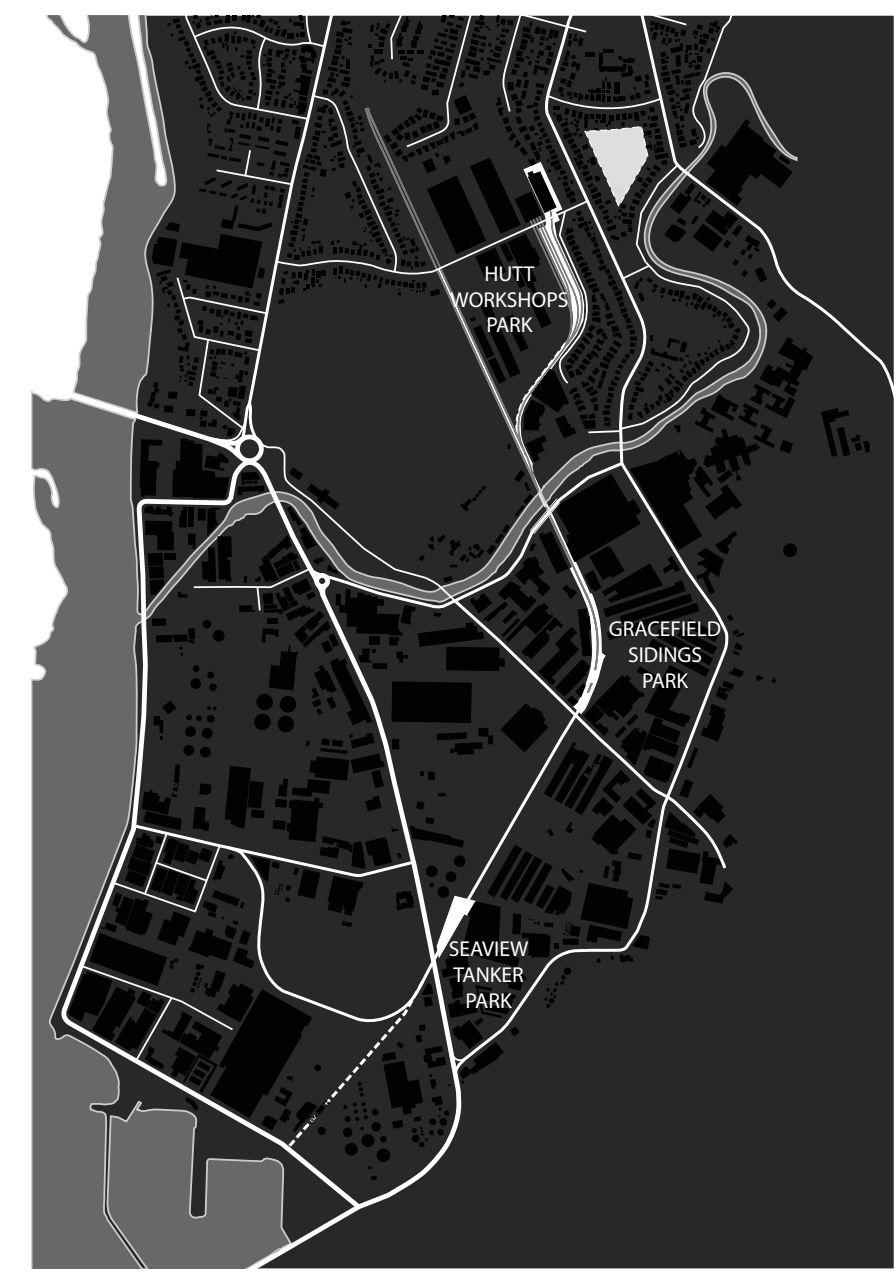

Fig. 2.15 Void stage II

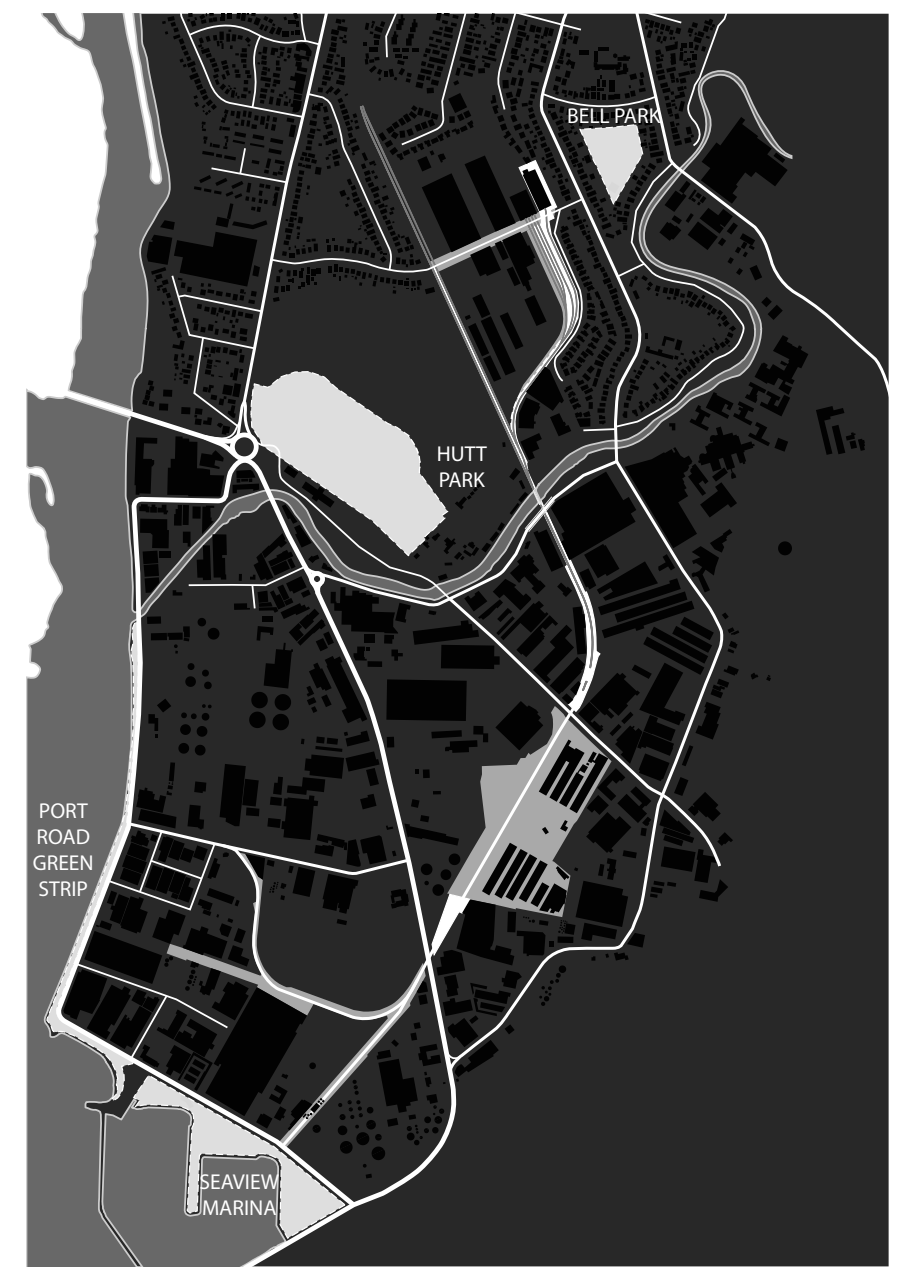

Fig. 2.16 Void stage III 


\section{Graphic Language}

The controlled nature of industrial spaces is reinforced by authoritative texts and graphic languages. Numbering systems, operational instructions, orders that deny entry to those without authority and directions keep these places operating under controlled spatial practises. These graphic languages become traces that that haunt forsaken territories. They indicate the former presence of people and operations that now cease to exist. Now the languages of regulation clash with those of rebellion. Graffiti claims the facades that once found themselves under strict surveillance.

We can draw from these traces of meaning and weave them into the creation of new 'parks' within the forsaken territories of Seaview/Gracefield so that they not only function with relevant way finding or information languages but they also allow for the layering of existing industrial operations with new 'park' programs. Connecting the evocative traces of the past with new ones, allows us to orientate these spaces within the larger residual rail corridor as well as allude to important social histories within an infrastructure that, as one of its roles, performs as an archive of industrial pasts. 

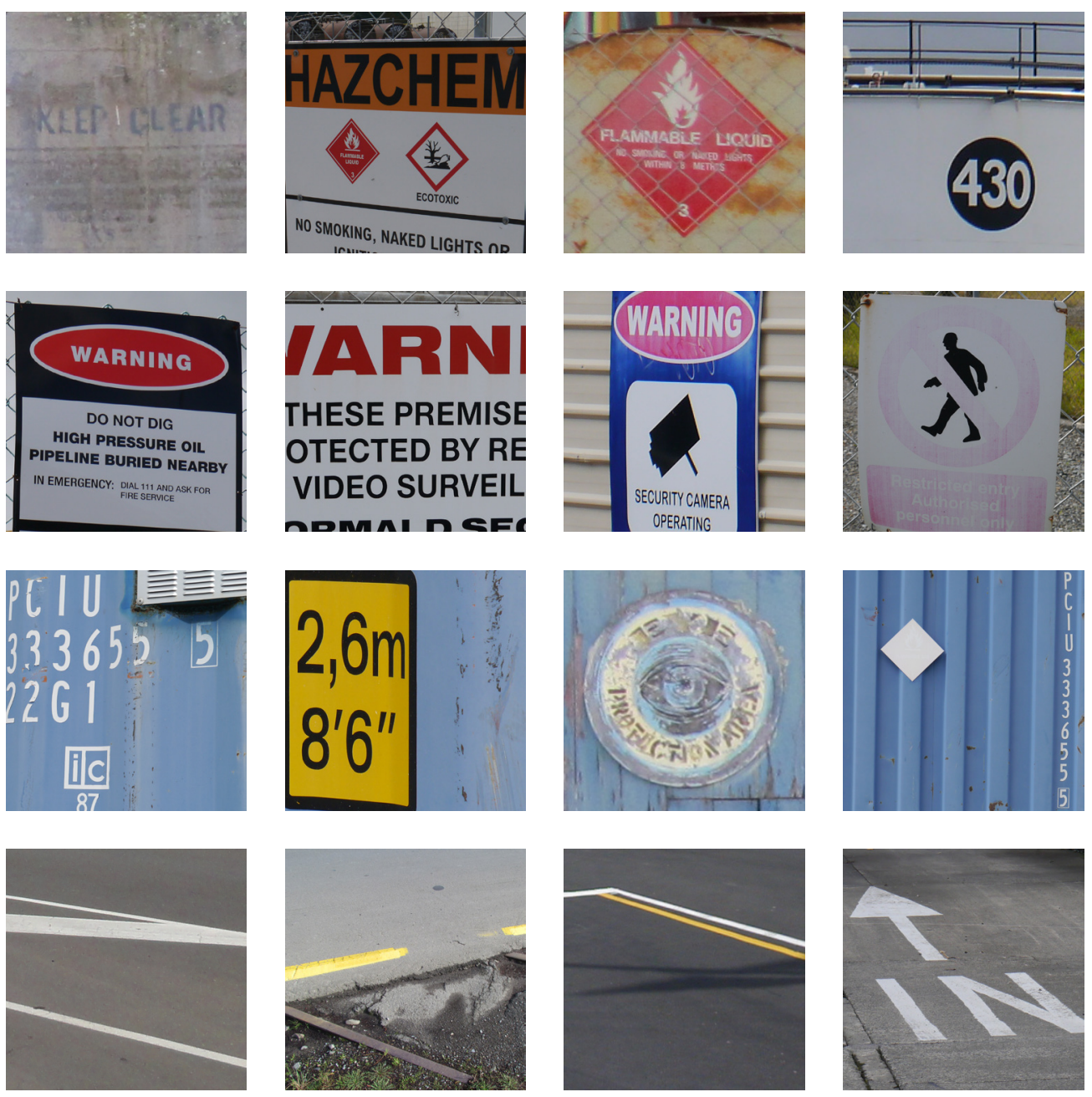

Fig. 2.17 Graphic language and visual traces 


\section{Ecology}

In forsaken territories we can experience the beginnings of a breaking down of the disconnection between industrial operation and the presence of ecological value. The boundaries of control and delineation disintegrate and cultural and ecological processes mix. Here the perceived industrial/ ecological dichotomy is interrupted by the reclamation of flora and fauna into the previously rigorously ordered spaces of mono-programmatic efficiency. While some contamination exists within their soils, the disturbed nature of these spaces adds to the seductive beauty of their decay that makes them such evocative sites for 'parks' that explore what identity, time, memory and place means within these environments. Do we leave them in their disturbed state; gritty and un-manicured, but retaining negative public site perceptions, as well as physical and visual disconnects? Should conventional remediation methods be employed, making these voids safe for recreation but disconnecting them from the events that shaped them? Or is it possible to reclaim and remediate through the development of catalysts that facilitate access throughout the process of remediation within nominated areas while leaving some unmanaged, triggering a change in the public perception of the site and engagement with meaningful social histories as well as developing new rituals or programs that develop communities that cultivate them? 


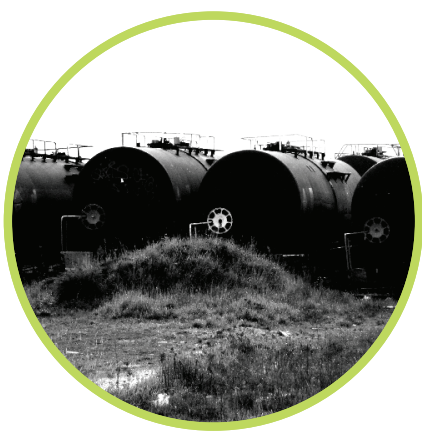

\section{disturbed site}

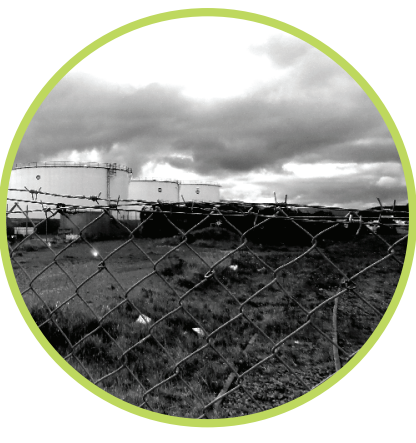

contaminated soils, lack of public visual and physical access, disused spaces

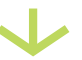

negative public site perception, physical and visual disconnect
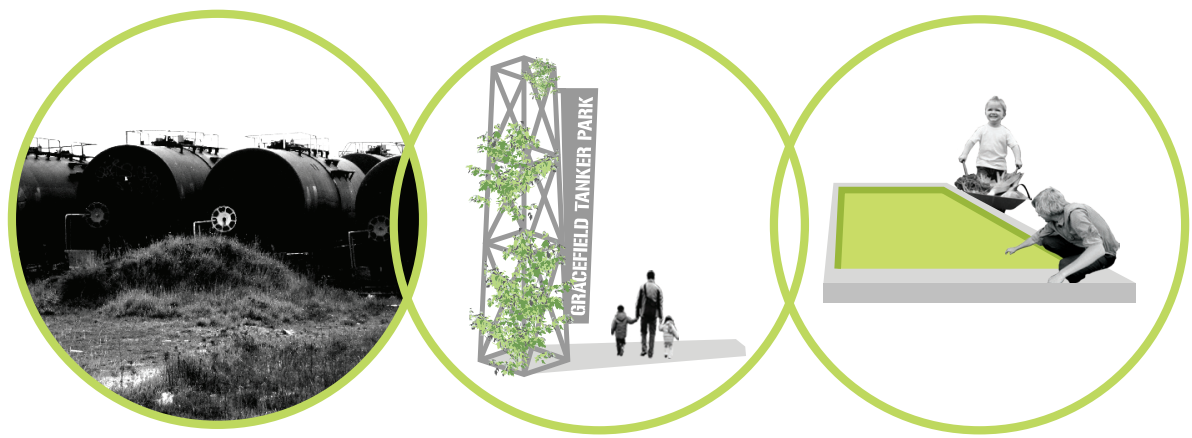

reclamation and remediation through catalysts

fencing off of site(s), restricted public access, contaminated soils buried under clay caps

a practice in forgetting and deception,

physical and psychological disconnect between

the sites and those that use them

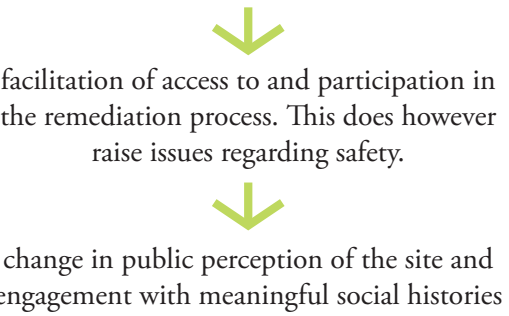

Fig. 2.18 Comparing ecological remediation scenarios 


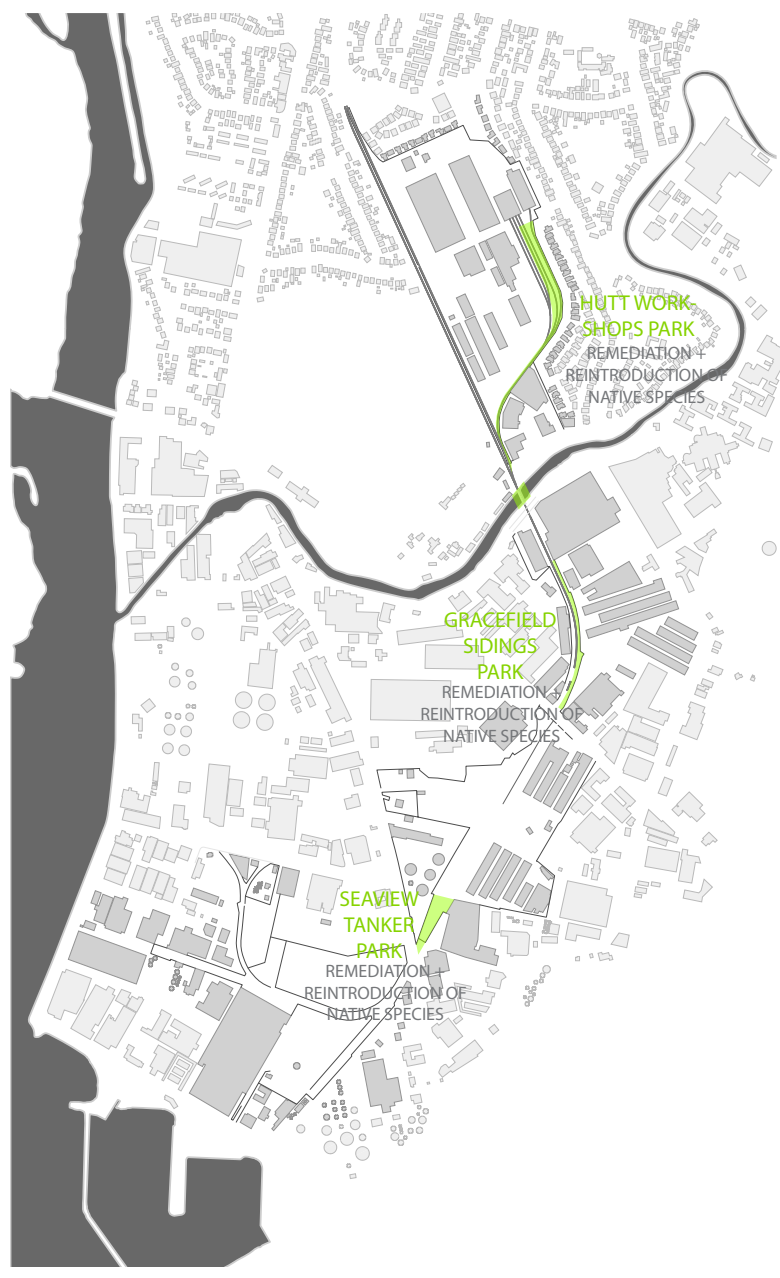

Fig. 2.19 Remediation scenario I

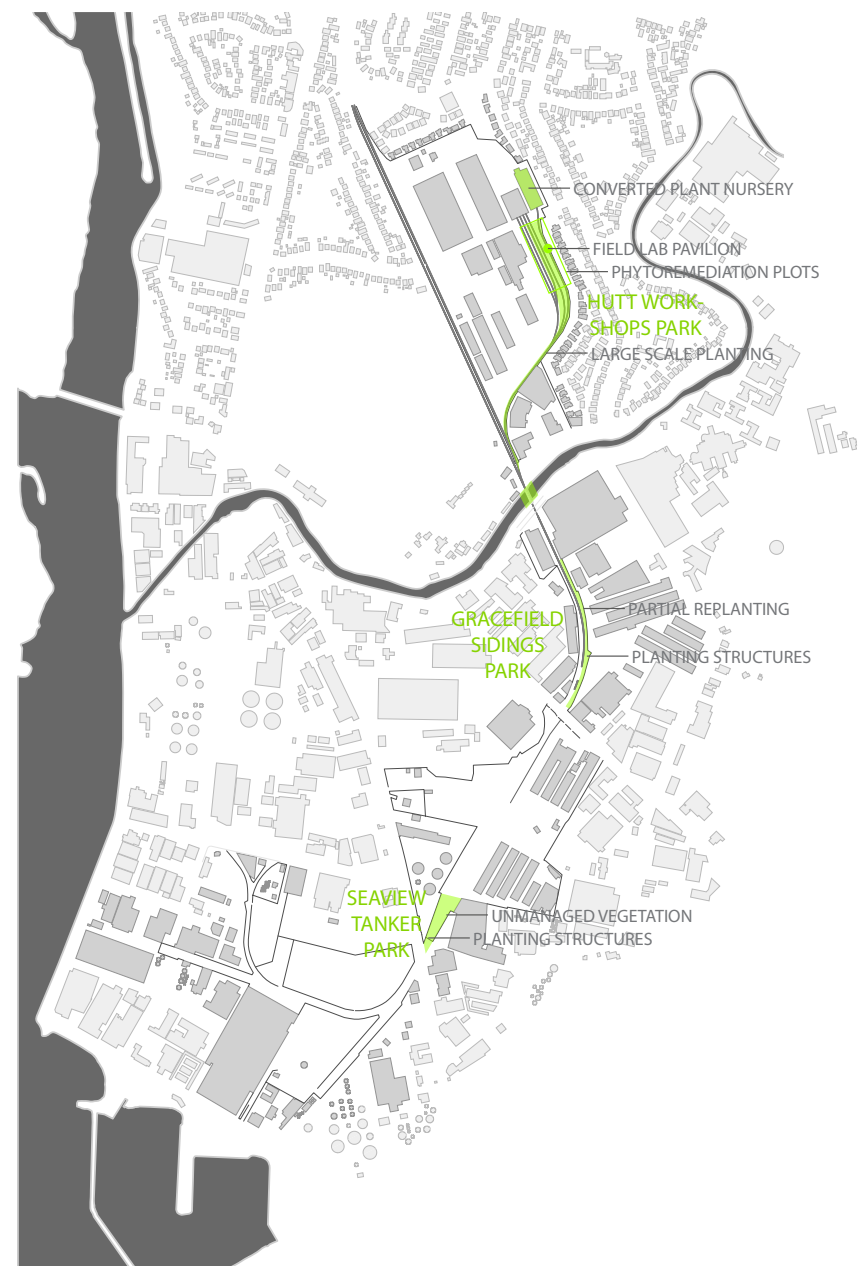

Fig. 2.20 Remediation scenario II

Fig. 2.19 explores the large scale implications across the site of the previously mentioned remediation scenario where the selected 'park' sites are closed off to undergo a remediation process. However, this maintains the state of disconnection between the public and the sites. Fig. 2.20 explores the large scale implications across the site of the previously mentioned remediation scenario where reclamation and remediation occurs as a series of catalysts. Here remediation is focussed within specific sites where the public are encouraged to engage with and participate in the process. A residual warehouse is converted into a plant nursery and mobile educational pavilions are proposed with the intention of developing a community investment in the process and the ongoing development of these spaces into 'parks'. 
FINAL DESIGN 
This part of the Design chapter presents the 'final design' or a landscape architectural framework for the development of the precinct of Seaview/Gracefield in Wellington, New Zealand. As much an exercise in breaking down the physical and psychological disconnects and negative public perception of forsaken industrial territories as a series of catalysts that seek to capitalise upon and make explicit or tangible the inert qualities of such landscapes, this project endeavours to disrupt the rigorous order and programming of industrial environments and interpret the notion of 'park' in such contexts as one that conveys and cultivates a genuine sense of time, memory and place.

The 'final design' process aims to be infrastructural while drawing on qualitative phenomena of time, memory and place, requiring mediation between two somewhat conflicting dialogues as is evident in the challenges posed by efforts to draw out principles for design that concern qualitative output from Allen's propositions for infrastructure. The initial generation of a more conventional larger scale planning strategy that responds to Hutt City Council's 'Vision Seaview Gracefield 2030' vision statement serves as a framework within which the notion of 'parks' in the industrial precinct of Seaview/ Gracefield perform as infrastructures that respond to the disturbed nature of such environments. 
Having generated the armature within which landscapes that challenge the perceived dichotomy between industrial operation and park space can unfold, the process shifts to focus on specific territories within the larger 'park' infrastructure. The process is then concerned with how these might be developed so as to convey a relevant, contemporary sense of place, articulating traces of the past as well as promoting potential development by presenting proving grounds for future operations. In response to the themes of program, materiality, form, graphic language and ecology, as outlined previously, these spaces are constructed as 'parks' that respond to their immediate contexts while also functioning as part of the larger scale 'park' infrastructure. The proposed designs aim to exercise a level of delicacy, touching the ground lightly so as to not destroy the very qualities that make these spaces so significant within their strictly regulated contexts. 


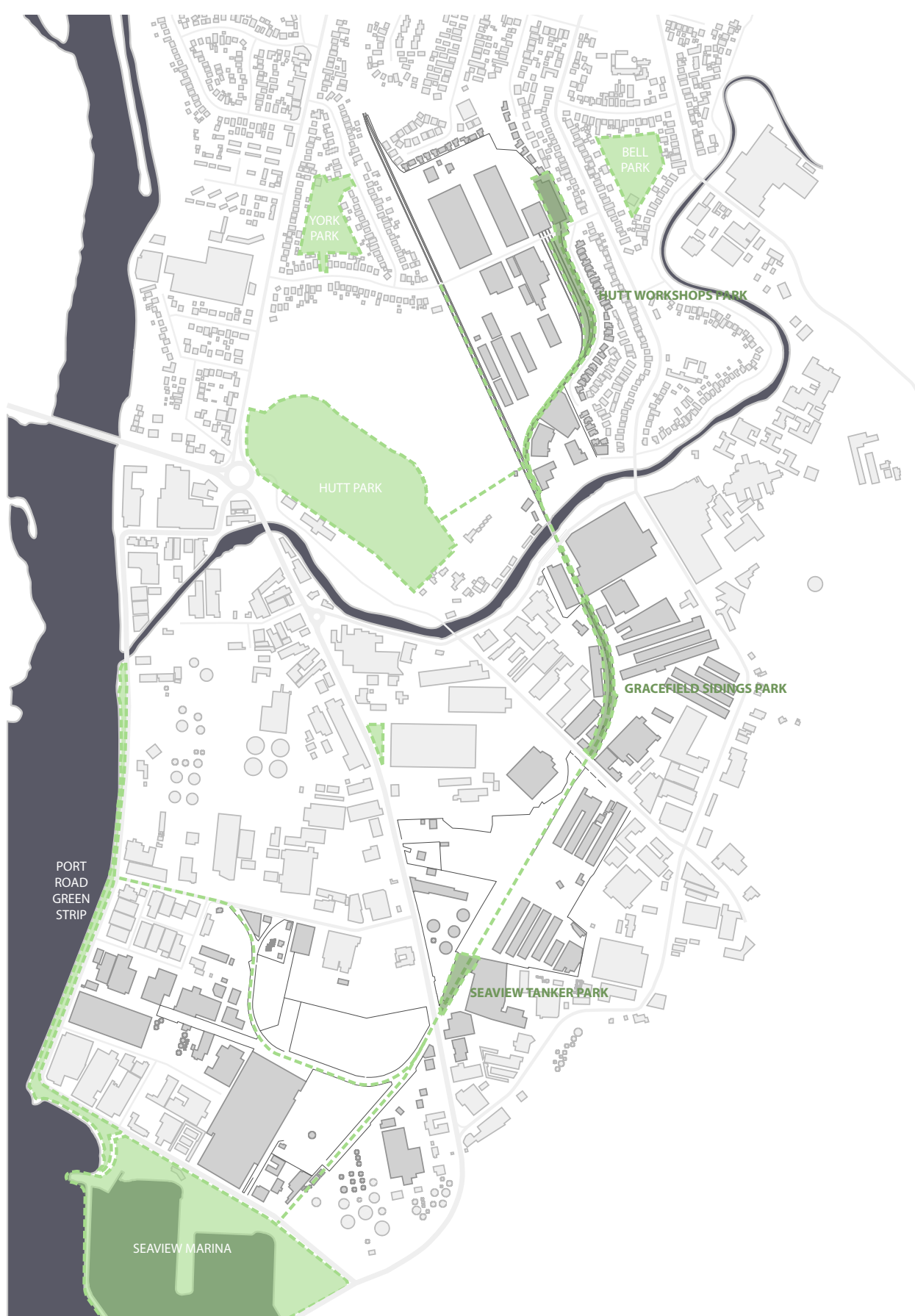

Fig. 3.01 Proposed park network - Scale 1:15000 


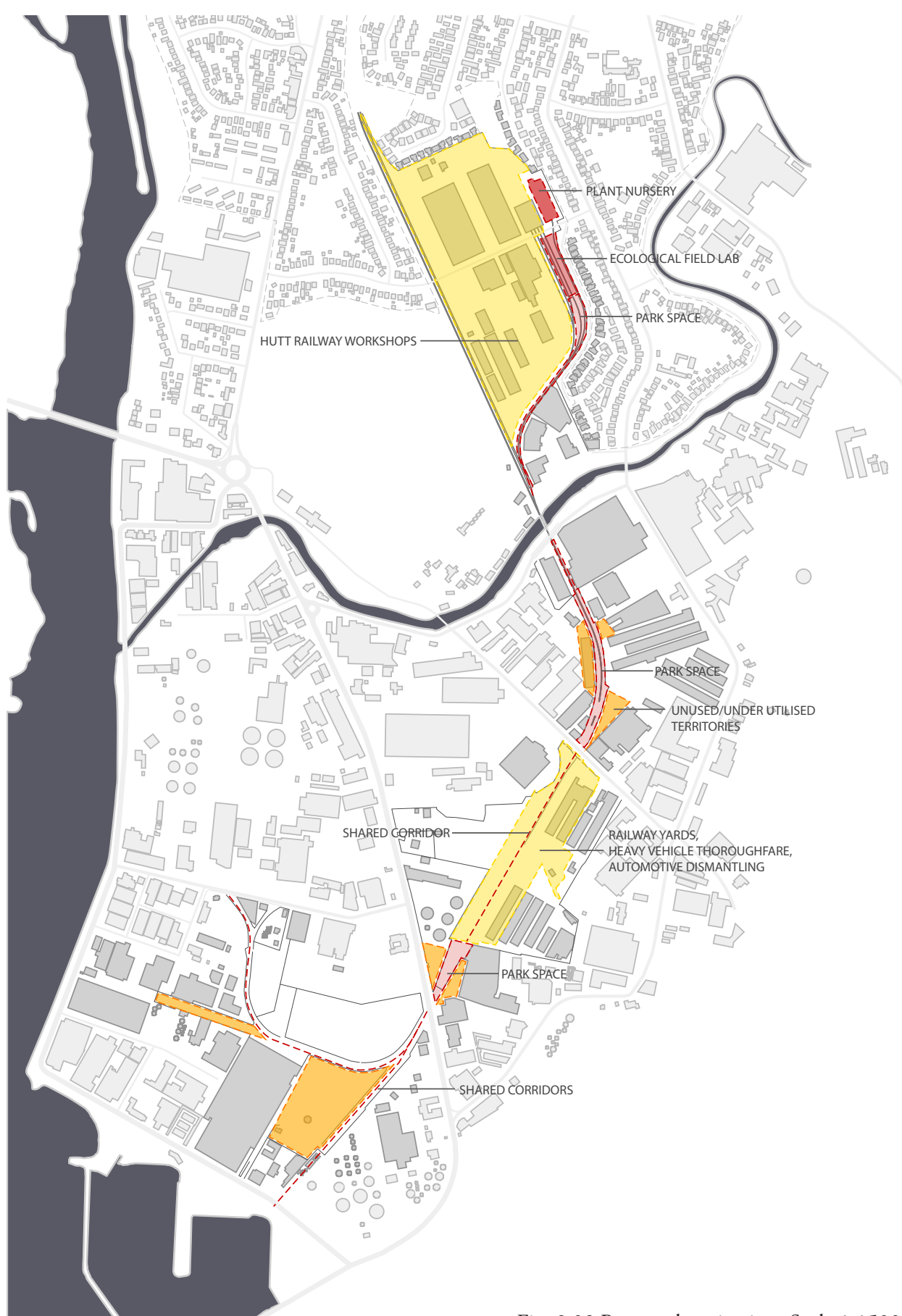




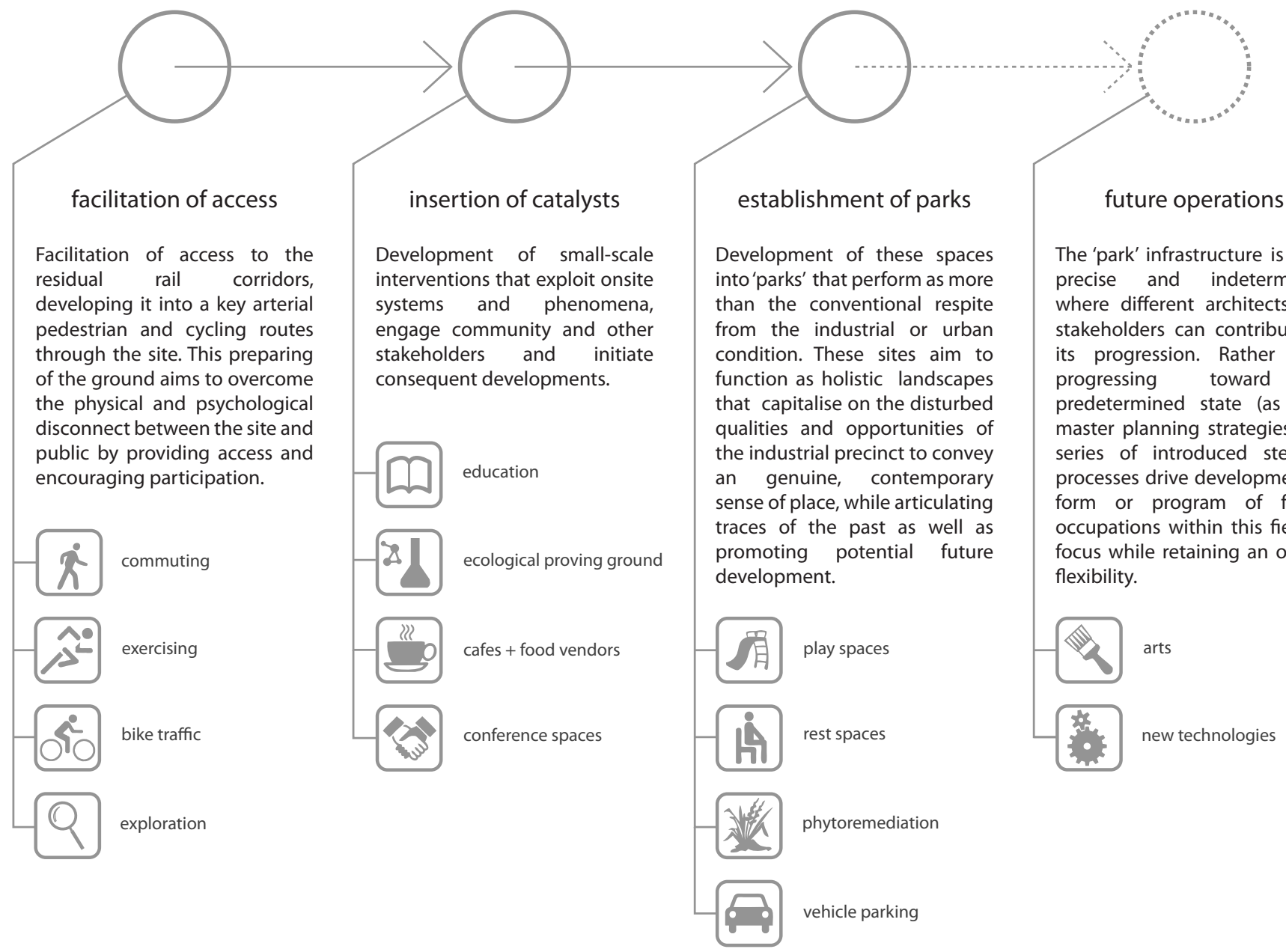

Fig. 3.03 Intervention strategy and proposed promotion or introduction of programs

The proposed strategy involves interventions designed to engage community participation and develop a public investment in the site, to test and promote new operations in field-labs, and to initiate a longer-term unfolding of development beyond the confines of the 'park' infrastructure. Fig. 3.03 outlines the intervention strategy and the corresponding promotion of existing or introduction of new programs, in response to the previously outlined themes of "providing stability and efficiency to support existing businesses," "creating a suitable environment for the growth of new/emerging businesses," "making better use of recreational opportunities" and "contributing towards a better environment," as covered in 'Vision Seaview Garcefield 2030 . 


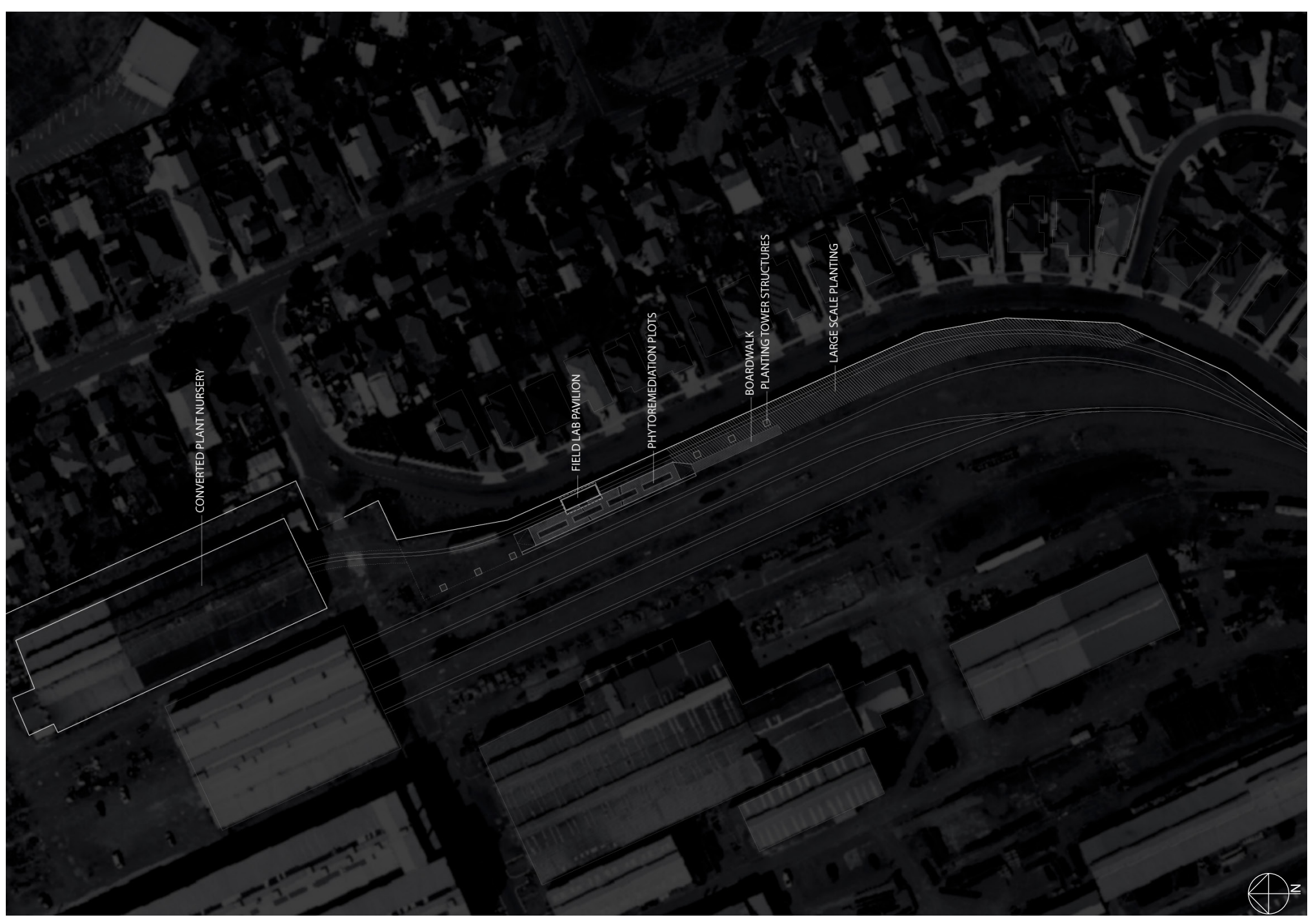

Fig. 3.04 Site I: Hutt Workshops Park plan - Scale 1:2000 


\section{Site I: Hutt Workshops Park}

Site I is a corridor along the eastern edge of the Hutt Railway Workshops, bordered by residential housing. This proximity to an established community is made use of by encouraging public participation and investment into the proposed 'park' infrastructure through the development of this area as a field lab site. A disused warehouse, located at the northern end where the 'park' network culminates, is partially deconstructed and converted into a plant nursery that cultivates plant species for placement throughout the sites as well as providing a strong and progressive image for the future of the precinct. Phytoremediation plots and a mobile field lab pavilion that sits on the residual rail track are proposed to function in conjunction with the schools within close proximity so that beyond functioning as part of a new public use network, the Hutt Workshops Park facilitates participation in the remediation process and provides educational programs that endeavour to trigger a shift in the public perception of the site and break down the industrial operation/public space dichotomy. 


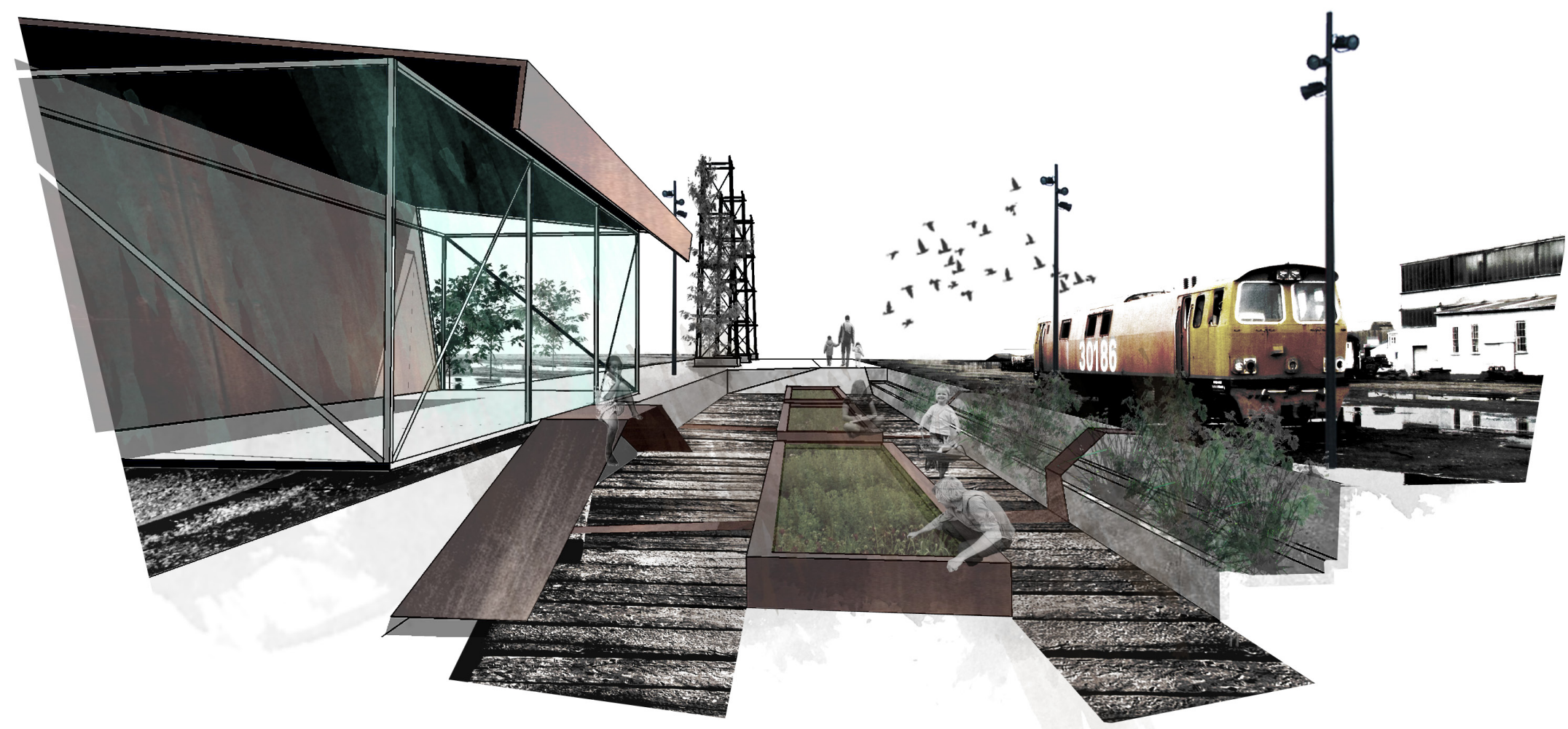

Fig. 3.05 Site I: Hutt Workshops Park - view south toward mobile field lab pavilion and phytoremediation plots 


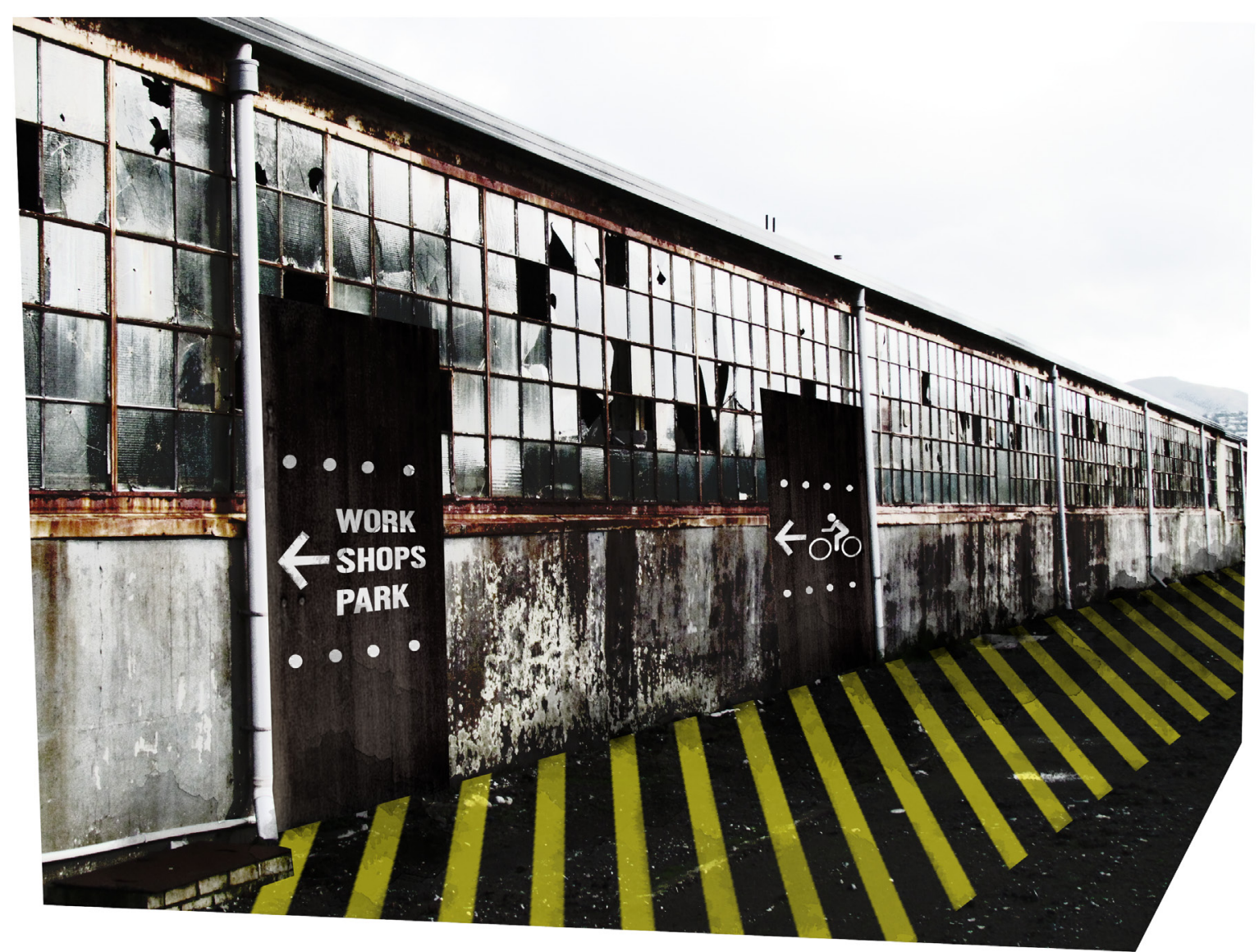

Fig. 3.06 Site I: Hutt Workshops Park - view along eastern edge of the converted nursery structure 


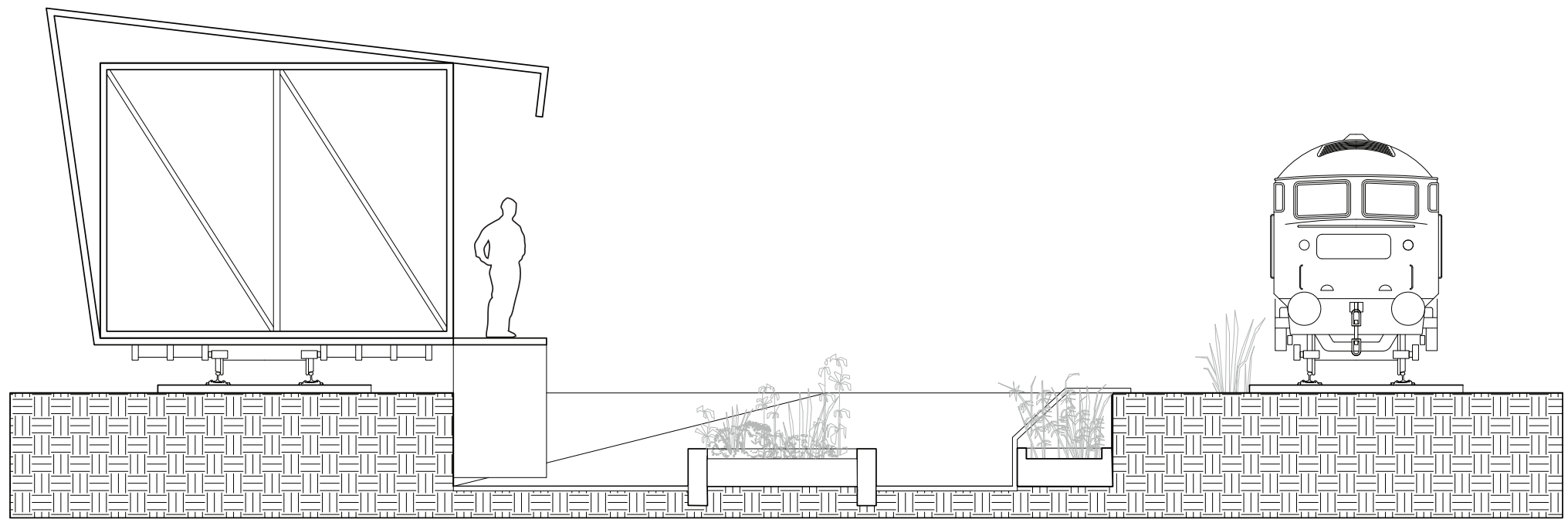

Fig. 3.07 Section through rail-mounted mobile field lab pavilion and phytoremediation plots - Scale 1:100 


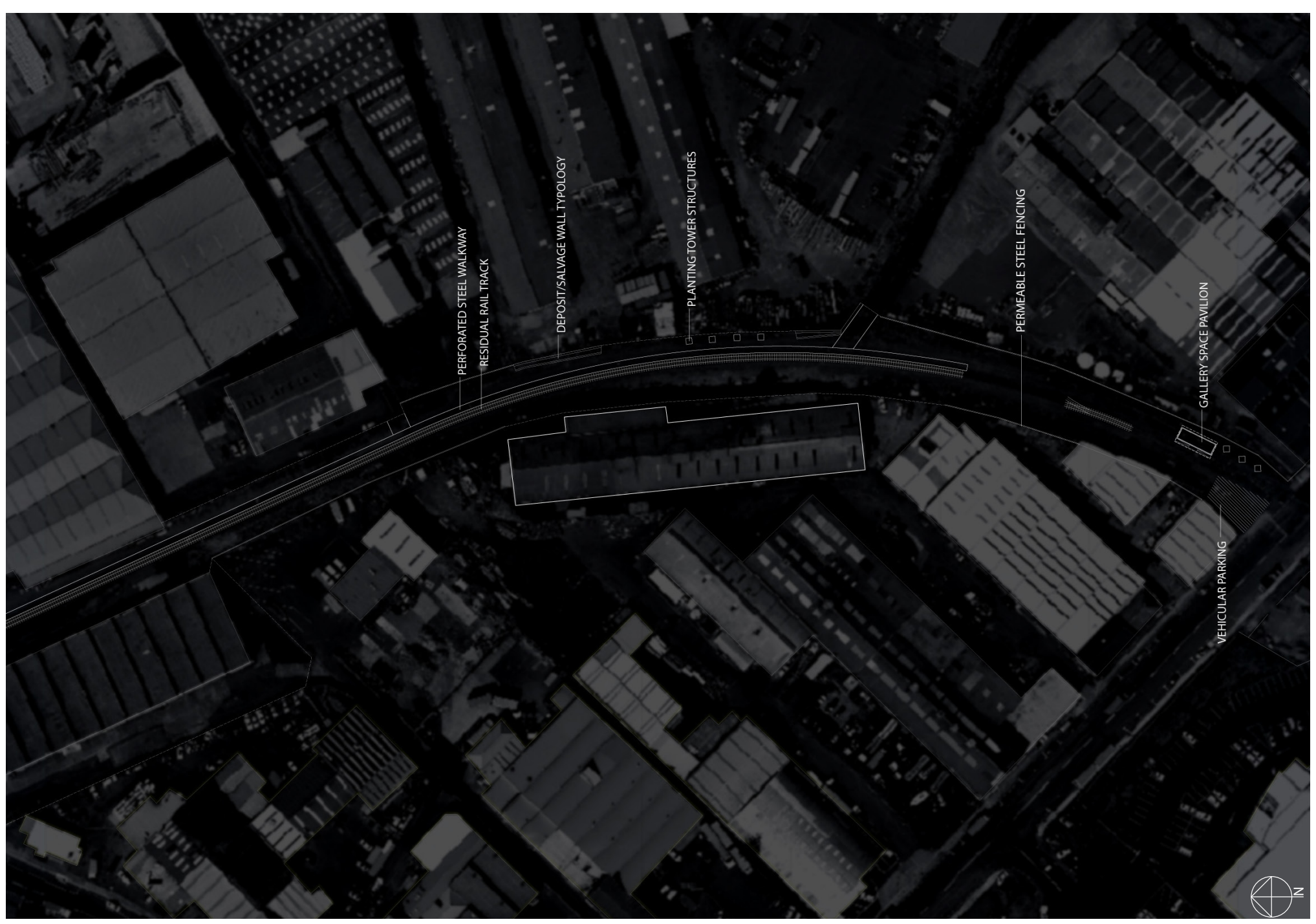

Fig. 3.08 Site II: Gracefield Sidings Park plan - Scale 1:2000 


\section{Site II: Gracefield Sidings Park}

The proposal for site II exhibits a much lighter touching on the ground. The path that runs alongside the rail tracks is a perforated steel walkway, allowing the textures and colours that make this void so evocative, to permeate through. The introduced planting is limited to contained planter structures and the wild, invasive species that have begun to reclaim the rail corridor as it has fallen into ruin are encouraged to spread. The physical and psychological disconnect between the corridor and the adjacent operations is addressed through a diversifying of the edge condition that aims to develop a greater dialogue with the surrounding context. A strong culture of dumping scrap materials exists but one of salvaging is developing, with arts studios and other operations capitalising on the reuse of materials. New fence typologies are proposed that allow for an exchange of material across boundaries so that the Gracefield Sidings Park performs as a kind of stage for exchange, where endorsed and illicit programs are made explicit but also exploited by new practices. Access points along this edge are proposed so that workers are able to use the residual rail corridor to commute to work by foot or cycle. Architectural follies frame the corridor, reinforcing the figural void of the park infrastructure and creating a strong image for the identity of the precinct. 


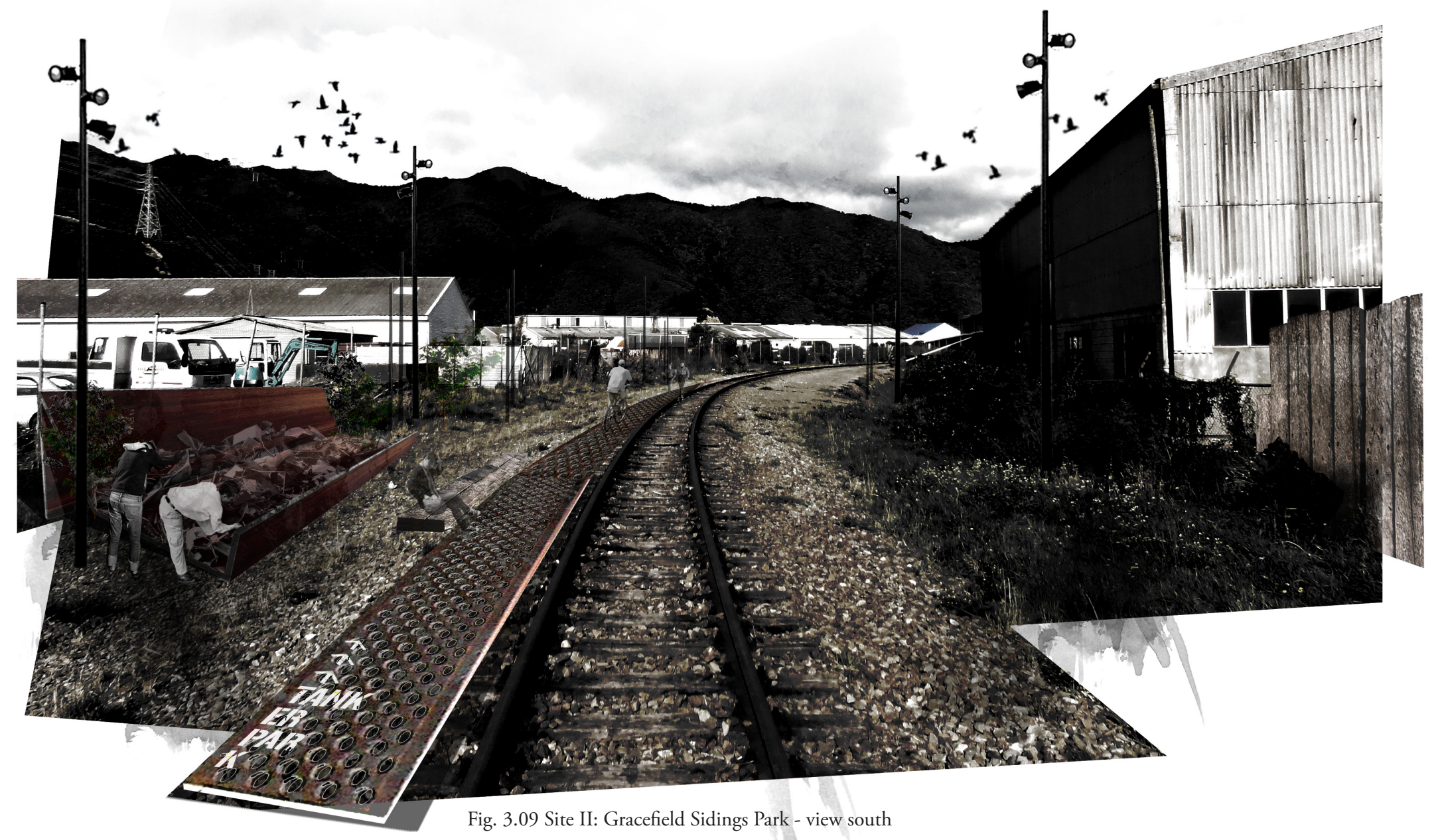




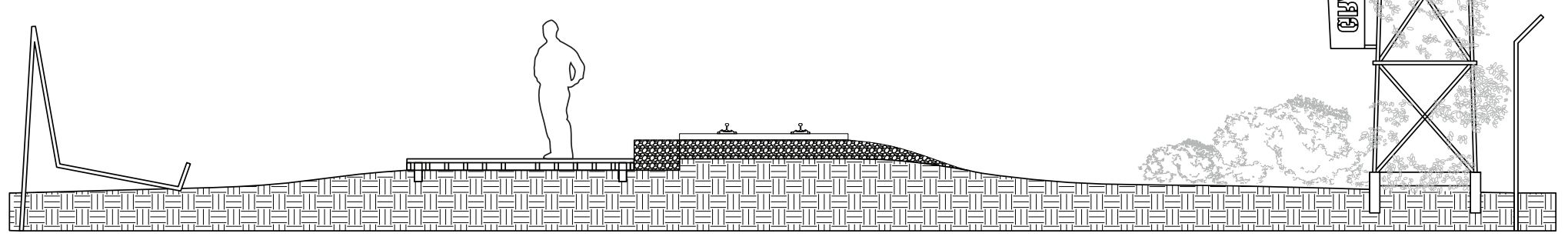

Fig. 3.10 Section through deposit/salvage wall typology + perforated steel walkway - Scale 1:100

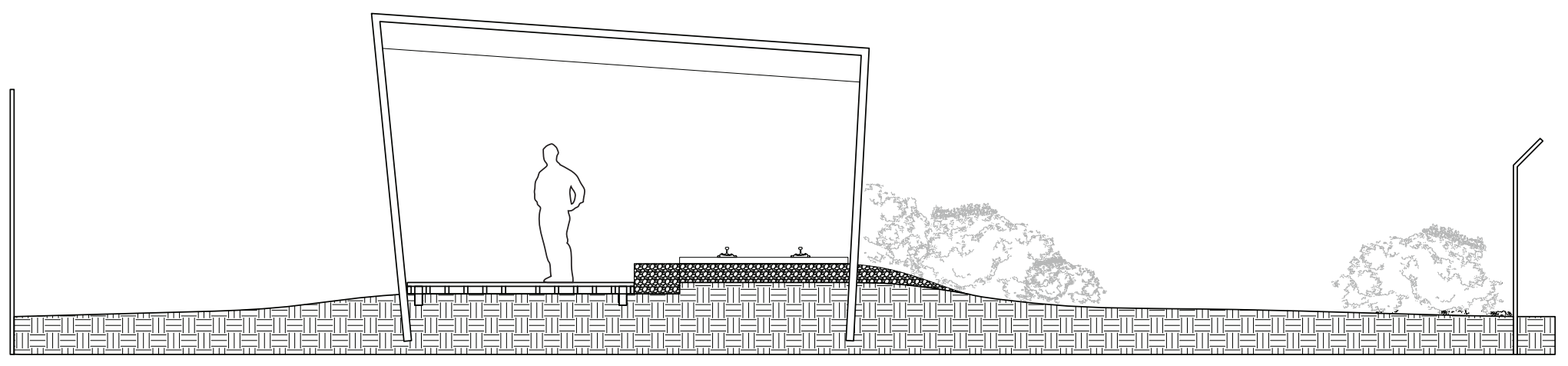

Fig. 3.11 Section through steel folly - Scale 1:100 


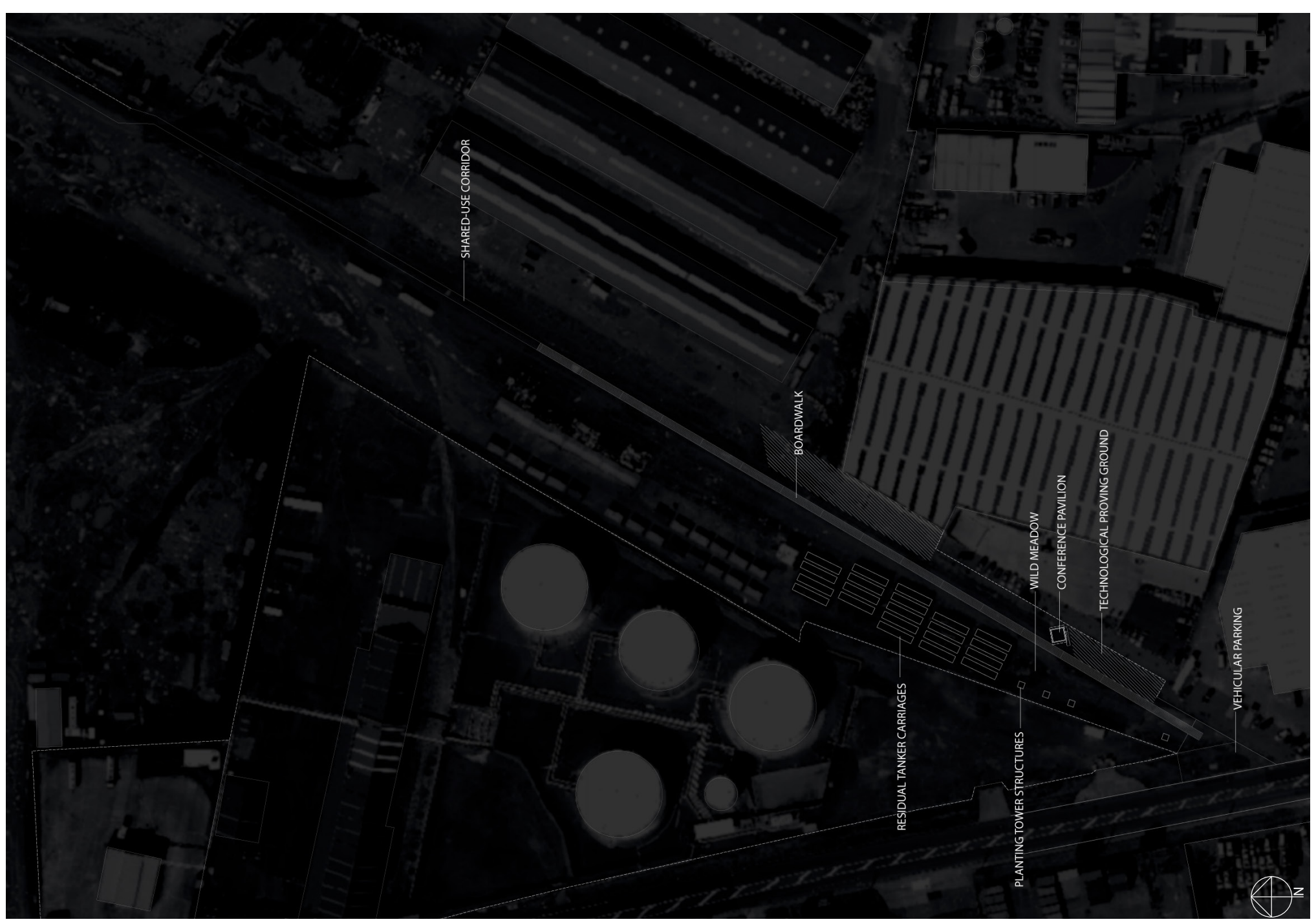

Fig. 3.12 Site III: Seaview Tanker Park plan - Scale 1:2000 


\section{Site III: Seaview Tanker Park}

Site III envisions a granting of public access to a pedestrian corridor through the northern end of the 'park' which currently facilitates programs of automotive dismantling and vehicular access on the former site of the rail yards. Rather than attempt to fix spatial contestation and programmatic conflicts, this approach accepts and celebrates these through a tweaking of the existing material and graphic language to allow for the 'park' to function as a public thoroughfare. Stimulated by the adjacent alternative energy operations, the proposal for the Seaview Tanker Park envisions the space to perform as a proving ground for technical innovation; an opportunity to test, showcase and advertise new developments. The space places itself in the middle of a dialogue between the industrial past of the precinct; exploiting the beauty found in the decay of the residual tanker carriages and the un-manicured vegetation, and speculative future operations that will continue to develop the area's growth and identity; providing pavilions for networking growing business relationships.

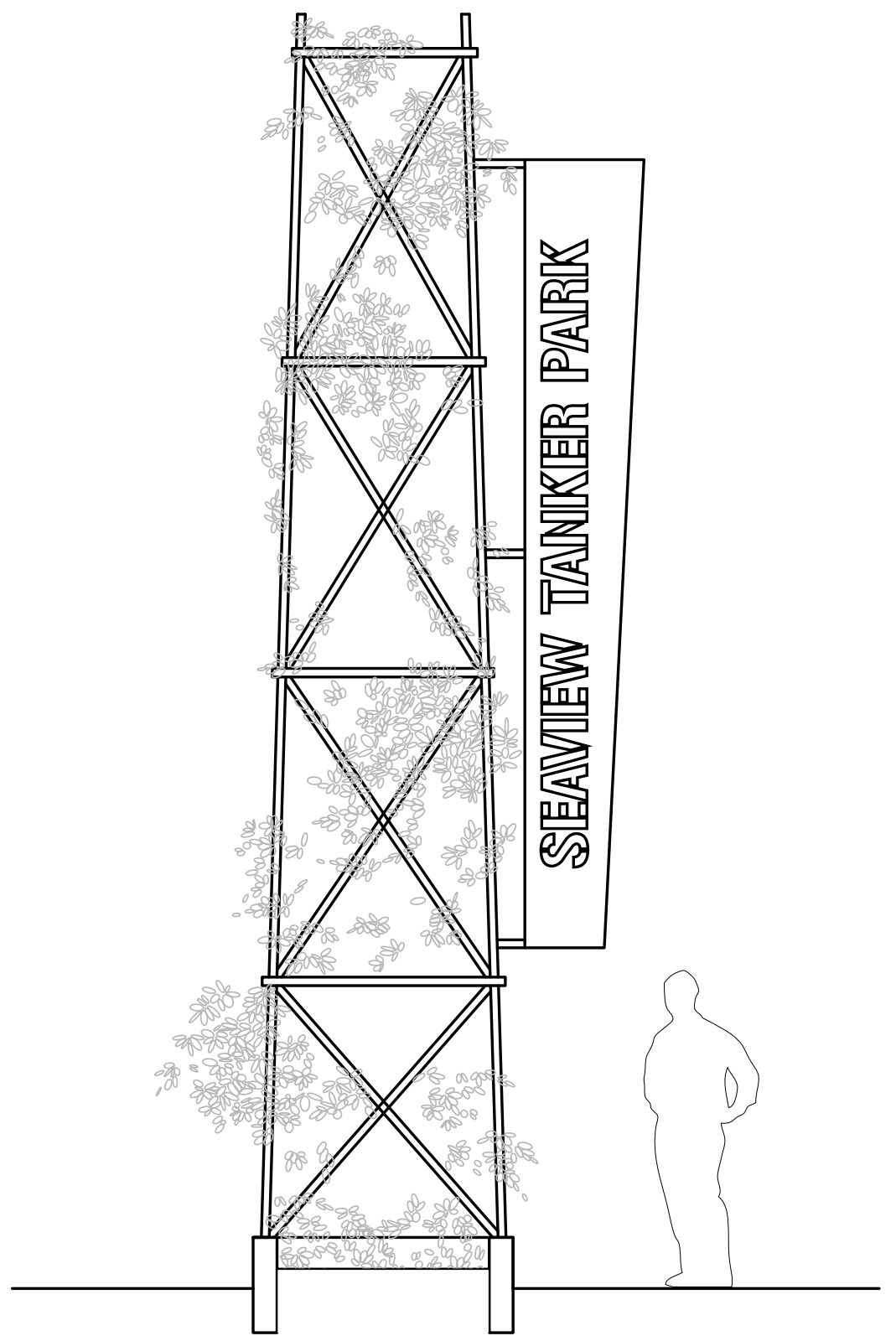

Fig. 3.13 Steel planter structure - Scale 1:50 


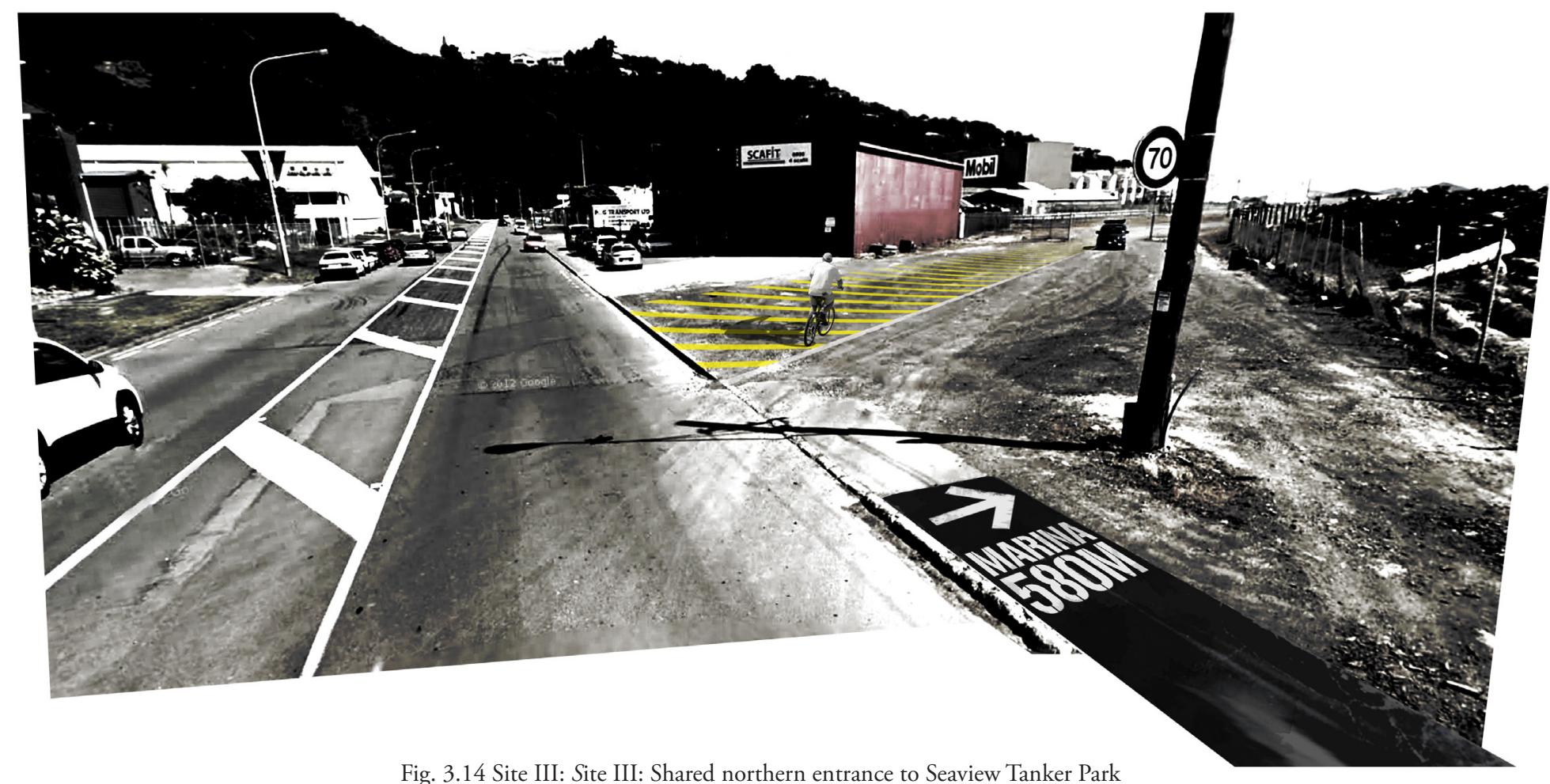

Fig. 3.14 Site III: Site III: Shared northern entrance to Seaview Tanker Park 


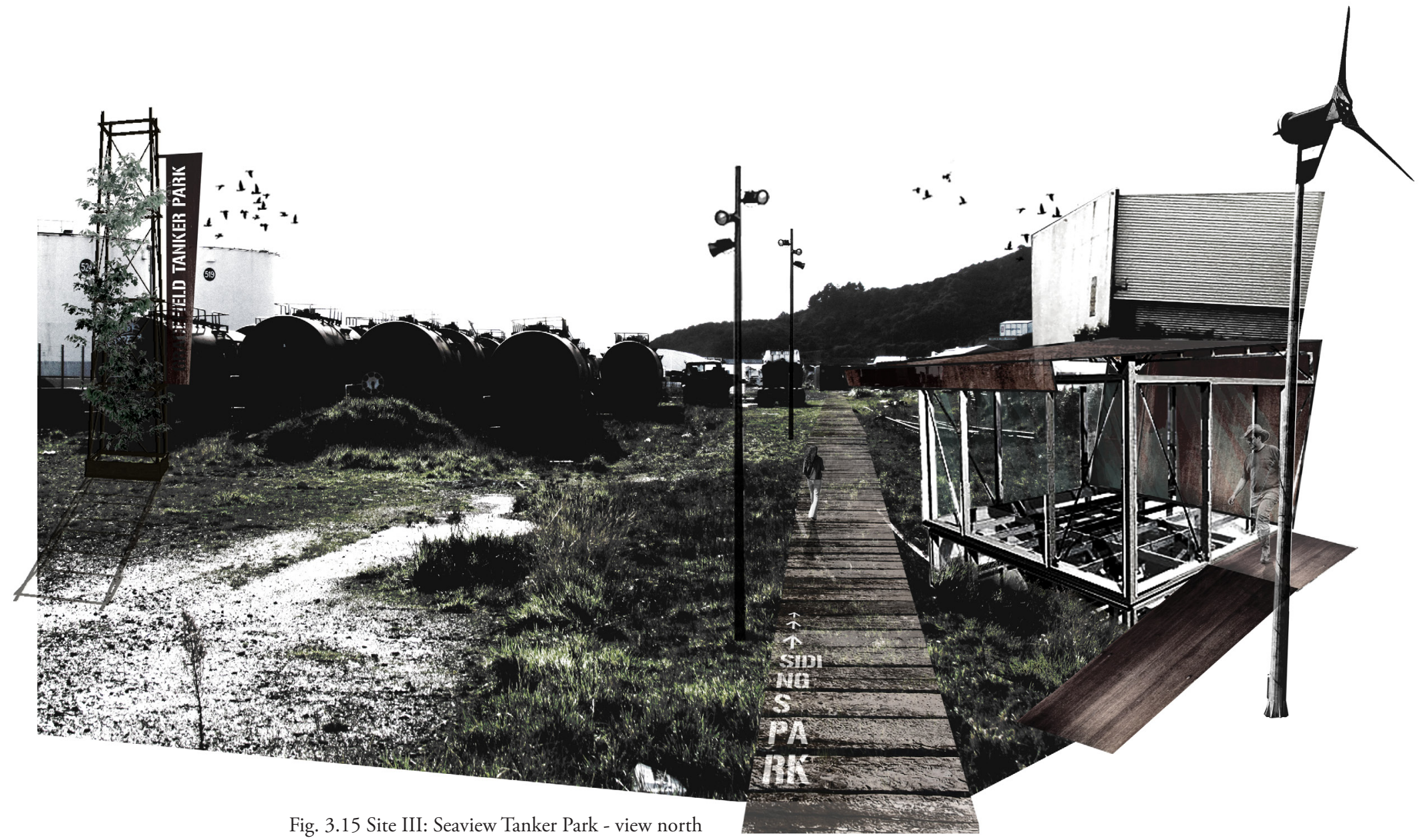


CONCLUSIONS AND REFLECTIONS 
Ultimately, in this research, the forsaken territories of the industrial area of Seaview/Gracefield serve as proving grounds for a landscape infrastructural method of intervention that focuses on the conveyance of qualitative phenomena with the aim of reimagining 'parks' in such contexts as places that reveal an authentic sense of place or identity. In these territories, authenticity is not the new heritage. It comes from providing a platform for all operations, sanctioned and unsanctioned, to occur; from expressing traces of past landscapes as well as suggesting potential new ones; it requires space to perform.

Trying to establish how an infrastructurally designed landscape can capitalise upon the qualitative phenomena found within the landscapes of industry proved difficult as it required mediation between two somewhat conflicting discourses, as is evident in the challenges posed by efforts to draw out principles for the design of such spaces from Allen's propositions for infrastructure. The resulting design proposal required the generation of a more conventional landscape infrastructural framework in which to position new territories that aim to question how the performance of landscape infrastructures can be valued beyond quantitative output but also qualitative terms. This research does not attempt to define a methodology for the infrastructural design of forsaken territories, nor does it suggest that precise methodologies should be employed. These are messy spaces. The qualities this 
design approach seeks to exploit within them are messy, often unquantifiable and abstract phenomena. What the design responses within this research aim to do is develop orderly frames or scaffolds that communicate human intention and make these messy qualities more explicit.

Forsaken territories resonate with memories of industrial brutality and ecological neglect. However, when we look to intervene within these spaces we ought not aspire to rid them of their disturbed nature. These are not landscapes of redemption. We are drawn to these sites by their inherent intricacy, the finer grain they offer in precincts founded in rough grain industrial planning. The seductive beauty of their decay and the meaningful social histories that emanate within such places are just as significant to their potential to function as catalysts as the innovative and experimental landscape operations that may be encouraged to occur here. The sites of focus and their residual nature present us with paradoxical typologies of urban territory. These spaces are at the same time nonplaces and holistic landscapes. They are unrestrained, not rigorously programmed like the industrial and commercial operations they sit within, yet provide a reflection of and allow an insight into the processes, consequences and opportunities of such locales.

Developing the notion of 'park' in this context as one that capitalises on the disturbed qualities and opportunities of industrial precincts, initiated the conception of landscapes that conveyed an genuine, contemporary sense of place, while articulating traces of the past as well as promoting potential development. It became clear that achieving this did not come through defining an identity but through expressing one that already existed and making it explicit, tangible and contestable. The infrastructural design process centred around identifying conflicts and opportunities and inserting 
scaffolds to promote and foster these.

The infrastructurally designed industrial 'park' is not a respite from the industrial or urban condition. While some level of conventional open space amenity can be found, much more exists within these places. These voids function as stages; their ruins as windows into their industrial past; and their forms, colours, textures, graphic language and materialities offer tactile encounters with a sense of place that is relevant; something so strikingly absent in conventional open spaces in industrial precincts. 


\section{List of Figures}

Fig. 1.01 Regional context. Author's own image.

Fig. 1.02 Residual rail corridor. Author's own image.

Fig. 1.03 Proposed sites of infrastructural intervention. Author's own image.

Fig. 1.04 Building mass. Author's own image.

Fig. 1.05 Street Network. Author's own image.

Fig. 1.06 Conventional open spaces. Author's own image.

Fig. 1.07 Zoning. Author's own image.

Fig. 1.08 Hutt City Libraries Local Studies Collection. Aerial view of the Woburn Railway Workshops ca.1930.

Fig. 1.09 NZ Railways Magazine. 1929. Interior of the old Railway Workshops at Petone ca. 1920

Fig. 2.01 Untitled. Author's own image.

Fig. 2.02 Untitled. Author's own image.

Fig. 2.03 Untitled. Author's own image.

Fig. 2.04 Site 1. Author's own image.

Fig. 2.05 Site 2. Author's own image.

Fig. 2.06 Site 3. Author's own image.

Fig. 2.07 Site 1 - Proposed programs. Author's own image.

Fig. 2.08 Site 2 - Proposed programs. Author's own image.

Fig. 2.09 Site 3 - Proposed programs. Author's own image.

Fig. 2.10 Program Framework. Author's own image.

Fig. 2.11 Selected Material Palette. Author's own image. 
Fig. 2.13 Diversification of the edge condition of the rail corridor. Author's own image.

Fig. 2.14 Void stage I. Author's own image.

Fig. 2.15 Void stage II. Author's own image.

Fig. 2.16 Void stage III. Author's own image.

Fig. 2.17 Graphic language and visual traces. Author's own image.

Fig. 2.18 Comparing ecological remediation scenarios. Author's own image.

Fig. 2.19 Remediation scenario I. Author's own image.

Fig. 2.20 Remediation scenario II. Author's own image.

Fig. 3.01 Proposed park network. Author's own image.

Fig. 3.02 Proposed territories. Author's own image.

Fig. 3.03 Intervention strategy and proposed promotion or introduction of programs. Author's own image.

Fig. 3.04 Site I: Hutt Workshops Park plan. Author's own image.

Fig. 3.05 Site I: Hutt Workshops Park - view south toward mobile field lab pavilion and phytoremediation plots. Author's own image.

Fig. 3.06 Site I: Hutt Workshops Park - view along eastern edge of the converted nursery structure. Author's own image. Fig. 3.07 Section through rail-mounted mobile field lab pavilion and phytoremediation plots. Author's own image.

Fig. 3.08 Site II: Gracefield Sidings Park plan. Author's own image.

Fig. 3.09 Site II: Gracefield Sidings Park - view south. Author's own image.

Fig. 3.10 Section through deposit/salvage wall typology + perforated steel walkway. Author's own image.

Fig. 3.11 Section through steel folly. Author's own image.

Fig. 3.12 Site III: Seaview Tanker Park plan. Author's own image. 
Fig. 3.13 Steel planter structure. Author's own image.

Fig. 3.14 Site III: Shared northern entrance to Seaview Tanker Park. Author's own image.

Fig. 3.15 Site III: Seaview Tanker Park. Author's own image. 
Allen, S. (1999). Infrastructure Urbanism. Points + Lines: Diagrams and Projects for the City. New York, United States: Princeton Architectural Press.

Armstrong, H. 2006. Time, Dereliction and Beauty: an Argument for 'Landscapes of Contempt'. The Landscape Architect, IFLA Conference Papers.

Armstrong, H. (2010). Writing In and On the Margins. Global Media Journal - Australian Edition, 4(2).

Beigel, F. (1997) as cited in Mostafavi \& Najle (Ed) (2003) Landscape Urbanism, London, United Kingdom: Architectural Association

Bélanger, P. (2009). Landscape as Infrastructure. Landscape Journal. Wisconsin, United States: University of Wisconsin Press.

Blood, J. (2006). Landscape as Infrastructure? How landscape can precede housing development and set the parameters for its location, density and relationship to the Maribyrnong River. (Master's thesis). RMI University, Melbourne, Australia.

Brand, R. (2005). Urban Infrastructures and Sustainable Social Practices. Journal of Urban Technology, 12(2). 1- 25.

Chan, E. C. (2009). What roles for ruins? Meaning and narrative of industrial ruins in contemporary parks. JoLA - Journal on Landscape Architecture. 2009(2).

Dourish, P., \& Bell, G. (2007). The infrastructure of experience and the experience of infrastructure: meaning and structure in everyday encounters with space. Environment and Planning B: Planning and Design, 34. 414-430.

Edensor, T. (2005). Industrial Ruins: Space, Aesthetics and Materiality. Oxford, United Kingdom: Berg Publishers.

Engler, M. (1995). Waste Landscape: Permissible Metaphors in Landscape Architecture. Landscape Journal, 14(1). 10-25.

Guattari, F. (2008). The Three Ecologies translated by Pindar, I. and Sutton, P., Continuum.

Holling, C.S. Resilience, Adaptability and Transformability in Social-Ecological Systems. Ecology and Society 9(2): 5. Retrieved 24 ${ }^{\text {th }}$ September 2010 from http://www.ecologyandsociety.org/vol9/iss2/art5/

Hood, W. (2004). Landscape as Social Infrastructure: Hybrid Modifications - Scrapping, Weaving, Stratifying and Lumping. The mesh book: Landscapelinfrastructure. Melbourne, Australia: RMIT University Press.

Hughes, T.P. (1988). The Seamless Web: Technology, Science, et Cetera. Social Studies of Science. Edinburgh, Scotland: Edinburgh University Press. 
Hung, Y. (2010). Landscape Infrastructure: Systems of Contingency, Flexibility, and Adaptability. Landscape Infrastructure: Case Studies by SWA. Basel, Switzerland: Birkhäuser GMBH.

Jackson, JB. (1994). A Sense of Place, a Sense of Time. New Haven, United States: Yale University Press.

Joerges, B. (1977). Gebaute Umwelt und Verhalten. Ueber das Verhaeltnis von Technikwissenschaften und Sozialwissenschaften am Beispiel der Architektur und der Verhaltenstheorie. Baden-Baden, Germany: Nomos.

Mayo, J. (2009). Time and Landscape. Journal of Architectural mand Planning Research, 26:2. Chicago, United States: Locke Science Publishing Company.

Mills, A. (2005). Cultural Landscapes Seminar Brief. 2005: 1. University of South Carolina.

Moos, R.H. (1975). Evaluating Correctional and Community Settings. New York, NY: John Wiley \& Sons.

Mossop, E. (2006). Landscapes of Infrastructure. The Landscape Urbanism Reader. New York, United States: Princeton Architectural Press.

Myer, E. (2007). Uncertain Parks: Disturbed Sites, Citizens, and Risk Society. In Czerniak, J. \& Hargreaves, G. (Ed.), Large Parks (pp. 59-85). New York, United States: Princeton Architectural Press.

Napawan, N. (2011). Multi-Productive Landscapes of the Sustainable City: Opportunities for Managing Resource Needs through Urban Landscapes. Davis, United States: University of California, Davis.

Paul, R. (2010). From object line to vector field - the social instrument, presented at the symposium Infrastruktururbanismus. Munich, Germany

Poole, K. (1998). Civitas Oecologie: Civic Infrastructure in the Ecological City. Harvard Architecture Review. Princeton Architectural Press.

Poole, K. (2004). Potentials for Landscape as Infrastructure. The mesh book: Landscape/infrastructure. Melbourne, Australia: RMIT University Press.

Raxworthy, J., \& Blood, J. (2004). Introduction. The mesh book: Landscape/infrastructure. Melbourne, Australia: RMIT University Press.

Sommer, R. (1969). Personal space: The behavioural basis of design. Englewood Cliffs, United States: Prentice-Hall.

Stalker. Stalker manifesto. Retrieved $18^{\text {th }}$ September 2011 from http://www.osservatorionomade.net/tarkowsky/manifesto/ manifesting.htm

Trigg, D (2004). 'The Uncanny Space of Decay' in Psy-Geo Provflux Vol 1 (1). Retrieved $20^{\text {th }}$ May 2011 from http://www. 
Waldheim, C. (2006). Landscape as Urbanism. The Landscape Urbanism Reader. New York, United States: Princeton Architectural Press.

Wall, A. (1999). Programming the Urban Surface. Recovering Landscape: Essays in Contemporary Landscape Architecture. Princeton Architectural Press.

Wasserman, J. (2002). Memory Embedded. Landscape Journal, 21(1). University of Wisconsin.

Weilacher, U. (2008). Syntax of Landscape: The Landscape Architecture of Peter Latz and Partners. London, United Kingdom: Springer.

Wingwall, A. (1984). Caring About Places: Time. Places, 2(2). College of Environmental Design, UC Berkeley.

Zelizer, B. (1995) Reading the Past Against the Grain: The Shape of Memory Studies. Critical Studies In Mass Communication, 12(2). 
